\title{
Human liver microbiota modeling strategy at the early onset of fibrosis
}

\section{Camille Champion ${ }^{1,2,3^{*}}$, Radu M. Neagoe ${ }^{4 *}$, Maria Effernberger ${ }^{5}$, Daniela T. Sala ${ }^{4}$,}

Florence Servant $^{6}$, Jeffrey E. Christensen ${ }^{1,2}$, Maria Arnoriaga-Rodriguez ${ }^{7}$, Jacques Amar $^{1,2,8}$, Benjamin Lelouvier ${ }^{6}$, Fabrice Gamboa ${ }^{3}$, Herbert Tilg ${ }^{5}$, Massimo Federici ${ }^{9}$, Jose-Manuel Fernández-Real ${ }^{7}$, Jean Michel Loubes ${ }^{3}$ and Rémy Burcelin ${ }^{1,2 \S}$.

${ }^{1}$ Institut National de la Santé et de la Recherche Médicale (INSERM), Toulouse, France.

${ }^{2}$ Université Paul Sabatier (UPS), Unité Mixte de Recherche (UMR) 1048, Institut des Maladies Métaboliques et Cardiovasculaires (I2MC), Team 2 : 'Intestinal Risk Factors, Diabetes, Dyslipidemia' F-31432 Toulouse Cedex 4, France.

${ }^{3}$ Institut de Mathématiques de Toulouse, Université Paul Sabatier, Toulouse, France

${ }^{4}$ University of Medicine Pharmacy, Science and Technology "George Emil Palade” Tîrgu Mures, Second Department of Surgery, Emergency Mureş County Hospital, Romania.

${ }^{5}$ Department of Internal Medicine I, Gastroenterology, Hepatology, Endocrinology \& Metabolism, Medical University of Innsbruck, Austria

${ }^{6}$ VAIOMER, 516 Rue Pierre et Marie Curie, 31670 Labège, France

${ }^{7}$ Department of Diabetes, Endocrinology and Nutrition, University Hospital of Girona 'Dr Josep Trueta'; Institut d'Investigacio Biomedica de Girona IdibGi; and CIBER Fisiopatologia de la Obesidad y Nutricion. Girona, Spain

${ }^{\mathbf{8}}$ Therapeutics department, Rangueil Hospital, Toulouse, France,

${ }^{9}$ Department of Systems Medicine, University of Rome "Tor Vergata", Via Montpellier 1, 00133 Rome, Italy

* contributed equally to this work 
bioRxiv preprint doi: https://doi org/10.1101/2020.12.10.419051; this version posted December 12, 2020. The copyright holder for this

preprint (which was not certified by peer review) is the author/funder, who has granted bioRxiv a license to display the preprint in perpetuity. It is made available under aCC-BY-NC-ND 4.0 International license.

${ }^{\S}$ Corresponding authors and Lead Contact: Pr Remy Burcelin remy.burcelin@inserm.fr; Pr Radu Mircea

Neagoe neagoerm@gmail.com, and Pr jean Michel Loubes loubes@ math.univ-toulouse.fr

Telephone: +33561325614

Running title: liver fibrosis and microbiota

Keywords: biomathematics/ liver diseases/metabolic disease/ microbiota/ tissue microbiota 
bioRxiv preprint doi: https://doi org/10.1101/2020.1210.419051; this version posted December 12,2020. The copyright holder for this

\begin{abstract}
To understand the pathophysiological impact of liver microbiota on the early stages of fibrosis we identified the corresponding microbiota sequences and overcome the impact of different group size and patient origins with adapted statistical approaches. Liver samples with low liver fibrosis scores (F0, F1, F2) were collected from Romania(n=36), Austria(n=10), Italy(n=19), and Spain( $n=17)$. The 16SrDNA gene was sequenced. We considered the frequency, sparsity, unbalanced sample size between cohorts to identify taxonomic profiles and statistical differences. Multivariate analyses, including adapted spectral clustering with L1-penalty fair-discriminant strategies, and predicted metagenomics were used to identify that $50 \%$ of liver taxa were Enterobacteriaceae and Pseudomonadaceae. The Caulobacteraceae, Flavobacteriaceae and Propionibacteriaceae discriminated between F0 and F1. The preQ0 biosynthesis and pathways involving glucoryranose and glycogen degradation were negatively associated with liver fibrosis F1-F2 vs F0. Altogether, our results suggest a role of bacterial translocation to the liver in the progression of fibrosis. This statistical approach can identify microbial signatures and overcome issues regarding sample size differences, the impact of environment, and sets of analyses.
\end{abstract}


bioRxiv preprint doi: https://doi.org/10.1101/2020.12.10.419051; this version posted December 12, 2020. The copyright holder for this preprint (which was not certified by peer review) is the author/funder, who has granted bioRxiv a license to display the preprint in perpetuity. It is made available under aCC-BY-NC-ND 4.0 International license.

\section{Introduction}

Non-alcoholic fatty liver disease (NAFLD) is a common consequence of obesity and type 2 diabetes [1,2]. In NAFLD, the origin of inflammation and hepatocyte injury is related to dietary lipids, bile acids, adipokines and cytokines, to cite a few. Furthermore, gut microbiota seems to be one of the key players of NAFLD development $[3,4]$. Markers and receptors of microbiota-related injury features have been described in this disorder such as TLRs, NODS, and NLRP3 [5-8] as well as the activation of the innate and adaptive immune systems [9]. In early sets of experiments, we initially showed that hepatic steatosis in the obese diabetic mouse was due to an increased circulating concentration of lipopolysaccharides (LPS) i.e. metabolic endotoxemia [10]. Lipoproteins transport LPS [11] to tissues, triggering the CD14/TRL4 pathway that increases liver inflammation and fat deposition [10]. Gut bacteria were also reported to translocate through the intestinal tract to tissues [12] such as the adipose depots and the liver, establishing a tissue microbiota as observed in rodents [13-15] and humans [16-18] which could trigger liver inflammation and the onset of fibrosis [13]. This mechanism activates immune cells, including Kupffer cells, to release various pro-inflammatory cytokines and chemokines [19] damaging the surrounding tissues initiating fibrosis. This hypothesis is now largely supported by recent major advances in NAFLD research, which show gut and blood microbiota dysbiosis of patients with advanced stages of NAFLD [20-22]. Hence, the identification of specific groups of translocated bacteria from dysbiotic gut microbiota could aid in the design of novel therapeutic strategies. To address this issue, we have sequenced and identified the bacterial 16S rDNA from liver tissue of a cohort of 36 Romanian, 17 Spanish, 19 Italians and 10 Austrian patients with different stages of liver fibrosis, notably at their early stages. We could design hypotheses regarding the putative causal role of liver microbiota in the development of liver fibrosis. We used this database to evaluate the efficacy of Principal Coordinate Analysis (PCoA) to visualize the different liver fibrosis group scores using Wilcoxon-Mann-Whitney statistical tests [23]. Eventually, since the overall database of patients issued from different separated cohorts we anticipated some degree of heterogeneity of the overall cohort therefore, we adapted and developed a specific statistical approach i.e. L1 spectral clustering with fairness. This approach establishes inter-relations between liver microbiota and low scores of liver fibrosis that allowed the identification of the translocated bacteria putatively causal to 
the disease and independent from the group size, the patient origins and sets of sequencing. Overall, we drew a European microbial profile of patients at early stages of liver fibrosis.

\section{Materials and Methods}

\section{Subjects and Ethics}

A multicentric observational study was conducted in the Second Department of Surgery, Emergency Mureş County Hospital of Romania, the Department of Systems Medicine of the Tor Vergata University of Rome, the Institut d'Investigacio Biomedica de Girona IdibGi, the Endocrinology and Nutrition Department of Dr. Josep Trueta University Hospital, and the University Hospital of Innsbruck. All research procedures performed in this study were in strict accordance with a pre-defined protocol and adhered to the Good Clinical Practice guidelines and the Declaration of Helsinki. The study was approved by the Coordinating Ethics Committee of the Emergency Mureş County Hospital, Romania (registration 4065/2014), the Institutional review board \& Ethics Committee and the Committee for Clinical Research (CEIC) of Dr. Josep Trueta University Hospital, Girona, Spain; the Policlinico Tor Vergata Ethics Committee, Rome, Italy as part of the FLORINASH Study the Institutional Ethics Commission at the medical University of Innsbruck (amendment to AN20170016 369/4.21). All participants provided informed consent prior to participation. The patients who gave their consent to perform a liver biopsy during the procedure were eligible. Exclusion criteria were serious liver diseases (eg hemochromatosis, alcoholic fatty liver disease, Hepatits B and Hepatitis C infection, chronic diseases, inflammatory systemic diseases, acute or chronic infections in the previous month, use of antibiotic, antifungal, antiviral drugs, protonpump inhibitors, anti-obesity drugs, laxatives, excessive use of vitamin D supplementation, fiber supplements or probiotics or participation in a weight loss program or weight change of $3 \mathrm{~kg}$ during the previous 6 weeks, pregnancy or breastfeeding, or major psychiatric antecedents; neurological diseases, history of trauma or injured brain, language disorders, and excessive alcohol intake ( $\geq 40 \mathrm{~g} /$ day in women or $80 \mathrm{~g}$ $\mathrm{OH} /$ day in men) or intravenous drug abuse, and previous bariatric surgery. 
bioRxiv preprint doi: https://doi.org/10.1101/2020.12.10.419051; this version posted December 12, 2020. The copyright holder for this

The cohort consists of 82 Caucasian patients where 34 were diagnosed with fibrosis stage 0 (F0); 37 stage 1 (F1) and 11 stage 2 (F2), as diagnosed from histological analyses of liver biopsies (Table 1). The patients suffered from morbid obesity with a mean BMI $42.6( \pm 7.3)$. The mean waist circumference was $121.49( \pm 18.73)$ in male and $123.23( \pm 18.26)$ in female participants.

\section{Liver biopsies and liver fibrosis diagnosis}

Liver biopsies were performed during laparoscopic surgical bariatric procedures or via ultrasound guided liver biopsy. No energy devices were used for collecting the samples since hemostasis was done afterwards when the samples were extracted from the abdomen. Ultrasound (US) guided percutaneous liver biopsy (UPLB) was performed in 10 patients. In all patients, antiplatelet drugs and oral anticoagulation therapy was paused 1 week before UPLB was performed. One experienced physician (> 3000 USexams and >100 UPLB) performed the US-examinations with the Philips EPIQ $5^{\circledR}$ (Philips Corporation, Amsterdam, The Netherlands). UPLB was performed using an $18 \mathrm{G}$ Temno II semi-automatic tru-cut biopsy needle (Cardinal Health, Dublin, Ohio, USA). After UPLB, all patients were monitored for any signs of pain or clinically suspected bleeding by nursing staff over a 6-h period. If no serious complications were evident, all patients would be discharged after the mandatory 6-h observation, a stable blood count and a normal ultrasound examination. All patients were follow-up in 2 weeks to review the results of the histology. All the samples were stored in a sterile container and kept at $-80^{\circ} \mathrm{C}$ until assayed. Furthermore, NAFLD was confirmed histologically by an independent pathologist.

\section{Clinical assessments:}

Anthropometric measurement of each subject was performed by trained nurses in the morning after fasting for at least $8 \mathrm{~h}$. Body height was recorded to the nearest $0.5 \mathrm{~cm}$ and body weight to the nearest $0.1 \mathrm{~kg}$. BMI was defined as body weight (kilograms) divided by the square of body height (meters). Waist circumference was measured in the horizontal plane midway between lowest rib and the iliac crest to the 
nearest $0.1 \mathrm{~cm}$ at the end of a normal expiration repeatedly in men and women by 3 trained nurses on 3 consecutive days. Blood pressure was recorded to the nearest $2 \mathrm{mmHg}$ by a mercury sphygmomanometer with the arm supported at heart level after sitting quietly for 10 min. Fasting plasma glucose was measured after fasting for at least $8 \mathrm{~h}$. A standard oral 75-g glucose tolerance test was performed to measure 2h postprandial plasma glucose. Hypertension was defined in accordance to the Guidelines of the European Heart Association or if the subject was taking medication for hypertension. Diabetes was diagnosed when fasting plasma glucose was $\geq 126 \mathrm{mg} / \mathrm{dL}$ ( $7 \mathrm{mmol} / \mathrm{L}$ ), 2-h postprandial plasma glucose $\geq 200 \mathrm{mg} / \mathrm{dL}$ (11.1 $\mathrm{mmol} / \mathrm{L})$, and $\mathrm{HbA}_{1 \mathrm{c}} \geq 6.5 \%$ or if the subject was taking medication for diabetes

\section{Biochemical and molecular analyses}

\section{Plasma parameters:}

Biochemical analyses including total fasted plasma glucose, cholesterol, high-density lipoprotein (HDL) cholesterol, plasma liver enzymes i.e. aspartate aminotransferase (AST/GOT), alanine aminotransferase (ALT/GPT), gamma-glutamyl transferase (GGT), hematocrit and leukocytes were determined by Cobas 8000, (Roche, Basel, Switzerland) according to the manufacturer's specification. Elevated liver enzymes were defined as aspartate aminotransferase and alanine aminotransferase. HbAlc was measured by highperformance liquid chromatography (Bio-Rad, Muenchen, Germany) and a Jokoh HS-10 autoanalyzer.

\section{$16 S$ rDNA sequencing and bioinformatic analysis}

The V3-V4 hypervariable regions of the 16S_rDNA were amplified by two steps PCR using v1 primers (Vaiomer) and sequenced using MiSeq Reagent Kit v3 (2x300 bp Paired-End Reads, Illumina, San Diego, CA, USA) as previously described [24]. The MiSeq sequences were then analyzed using the bioinformatics pipeline established by Vaiomer using FROGS v1.4.0 [25]. Briefly, after demultiplexing of the bar-coded Illumina paired reads; single read sequences are cleaned and paired for each sample independently into longer fragments. Operational taxonomic units (OTU) are produced with via single- 
bioRxiv preprint doi: https://doi.org/10.1101/2020.1210.419051; this version posted December 12, 2020. The copyright holder for this preprint (which was not certified by peer review) is the author/funder, who has granted bioRxiv a license to display the preprint in perpetuity. It is made available under aCC-BY-NC-ND 4.0 International license.

linkage clustering and taxonomic assignment is performed in order to determine community profiles (generated by Blast+ v2.2.30+ against the Silva v128 Parc databank restricted to the bacterial kingdom).

\section{Linear Discriminant Analysis (LDA) Effective Size (LEfSe)}

The bacterial profiles were further compared between the three groups using LEfSe pairwise analysis with an alpha cut-off of 0.05 and an effect size cut-off of 2.0. The bacterial diversity analyses (alpha and beta diversity, MDS ordinations and taxonomic composition barplots) were generated using the Phyloseq (v1.14.0), vegan (v2.4.0) and ape (v3.5) packages under R environment v3.3.1. LEfSe analysis was performed on the OTU table using the online Galaxy interface to identify bacterial taxa that were differentially abundant in the three liver fibrosis groups [27]. Respective cladograms were generated with genus at the lowest level. Quantitative plots of differential features were generated from genus level percent relative abundance data showing means with standard deviation using GraphPad Prism 6 software. Using the LEfSe algorithm, bacterial taxa that were differentially abundant in analysis of liver fibrosis groups were first identified and tested using the Kruskal Wallis test.

\section{Beta diversity analysis}

The bacterial diversity (alpha and beta diversity) was analyzed and represented using the phyloseq (v1.14.0), vegan (v2.4.0), ape (v3.5), and ggplot (3.3.0) packages under R environment v3.5.1 with Chao, Inverse Simpson, Simpson and Shannon as indexes. The alpha diversity statistical significance was determined by Wilcoxon rank-test. The beta diversity was calculated for every pair of variables to generate a matrix of distance using Bray-Curtis, Jaccard, Unifrac, and weighted Unifrac indexes. From distance matrices, Multiple Dimension Scale (MDS) and hierarchical clustering were conducted for graphical representation of beta diversity. PERMDISP2 procedure was used for the analysis of multivariate homogeneity of group dispersions. The Kruskall-Wallis test was performed to compare abundance across the three groups.

\section{Multivariate analyses}


bioRxiv preprint doi: https://doi.org/10.1101/2020.12.10.419051; this version posted December 12, 2020. The copyright holder for this preprint (which was not certified by peer review) is the author/funder, who has granted bioRxiv a license to display the preprint in perpetuity. It is made available under aCC-BY-NC-ND 4.0 International license.

To visualize the distribution of patients according to their clinical parameters, we performed a Principal Component Analysis (PCA) using FactoMineR and factoextra R packages. For the study of 16SrDNA diversity, we first filtered the less abundant OTUs to reduce the noise within the matrix before running the PCA. We eliminated those with abundance $<0.01$. We then normalized the OTU table by using the Cumulative Sum Scaling normalization followed by a log transformation, using mixOmics package (https://pubmed.ncbi.nlm.nih.gov/29099853/). To explore the metagenomic data and identify the largest sources of variation, another Principal Component Analysis was conducted. Also based on the projection of the dataset into a space of lower dimension and originally designed for regression we performed a Partial Least Square Discriminant Analysis (PLS-DA) and its sparse version (sPLS-DA) on the normalized OTU table count to predict and select the most discriminative features in the data that help to classify the samples according to the fibrosis variable (package mixOmics).

Since we observed the influence of the metagenomic data on the outcome, we used alternative method of classification such as random forest (package randomForest). The random forest is built from a multitude of different decision trees and classifiers at training time thereby predicting and storing the predicted target outcome.

Cluster graphical analyses. The abundance matrix of OTUs can be modeled by a graph using PLNmodels package under $\mathrm{R}$ where nodes represent OTUs and edges interactions between each pair of nodes. We developed an analysis in clusters i.e. the L1-spectral clustering, implemented in R, a robust variant of the well-known spectral clustering that aims to detect the natural structures of a graph by taking advantage of its spectral properties. The adjacency matrix modeling the variable associations of the graph is used as an input of the 11-spectralclustering algorithm. In front of the influence of the origin of the cohort on the graphical classification through clusters we applied "fair" technics with k-median clustering objectives. We identified $\mathrm{k}$ centers and assign each input point to one of the centers so that the average distance of points to their cluster center is minimized. In the fair-variant, the points are colored while the goal is to minimize the same average distance objective ensuring all clusters to have an approximately equal num- 
ber of points of each color. This technique called "fairtree" and developed in python takes as input the desired number of clusters, the desired cluster balance and the normalized table count.

\section{Functional metagenomic prediction}

Metagenome inference and predicted functional analysis were initiated by analysis of the OTU clustered 16S sequence count table data and the OTU representative sequences using the PICRUSt2 tool [26] (https://pubmed.ncbi.nlm.nih.gov/32483366/) version 2.3.0b for each sample. The metagenome prediction process included four main steps: 1) The input OTU representative sequences were aligned against the PICRUSt2 reference alignment, 2) From this alignment, the input OTU were placed into the PICRUSt2 reference phylogenetic tree, 3) The metagenome functions were inferred by the hidden state prediction method using this phylogenetic tree. During this inference process, the abundance values of each OTU were normalized to their respective predicted $16 \mathrm{~S}$ rDNA copy numbers and then multiplied by the respective gene counts of the target bacteria, 4) The predicted functions were mapped to the MetaCyc database to determine the minimum set of pathways present in the samples. The resulting core output was a list of enzyme functions (Enzyme Commission numbers) with predicted count data for each sample from step 3 as well as a list of MetaCyc pathways with predicted count data for each sample from step 4.

\section{Data Availability Section}

- MiSeq 16S_rDNA sequences were deposited under the primary accession number PRJEB41831 and a secondary number ERP125667 on December $9^{\text {th }} 2020$ with a release date on the $31^{\text {st }}$ of December 2021.

\section{Results}

Graphical classification of the clinical variables by principal component analyses 
bioRxiv preprint doi: https://doi.org/10.1101/2020.12.10.419051; this version posted December 12, 2020. The copyright holder for this preprint (which was not certified by peer review) is the author/funder, who has granted bioRxiv a license to display the preprint in perpetuity. It is made available under aCC-BY-NC-ND 4.0 International license.

We aimed at identifying liver 16SrDNA profiles associated with the early onset of fibrosis. We aggregated together a library of liver biopsies from patients from four cohorts of different European countries. We first visualized the distribution of the patients according to the cohorts by performing a principal component analysis using the anthropomorphic and clinical data where the projection of the different clinical variables is represented (Fig1A,B). The ellipses calculated for each cohort show some degree of differential distribution suggesting that specific environmental factors have influenced the clinical outcomes. Interestingly, the Romania cohort was unifying all cohorts and could be used as a reference. In addition, we could detect numerous outlier patients from each cohort.

It is noteworthy that we voluntarily included all anthropomorphic and biochemical data, even if some were redundant and confounding, to remain within the frame of a non-a priory statistical approach. The age, diabetes and hypertension variables were the main drivers of the F2 classification while HDL cholesterol and liver enzymes were drivers for the F1 histological phenotype. These observations are supported by significant ANOVA tests (Table $\mathbf{1}$ ).

\section{Analyses of the liver bacterial 16SrDNA ecology.}

To identify whether the graphical differences between the three liver fibrosis scores are associated with a differential liver bacterial DNA signature, we then performed PCA on the OTUs as entries in the database. The analysis using countries as groups shows that the different cohorts poorly overlapped suggesting the existence of specific environmental factors specific of each country cohort (Fig $\mathbf{2 A})$. Using the liver fibrosis scores as groups we could not clearly graphically discriminate the fibrosis scores since the distribution of the patients according to their OTU profiles were too scattered and seemed to be depending upon the largest Romanian cohort (Fig 2B). To analyze differently the putative signatures according to the cohorts or the liver fibrosis scores, we studied the frequencies of the phylum and family taxonomic levels. The barplot analysis shows first a large degree of heterogeneity between all individuals at the phylum level (Fig 2C) but still, we identified that the liver microbiota of the overall cohort was composed mostly of Proteobacteria, (>75\%) (Fig 2D). Group comparisons showed that statistical differences were 
bioRxiv preprint doi: https://doi.org/10.1101/2020.12.10.419051; this version posted December 12, 2020. The copyright holder for this preprint (which was not certified by peer review) is the author/funder, who has granted bioRxiv a license to display the preprint in perpetuity. It is made available under aCC-BY-NC-ND 4.0 International license.

observed between the F0 and F1 groups for the Proteobacteria, Actinobacteria and Firmicutes phyla (Supplementary Fig1 A,B,C). At the family taxonomic level, the most prominent taxa were the Enterobacteriaceae and the Pseudomonadaceae which accounted for more than $50 \%$ of the overall taxa (Fig 2E). Group comparisons showed that the Caulobacteraceae, Flavobacteriaceae and Propionibacteriaceae families were statistically different when comparing F0 and F1 (Supplementary Fig1 D,E,F).

To further identify whether liver fibrosis scores could be characterized by specific signatures we explored indexes of alpha and beta diversity of 16SrDNA in liver tissue. The data show that differences in abundances at the phylum, and family taxonomic levels were also associated with differences of the alpha diversity (Supplementary Fig 2A,B,C). Notably, the Observed, Shannon and Simpson indexes were significantly different between the F0 and F1 groups at the phylum and family levels. In addition to alpha diversity, we analyzed beta diversity and performed a principal coordinate analysis (PCoA) considering distances between variables (using Bray-curtis distance). The PCoA analyses showed that the F0 group was distant from the two others which suggests a specific 16SrDNA signature (Supplementary Fig 2D,E). It is noteworthy that outlier patients were also detected. Although, when analyzed together the three groups could not be classified clearly. The F0 group differed graphically from the F1, F2 groups suggesting a specific signature discriminating between F0 and F1,F2. To determine if the ellipse centers of the F0 group differs from the ellipse center of the other groups, a Permutational Multivariate Analysis of variance (PERMANOVA) followed by a Kruskall-Wallis test were performed and found a difference between F0 and F1 groups ( $<<0.03)$. Along the same line of investigation, we performed different graphical representations such as heatmaps and Venn diagrams.

\section{Identification of specific bacterial signatures.}

To identify the variables that are specific to Fibrosis scores we performed a first Venn diagram on the overall set of variables (Fig 3A). Eighty-nine variables were common to all groups and considered as the core of the cohort while 21, 77, and 108 OTUs were specific of the F2, F1, F0 groups, respectively. To isolate extremely rare variables and unbalanced distribution between groups we next considered only 
bioRxiv preprint doi: https://doi.org/10.1101/2020.12.10.419051; this version posted December 12, 2020. The copyright holder for this preprint (which was not certified by peer review) is the author/funder, who has granted bioRxiv a license to display the preprint in perpetuity. It is made available under aCC-BY-NC-ND 4.0 International license.

OTUs with more than $25 \%$ of non-zero counts and an average number of counts per group higher than 150 and similarly drew a second Venn diagram. We identified 12, 5, and 5 OTUs specific to F2, F1, and F0 scores, respectively (Fig 3B) and (Table 2). To identify if these specific OTUs could be picked up using another approach we generated a heatmap where each OTUs was positioned while the fibrosis scores was fixed (Fig 3C). We noted that the frequencies of the majority of OTUs equal 0 or are extremely low $(<0.01 \%)$ thereby, most of these variables do not bring information. Similarly, a minority of the variables of high frequencies were common to all liver fibrosis groups and did not provide discriminant information neither. Such OTUs could be considered as the core variable of liver microbiota. Conversely, a subset of OTUs could be considered as discriminant that was identified on a different heatmap following the removing of the non-informative OTUs (Fig 3D).

To refine the identifications of the discriminant bacteria we performed a Linear discriminant analysis (LDA) coupled with effect size measurements (Fig 3E, Supplementary Fig 3A,B). The data show that most of the discriminant information was identified when comparing between F0 and F1. The Firmicutes, Flavobacteriaceae, Caulobacteraceae and Actinobacteria were specific to F0 group and the Proteobacteria was specific to F1 (Fig 3F). On the boxplot the taxa enriched in patients with no fibrosis are indicated with a negative score and mild fibrosis enriched taxa are indicated with a positive score. We performed LEFSe between each score pairs and identified much less differences between F1 F2 suggesting that they could have a similar liver microbiota, as suggested in Fig $\mathbf{2 B}$ despite the discriminant clinical variables identified in Fig1B.

On these first sets of analyses, the number of fibrosis scores of each patient was too heterogeneous to perform a discriminant analysis (overfitting). As shown on supplementary Fig 2D,3A they were almost no difference between F1 and F2, therefore we merged F1 and F2 scores as F1/2 group, increasing hence the number of patients of that group.

To validate the pertinence of such strategy we performed a partial least square discriminant analysis i.e. PLS-DA. To select the most discriminative features in the model we used its sparse version sPLSDA based on a Lasso penalization. The number of variables to be selected per component involved in the 
bioRxiv preprint doi: https://doi.org/10.1101/2020.12.10.419051; this version posted December 12, 2020. The copyright holder for this preprint (which was not certified by peer review) is the author/funder, who has granted bioRxiv a license to display the preprint in perpetuity. It is made available under aCC-BY-NC-ND 4.0 International license.

visualization is optimized using leave-one-out cross-validation. On the sample plot (Fig $\mathbf{3 F}$ ), we observe a slight separation of the two fibrosis scores ellipses compared to the unsupervised PCA. From the most discriminant OTUs selected on each sPLS-DA component, a dissociation between the two groups can be visualized using a Clustering Image Map (CIM) $($ Fig 3 G,H). The graphs show a clear classification of the patients based on the identified discriminant variables. Eventually, we calculated the ROC curve with all discriminant variables that shows an increased specificity and sensitivity above baseline (Fig 3I).

Altogether, some degree of graphical classification of the liver fibrosis score could be observed using the clinical database and the 16SrDNA database. However, in both instances the individuals appear to be still distributed according to the countries. Therefore, to overcome this issue we developed an ad hoc fairness statistical strategy allowing the classification of variables i.e. OTUs independently from the cohort.

\section{Identification of clusters of cohort-independent 16SrDNA associated with different mild scores of}

\section{fibrosis}

In front of these numerous signatures and the influence of confounding factors such as the impact of the cohort set there is a need to identify clusters of variables specific to each liver fibrosis score but independent of the cohort impact. To this aim we considered three different fair approaches on the overall cohorts and then defined clusters of OTU variables independent from the cohort. The first fair approach consists in identifying principal components from the metagenomic dataset as signatures of the cohorts and removing them to generate a new dataset where no components would be cohort sensitive. To this aim we compared the largest cohort i.e. from Romania to the others. Principal components conditional distributions with respect to the cohorts were visualized (Fig 4A). Then, we removed the principal components the most correlated with the cohorts when the absolute value of Pearson correlation was above a threshold. The remaining non-overlapping components are cohort-insensitive and used to identify the variables associated with the mild fibrosis score. Remarkably, more than $78 \%$ of the variation from the original data was still included into the selected principal components suggesting that the discriminant 
bioRxiv preprint doi: https://doi.org/10.1101/2020.12.10.419051; this version posted December 12, 2020. The copyright holder for this preprint (which was not certified by peer review) is the author/funder, who has granted bioRxiv a license to display the preprint in perpetuity. It is made available under aCC-BY-NC-ND 4.0 International license.

information was only marginally affecting our previous results. On this "fair" dataset we applied the standard random forest classification to predict fibrosis scores. From the variable importance plot, indicating the contribution of the variables to classify the data, we selected the 10 more predictive principal components and identified 3 significantly associated with fibrosis scores (Fig 4B,C,D).

The second fair clustering approach directly selects OTUs which are the most influenced by the cohorts and removes them from the analysis. The associated matrix is then modeled by a graph and subjected to a spectral clustering algorithm to which we applied an L1 penalty. The nodes represent OTUs and the edges show interactions between each pair of variables (Fig 4E). Using this novel 11-spectral clustering algorithm we identified 5 clusters of OTUs among which 3 were significantly associated with the liver fibrosis scores $($ Fig $\mathbf{4 F})$.

Eventually, we performed the fair clustering method called "fair-tree". We used the 16SrDNA normalized table count to identify clusters with approximately equal number of patients from each cohort. Two of the three clusters found containing respectively 36 and 97 OTUs, were statistically significant when comparing F0 versus F1 scores (Fig 4G,H).

To summarize all the identified OTUs significantly associated with the different low scores of fibrosis, we compiled them in (Table 3) and identified their respective taxa. From the fair principal components identified, we only considered the five OTUs that contribute most to create each of these components. Then, from the Venn diagram we identified common OTUs signatures of low fibrosis scores from standard (sPLS-DA) and fair approaches (fair-tree, random forest, 11-spectral clustering) (Fig 4I). Interestingly, from all selected OTUs eight common OTUs were from the same phylum i.e. Proteobacteria (Table 4) suggesting that most of the discriminant information could be due to these taxa. However, there is still most likely some information that this predominant family could be hiding. We therefore set a new mathematical strategy to exemplify the low frequency and meaningful bacteria by using the TF-IDF (Term frequency-inverse document frequency) approach. 
bioRxiv preprint doi: https://doi.org/10.1101/2020.12.10.419051; this version posted December 12, 2020. The copyright holder for this preprint (which was not certified by peer review) is the author/funder, who has granted bioRxiv a license to display the preprint in perpetuity. It is made available under aCC-BY-NC-ND 4.0 International license.

\section{Low frequency bacterial 16SrDNA gene contains classifying information.}

From the table count of all significant OTUs detected we generated a "word-cloud" (Fig 5A, B) to visualize the most abundant TF-IDF transformed OTU counts, regardless of fibrosis scores when compared to those non-normalized. Cluster 2 emerged as the most important discriminant OTU (taxonomic identifac-

tion=Bacteria|Proteobacteria|Gammaproteobacteria|Enterobacteriales|Enterobacteriaceae|EscherichiaShigella) further confirming the important amount of information contained in the Proteobacteria.

Based on the identified specific signatures the next step was to generate hypotheses regarding their putative mode of action to the induction of the early events of liver fibrosis. We therefore performed predicted functional metagenomics.

\section{Predicted functional metagenome pathways}

To identify the pathways and enzymes involved in the early development of fibrosis, we run predicted functional metagenomics algorithms based on the fairness-selected bacterial taxa. The heatmap shows clusters of enzymes that are associated with the F0 vs F1-2 fibrosis scores (Fig 6A). Eventually, sPLSDA showed also a clear discrimination between the F0 vs F1-2 fibrosis scores. To evaluate the accuracy and sensitivity of our analyses as potential diagnostic tool, we drew a ROC and quantified the urea under curve with a score of $81.4 \%$ of accuracy $(\mathbf{F i g}$ 6B,C). We performed a similar analysis on pathways and showed specific clusters also discriminately associated with the fibrosis scores with a score of accuracy of 81.2\% (ROC curve) (Fig 6D-F). We then represented an listed all selected enzymes and pathways highly expressed in the two major discriminant components (Fig 6G-J) and (Table5). Three pathways were highly and negatively associated with the liver fibrosis score of F1-2 when compared to the F0. We identified from the MetaCyc database (https://metacy.org/) that the preQ ${ }_{0}$ biosynthesis (PWY-6703), specific to Enterobacteriaceae such as E. coli, is involved notably in the synthesis of tetrahydrofolate and a class of nucleoside analogues that often possesses antibiotic, antineoplastic, or antiviral activities [29,30] (Fig 6K). In addition, two other pathways related to glucoryranose (PWY 6737) and glycogen (GLYCOCATPWY) degradation were identified probably providing energy to the main preQ $\mathrm{Q}_{0}$ biosynthesis pathway. 
bioRxiv preprint doi: https://doi.org/10.1101/2020.12.10.419051; this version posted December 12, 2020. The copyright holder for this preprint (which was not certified by peer review) is the author/funder, who has granted bioRxiv a license to display the preprint in perpetuity. It is made available under aCC-BY-NC-ND 4.0 International license.

On the other hand, six major metabolic pathways were positively associated with the F0 score from both components. One involves the glycolysis and pentose phosphate pathway (PWY-6629), while the 5 others are all involved in the menaquinones and demethylmenaquinones pathway (Fig 6L). The low-molecular weight lipophilic components of the cytoplasmic membrane are considered vitamin $\mathrm{K}_{2}$ components that is found in most aerobic Gram-positive bacteria and are the main quinones that function as a reversible redox component of the electron transfer chain, mediating electron transfer between hydrogenases and cytochromes. Altogether the functional metagenomics prediction suggests that gram negative bacteria from the Proteobacteria family composed of preQ $_{0}$ biosynthesis and glycolytic pathway are signature of F1-2 fibrosis scores while the vitamin $\mathrm{K}_{2}$ biosynthesis pathway from gram negative bacteria such as Actinobateriaceae [31,32] would be signing F0 liver fibrosis score.

\section{Discussion}

We here report a mathematical approach to identify a bacterial 16S rDNA signature in liver tissue and corresponding putative biochemical pathways in patients with low scores of fibrosis. Our main finding is that even low scores of fibrosis (F0 vs F1-2) can be classified by biomarkers from the Proteobacteriaceae family within the liver. The second observation is related to the importance of cohort heterogeneity in term of size and data variability which could be major confounding factors that must be taken into account in multi-centric clinical trials or database. We here present a mathematic approach that could help solving this major and common issue.

A gut metagenomics signature of liver fibrosis in humans has been recently described, suggestive of its causal role in the disease [21]. However, such patients where mostly characterized by a high score of liver fibrosis questioning the putative causal role of the liver microbiota in the disease. We here focused our attention on low scores of liver fibrosis to putatively identify causal factors. We identified mostly gram negative bacteria and notably the Proteobacteria as signature of the F1-2 liver fibrosis scores. Among the families the Proteobacteriaceae, Flavobacteriaceae, and Propionibacteriaceae were discriminating the low fibrosis scores from each other's. They synthesize LPS, a dramatically inflamma- 
bioRxiv preprint doi: https://doi.org/10.1101/2020.12.10.419051; this version posted December 12, 2020. The copyright holder for this preprint (which was not certified by peer review) is the author/funder, who has granted bioRxiv a license to display the preprint in perpetuity. It is made available under aCC-BY-NC-ND 4.0 International license.

tory suggesting a pathophysiological role in development of liver fibrosis, probably via the maintenance of a certain degree of immune vigilance. We further refined our analyses and mostly selected Enterobacteriaceae family from the Proteobacteria phylum suggesting that the liver proinflammation observed during fibrosis would be due or associated with genera from the Enterobacteriaceae family [10]. The Enterobacteriaceae encompass the genera Arthrobacter and Acinetobacter. The mechanisms through which such bacteria could induce inflammation might be linked to the unique structures of their LPS or peptidoglycans [32]. Furthermore, since such bacteria are motile with flagella, one could also contemplate that the flagellar proteins are involved in the liver fibrosis process. However, data report that the TLR5 receptor of flagellin is rather associated with protection against metabolic syndrome, putatively ruling out this hypothesis [33]. Through functional metagenomics production we identified the preQ $_{0}$ biosynthesis pathway as a signature of F1-2 fibrosis scores. Such pathway is notably identified from gram negative bacterial such as Proteobacteriaceae [28,29]. Conversely, the menaquinones and demethylmenaquinones pathways involved in K12 vitamin synthesis were the signature of the F0 score. They are notably produced by the gram positive Actinobacteriaceae such as Bacillus subtilis [31], therefore coherence with our metagenomics findings.

A major hurdle of aggregation of different cohort altogether is related to the heterogeneity of the size of the groups and of the diversity of the variables considered. Regarding invasive analyses such as liver biopsies the group size at completion of the inclusions could be different from what predicted during the calculation of power of the trial. Eventually, the distribution of the variables to be studied could be highly heterogeneous for a given disease. Altogether, we here faced several statistical challenges which are linked to liver fibrosis. The first major step preceding the microbial analysis was a prefiltering and then an adapted pathway to normalize the data to deal with their sparse nature. The package Mixomics [35] used for this study recommends CSS normalization on sparse OTU table counts that could prevent the bias included in the TSS normalization. In addition, it includes multivariate methods for microbiome studies and addresses its limits. In addition, we observed a strong impact of the cohort of origin since the largest cohort from Romania could discriminate the patients from the others based on the 16SrDNA OTU variables. The patients could even be classified by cohort when we used the clinical data as entries show- 
ing that this issue also has to be taken into account when analyzing the data. Mathematical approaches to overcome this issue are currently being developed however, little has been done regarding the handling of the 16sRDNA data now widely used by the scientific community that addresses the role of microbiota on diseases and notably liver diseases. Therefore, we here developed several approaches of fairness to overcome the classical cohort impact. Eventually, we noticed that two patients from the F1 groups were distributed with the F2 group. This ectopic distribution could be due to the extreme BMI (>55) featuring a specific clinical phenotype. Conversely, a patient from the F2 group was associated with the F0/F1 distribution. This patient was characterized by his young age ( $<40$ years old) while the mean age of the F2 group was of 54 years old.

The statistical approach required to properly analyze microbial data sets needed to be better fitted to the nature of the data. As a preliminary analysis we performed PCoA since better adapted than PCA to dissimilar and sparse data then followed by a sPLS-DA to identify subsets of 16S rDNA that are discriminatory for the liver fibrosis scores. PLS-DA aims to classify a data set according to the values of a qualitative variable by maximizing the covariance between linear combinations of the observed variables and the qualitative outcome. The sparse version, on the other hand, delivers variables per each component, only selected in the OTU dataset, that are the most discriminatory for the liver fibrosis scores. We focused our attention on the identification of the OTU frequencies within and across each group of patients and on the understanding of the importance that OTUs carry within and across the cohort. We found that the data set is mostly populated by a few high frequency OTUs. However, beside the level of information gained form this approach where overrepresented OTUs we identified cannot rule out that some more information could be obtained from OTUs rarely represented. Therefore, some information could be hidden in the low frequency OTUs. To test this hypothesis we introduced a new normalization approach called TF-IDF [36] originally developed for text mining, to attenuate the effects of the high frequencies OTUs in the data set. Furthermore, aside from the fibrosis scores, it reveals some new predominant taxa at the different taxonomic levels. 
bioRxiv preprint doi: https://doi.org/10.1101/2020.12.10.419051; this version posted December 12, 2020. The copyright holder for this

In conclusion, the first evidence of the existence of a liver microbiota opens alternate routes for novel therapeutic strategies since specific bacteria could be involved in the process of liver fibrosis. However, to generate information which could serve as a substratum to reach this aim, we here adapted predicted metagenomics and mathematical approaches to the original and novel nature of the tissue metagenomics data set. We here found that these data are constituted of high heterogeneity variables which are dominated by a few high frequency taxa such as Proteobacteria, signature of F1-2 liver fibrosis scores, and Actinobacteria/Firmucutes, signature of F0 liver fibrosis scores. These major taxa are masking information residing in the lower frequency taxa. Predicting metabolic pathways from selected 16S_rDNAbased taxa revealed a role of folate metabolism in F1-2 liver fibrosis scores while a role of vitamin $\mathrm{k} 12$ biosynthesis was characterizing F0 liver fibrosis score. Altogether, the combined use of metagenomics, sPLS-DA, TF-IDF and fainess strategies appeared useful since we identified signatures specific to the lower scores of liver fibrosis i.e. at the onset of the disease.

\section{Acknowledgements:}

We wish to extend our gratitude to the study participants, investigators, monitors and study nurses who enabled this study. We are grateful to Bogdana Dorcioman MD and the corresponding team from the Laboratory Department and Emergency of the Mures County Hospital, who performed blood analysis and who provided some technical help. This grant was supported by subsides from the Agence Nationale de la Recherche, Novo-Nordisk and Sanofi-Aventis, and the Région Midi Pyrénées to R.B. This research program was partly funded by VAIOMER SAS (project no. 6869/12.06.2014) through the University of Medicine and Pharmacy Tirgu Mures, A subside was allocated to Camille Champion from Institut National des Sciences Appliquées and the Région Occitanie. HT is supported by the excellence initiative VASCage (Centre for Promoting Vascular Health in the Ageing Community), an R\&D K-Centre (COMET program - Competence Centers for Excellent Technologies) funded by the Austrian Ministry for Transport, Innovation and Technology, the Austrian Ministry for Digital and Economic Affairs and the federal states Tyrol, Salzburg and Vienna.

\section{Author contribution}


bioRxiv preprint doi: https://doi.org/10.1101/2020.12.10.419051; this version posted December 12,2020 . The copyright holder for this preprint (which was not certified by peer review) is the author/funder, who has granted bioRxiv a license to display the preprint in perpetuity. It is made available under aCC-BY-NC-ND 4.0 International license.

The study was designed by RB, RMN and JML. The experiments and analyses were done by CC, JEC,

FG, BL and FS. The Clinical study was designed, surgeries performed by MAR, ME, HT, RMN, DTS,

JMF, MF, and JA. The manuscript was written by RB, FB, CC, RMN, JML.

\section{Conflict of interest}

$\mathrm{RB}$ and JA receive honorarium from Vaiomer and have shares.

BL and FS are employees of Vaiomer.

\section{Appendix A. Supplementary data}

\section{References}

1. G DIM, Pastore M, Marra F (2018) Liver fibrosis in the context of Non-alcoholic steatohepatitis: the role of adipokines. Minerva gastroenterologica e dietologica 64 (1):39-50. doi:10.23736/s1121-421x.17.02427-8 2. Rinella ME (2015) Non-alcoholic fatty liver disease: a systematic review. JAMA 313 (22):2263-2273. doi:10.1001/jama.2015.5370

3. Brandl K, Schnabl B (2017) Intestinal microbiota and Non-alcoholic steatohepatitis. Curr Opin Gastroenterol 33 (3):128-133. doi:10.1097/MOG.0000000000000349

4. Hoyles L, Fernandez-Real JM, Federici M, Serino M, Abbott J, Charpentier J, Heymes C, Luque JL, Anthony E, Barton RH, Chilloux J, Myridakis A, Martinez-Gili L, Moreno-Navarrete JM, Benhamed F, Azalbert V, Blasco-Baque V, Puig J, Xifra G, Ricart W, Tomlinson C, Woodbridge M, Cardellini M, Davato F, Cardolini I, Porzio O, Gentileschi P, Lopez F, Foufelle F, Butcher SA, Holmes E, Nicholson JK, Postic C, Burcelin R, Dumas ME (2018) Molecular phenomics and metagenomics of hepatic steatosis in non-diabetic obese women. Nat Med 24 (7):1070-1080. doi:10.1038/s41591-018-0061-3

5. Denou E, Lolmede K, Garidou L, Pomie C, Chabo C, Lau TC, Fullerton MD, Nigro G, Zakaroff-Girard A, Luche E, Garret C, Serino M, Amar J, Courtney M, Cavallari JF, Henriksbo BD, Barra NG, Foley KP, McPhee JB, Duggan BM, O'Neill HM, Lee AJ, Sansonetti P, Ashkar AA, Khan WI, Surette MG, Bouloumie A, Steinberg GR, Burcelin R, Schertzer JD (2015) Defective NOD2 peptidoglycan sensing promotes diet-induced inflammation, dysbiosis, and insulin resistance. EMBO molecular medicine 7 (3):259-274. doi:10.15252/emmm.201404169

6. Miura K, Yang L, van Rooijen N, Brenner DA, Ohnishi H, Seki E (2013) Toll-like receptor 2 and palmitic acid cooperatively contribute to the development of Non-alcoholic steatohepatitis through inflammasome activation in mice. Hepatology 57 (2):577-589. doi:10.1002/hep.26081

7. Pierantonelli I, Rychlicki C, Agostinelli L, Giordano DM, Gaggini M, Fraumene C, Saponaro C, Manghina V, Sartini L, Mingarelli E, Pinto C, Buzzigoli E, Trozzi L, Giordano A, Marzioni M, Minicis S, Uzzau S, Cinti S, Gastaldelli A, Svegliati-Baroni G (2017) Lack of NLRP3-inflammasome leads to gut-liver axis derangement, gut dysbiosis and a worsened phenotype in a mouse model of NAFLD. Scientific reports 7 (1):12200. doi:10.1038/s41598-017-117446

8. Roh YS, Seki E (2013) Toll-like receptors in alcoholic liver disease, non-alcoholic steatohepatitis and carcinogenesis. J Gastroenterol Hepatol 28 Suppl 1:38-42. doi:10.1111/jgh.12019

9. Bieghs V, Trautwein C (2014) Innate immune signaling and gut-liver interactions in non-alcoholic fatty liver disease. Hepatobiliary Surg Nutr 3 (6):377-385. doi:10.3978/j.issn.2304-3881.2014.12.04

10. Cani PD, Amar J, Iglesias MA, Poggi M, Knauf C, Bastelica D, Neyrinck AM, Fava F, Tuohy KM, Chabo C, Waget A, Delmee E, Cousin B, Sulpice T, Chamontin B, Ferrieres J, Tanti JF, Gibson GR, Casteilla L, Delzenne NM, Alessi MC, Burcelin R (2007) Metabolic endotoxemia initiates obesity and insulin resistance. Diabetes 56 (7):1761-1772 11. Verges B, Duvillard L, Lagrost L, Vachoux C, Garret C, Bouyer K, Courtney M, Pomie C, Burcelin R (2014) Changes in lipoprotein kinetics associated with type 2 diabetes affect the distribution of lipopolysaccharides 
bioRxiv preprint doi: https://doi.org/10.1101/2020.12.10.419051; this version posted December 12, 2020. The copyright holder for this preprint (which was not certified by peer review) is the author/funder, who has granted bioRxiv a license to display the preprint in perpetuity. It is made available under aCC-BY-NC-ND 4.0 International license.

among lipoproteins. The Journal of clinical endocrinology and metabolism 99 (7):E1245-1253. doi:10.1210/jc.2013-3463

12. Berg RD, Wommack E, Deitch EA (1988) Immunosuppression and intestinal bacterial overgrowth synergistically promote bacterial translocation. Arch Surg 123 (11):1359-1364

13. Amar J, Chabo C, Waget A, Klopp P, Vachoux C, Bermudez-Humaran LG, Smirnova N, Berge M, Sulpice T, Lahtinen S, Ouwehand A, Langella P, Rautonen N, Sansonetti PJ, Burcelin R (2011) Intestinal mucosal adherence and translocation of commensal bacteria at the early onset of type 2 diabetes: molecular mechanisms and probiotic treatment. EMBO Mol Med 3 (9):559-572. doi:10.1002/emmm.201100159

14. Garidou L, Pomie C, Klopp P, Waget A, Charpentier J, Aloulou M, Giry A, Serino M, Stenman L, Lahtinen S, Dray C, lacovoni JS, Courtney M, Collet X, Amar J, Servant F, Lelouvier B, Valet P, Eberl G, Fazilleau N, Douin-Echinard V, Heymes C, Burcelin R (2015) The Gut Microbiota Regulates Intestinal CD4 T Cells Expressing RORgammat and Controls Metabolic Disease. Cell Metab 22 (1):100-112. doi:10.1016/j.cmet.2015.06.001

15. Pomie C, Blasco-Baque V, Klopp P, Nicolas S, Waget A, Loubieres P, Azalbert V, Puel A, Lopez F, Dray C, Valet P, Lelouvier B, Servant F, Courtney M, Amar J, Burcelin R, Garidou L (2016) Triggering the adaptive immune system with commensal gut bacteria protects against insulin resistance and dysglycemia. Mol Metab 5 (6):392-403. doi:10.1016/j.molmet.2016.03.004

16. Sookoian S, Salatino A, Castano GO, Landa MS, Fijalkowky C, Garaycoechea M, Pirola CJ (2020) Intrahepatic bacterial metataxonomic signature in non-alcoholic fatty liver disease. Gut. doi:10.1136/gutjnl-2019-318811 17. Amar J, Serino M, Lange C, Chabo C, lacovoni J, Mondot S, Lepage P, Klopp C, Mariette J, Bouchez O, Perez L, Courtney M, Marre M, Klopp P, Lantieri O, Dore J, Charles M, Balkau B, Burcelin R (2011) Involvement of tissue bacteria in the onset of diabetes in humans: evidence for a concept. Diabetologia 54 (12):3055-3061. doi:10.1007/s00125-011-2329-8

18. Burcelin R, Serino M, Chabo C, Garidou L, Pomie C, Courtney M, Amar J, Bouloumie A (2013) Metagenome and metabolism: the tissue microbiota hypothesis. Diabetes Obes Metab 15 Suppl 3:61-70. doi:10.1111/dom.12157 19. Balmer ML, Slack E, de Gottardi A, Lawson MA, Hapfelmeier S, Miele L, Grieco A, Van Vlierberghe H, Fahrner R, Patuto N, Bernsmeier C, Ronchi F, Wyss M, Stroka D, Dickgreber N, Heim MH, McCoy KD, Macpherson AJ (2014) The liver may act as a firewall mediating mutualism between the host and its gut commensal microbiota. Sci Transl Med 6 (237):237ra266. doi:10.1126/scitranslmed.3008618

20. Lelouvier B, Servant F, Paisse S, Brunet AC, Benyahya S, Serino M, Valle C, Ortiz MR, Puig J, Courtney M, Federici M, Fernandez-Real JM, Burcelin R, Amar J (2016) Changes in blood microbiota profiles associated with liver fibrosis in obese patients: A pilot analysis. Hepatology (Baltimore, Md) 64 (6):2015-2027. doi:10.1002/hep.28829

21. Loomba R, Seguritan V, Li W, Long T, Klitgord N, Bhatt A, Dulai PS, Caussy C, Bettencourt R, Highlander SK, Jones MB, Sirlin CB, Schnabl B, Brinkac L, Schork N, Chen CH, Brenner DA, Biggs W, Yooseph S, Venter JC, Nelson KE (2017) Gut Microbiome-Based Metagenomic Signature for Non-invasive Detection of Advanced Fibrosis in Human Non-alcoholic Fatty Liver Disease. Cell Metab 25 (5):1054-1062 e1055. doi:10.1016/j.cmet.2017.04.001 22. Schierwagen R, Alvarez-Silva C, Madsen MSA, Kolbe CC, Meyer C, Thomas D, Uschner FE, Magdaleno F, Jansen C, Pohlmann A, Praktiknjo M, Hischebeth GT, Molitor E, Latz E, Lelouvier B, Trebicka J, Arumugam M (2018) Circulating microbiome in blood of different circulatory compartments. Gut. doi:10.1136/gutjnl-2018-316227 23. Jolliffe IT, Cadima J (2016) Principal component analysis: a review and recent developments. Philos Trans A Math Phys Eng Sci 374 (2065):20150202. doi:10.1098/rsta.2015.0202

24. Luche E, Cousin B, Garidou L, Serino M, Waget A, Barreau C, Andre M, Valet P, Courtney M, Casteilla L, Burcelin R (2013) Metabolic endotoxemia directly increases the proliferation of adipocyte precursors at the onset of metabolic diseases through a CD14-dependent mechanism. Mol Metab 2 (3):281-291.

doi:10.1016/j.molmet.2013.06.005

25. Escudie F, Auer L, Bernard M, Mariadassou M, Cauquil L, Vidal K, Maman S, Hernandez-Raquet G, Combes S, Pascal G (2018) FROGS: Find, Rapidly, OTUs with Galaxy Solution. Bioinformatics (Oxford, England) 34 (8):12871294. doi:10.1093/bioinformatics/btx791

26. Douglas GM, Maffei VJ, Zaneveld JR, Yurgel SN, Brown JR, Taylor CM, Huttenhower C, Langille MGI (2020) PICRUSt2 for prediction of metagenome functions. Nat Biotechnol 38 (6):685-688. doi:10.1038/s41587-020-05486

27. Segata N, Izard J, Waldron L, Gevers D, Miropolsky L, Garrett WS, Huttenhower C (2011) Metagenomic biomarker discovery and explanation. Genome biology 12 (6):R60. doi:10.1186/gb-2011-12-6-r60 28. Kanehisa M, Goto S, Sato Y, Furumichi M, Tanabe M (2012) KEGG for integration and interpretation of largescale molecular data sets. Nucleic Acids Res 40 (Database issue):D109-114. doi:10.1093/nar/gkr988 
bioRxiv preprint doi: https://doi.org/10.1101/2020.12.10.419051; this version posted December 12, 2020. The copyright holder for this preprint (which was not certified by peer review) is the author/funder, who has granted bioRxiv a license to display the preprint in perpetuity. It is made available under aCC-BY-NC-ND 4.0 International license.

29. Iwata-Reuyl D (2003) Biosynthesis of the 7-deazaguanosine hypermodified nucleosides of transfer RNA. Bioorg Chem 31 (1):24-43. doi:10.1016/s0045-2068(02)00513-8

30. McCarty RM, Somogyi A, Lin G, Jacobsen NE, Bandarian V (2009) The deazapurine biosynthetic pathway revealed: in vitro enzymatic synthesis of $\operatorname{PreQ}(0)$ from guanosine 5 '-triphosphate in four steps. Biochemistry 48 (18):3847-3852. doi:10.1021/bi900400e

31. Dunphy PJ, Phillips PG, Brodie AF (1971) Separation and identification of menaquinones from microorganisms. J Lipid Res 12 (4):442-449

32. Farrand SK, Taber HW (1973) Physiological effects of menaquinone deficiency in Bacillus subtilis. J Bacteriol 115 (3):1035-1044. doi:10.1128/JB.115.3.1035-1044.1973

33. Latino L, Caroff M, Pourcel C (2017) Fine structure analysis of lipopolysaccharides in bacteriophage-resistant Pseudomonas aeruginosa PAO1 mutants. Microbiology 163 (6):848-855. doi:10.1099/mic.0.000476

34. Vijay-Kumar M, Aitken JD, Carvalho FA, Cullender TC, Mwangi S, Srinivasan S, Sitaraman SV, Knight R, Ley RE, Gewirtz AT (2010) Metabolic syndrome and altered gut microbiota in mice lacking Toll-like receptor 5. Science 328 (5975):228-231. doi:10.1126/science.1179721

35. Le Cao KA, Rossouw D, Robert-Granie C, Besse P (2008) A sparse PLS for variable selection when integrating omics data. Statistical applications in genetics and molecular biology 7 (1):Article 35. doi:10.2202/1544-6115.1390 36. Wang L, Zhang Y, Zhang Y, Xu X, Cao S (2017) Prescription Function Prediction Using Topic Model and Multilabel Classifiers. Evid Based Complement Alternat Med 2017:8279109. doi:10.1155/2017/8279109

\section{Figure and table legends}

Fig. 1: Visualization of clinical variables by principal component analysis according to countries and fibrosis scores.

The clinical variables were used as entries for a principal component analysis (PCA). PCA-biplot from package Factoextra and FactomineR of individuals for the first two principal components are shown. They sum up $30.4 \%$ of the total variance of the dataset. Patients were grouped by A, countries (red dots=Austria, green triangle=Italy, blue square=Romania, purple cross=Spain) and by $\mathbf{B}$, fibrosis scores (red dots $=\mathrm{F} 0$, green triangle $=\mathrm{F} 1$, blue square $=\mathrm{F} 2$ ). The vectors corresponding to the clinical variables are shown as arrows.

Fig. 2: Visualization of liver 16SrDNA sequences by principal component analyses according to countries and fibrosis scores.

The 16SrDNA OTUs sequences were used as entries for a principal component analysis (PCA). PCAbiplot from package Factoextra and FactomineR of individuals for the first two principal components are shown. They sum up $10.0 \%$ of the total variance of the dataset. Patients were grouped by A, countries 
(red dots=Austria, green triangle=Italy, blue square=Romania, purple cross=Spain) and by $\mathbf{B}$, fibrosis scores (red dots=F0, green triangle $=\mathrm{F} 1$, blue square $=\mathrm{F} 2$ ). The vectors corresponding to the clinical variables are shown as arrows. C Barplot depicting the frequencies of liver microbial composition of each patient at the phylum level or $\mathbf{D}$ as means of the phyla frequencies or $\mathbf{E}$ the family frequencies for the overall cohort (total) or according to the fibrosis scores (F0, F1, F2).

Fig. 3: Discriminant analysis strategies of the liver microbiota 16SrDNA OTUs according to the fibrosis scores.

Venn diagrams where $\mathbf{A}$ all the 16SrDNA taxa or $\mathbf{B}$ data after removing those extremely rare and with unbalanced distribution within the 3 groups of patients with liver fibrosis, were used as entry variables characterizing the 3 liver fibrosis scores (red=F0, green=F1, blue=F2). C Heatmap of normalized OTU counts according to the 3 groups of patients with liver fibrosis scores and $\mathbf{D}$ a corresponding subset of normalized OTU counts with groups of patients fixed. E LEfSe cladogram of taxonomic assignments from 16SrDNA sequence data of the two liver biopsy fibrosis groups (F0 and F1). The cladogram shows the taxonomic levels represented by rings with phyla at the innermost ring and genera at the outermost ring, and each circle is a member within that level. Taxa at each level are shaded according to the liver fibrosis group in which it is more abundant ( $\mathrm{P}<0.05$; LDA score $\geq 2.0$ ). LDA scores are shown on the right panel for each taxon. F sPLSDA classification performance on a CSS normalized microbial table count of the F0 versus F1/2 groups of patients. Sample plot, each point corresponds to an individual and is colored according to its fibrosis score (red=F0, green=F1/2). G Clustering Image Map (CIM) of the OTUs selected on each sPLS-DA component. H Heatmap of the OTUs selected on each sPLS-DA component with groups of patients fixed. I ROC calculated on the predicted scores obtained from the sPLSDA model.

\section{Fig.4: discriminant analyses of the 16SrDNA OTUs variables using fairness strategies}

A Distribution curves (or densities) of the coordinate of individuals, split into two cohort types

(black=Romania, red= the other countries: Italy, Austria, and Spain), when projected on the five first 
principal components built from the 16SrDNA OTUs normalized table count. The non-overlapping plots (for example components 1,2,3) correspond to cohort discriminant components and will be removed from the final analysis to identify the liver fibrosis discriminant variables.

Boxplot representing the frequencies of the most significant OTUs contributing to $\mathbf{B}$ the $6^{\text {th }}, \mathbf{C}$ the $24^{\text {th }}, \mathbf{D}$ the $52^{\text {nd }}$ principal components for the different groups of liver fibrosis scores (red=F0, green=F1, blue $=\mathrm{F} 2$ ).

E Graphical representation of the normalized OTU table counts whose nodes are colored according to the 5 clusters identified by the 11 -spectral clustering algorithm ( $\mathrm{red}=1$, green $=2$, blue, 3 , pink $=4$ and yellow= 5).

F Boxplot representing the mean frequencies of the OTUs in cluster 3, 4 and 5, identified by the 11spectral clustering algorithm, for the different groups of liver fibrosis scores (red=F0, green=F1, blue $=$ F2).

G, H Boxplot representing the frequencies of OTUs in cluster 1, and 2, identified by fair-tree algorithm, for the different groups of liver fibrosis scores (red=F0, green=F1, blue=F2).

I Venn diagram depicting the liver microbial taxonomies of common OTUs identified by standard (sPLSDA) and fair approaches (fairtree, random forest, 11-spectral clustering) as signatures of low fibrosis scores $($ green $=$ sPLSDA, red $=$ fair algorithms).

Fig.5: identification of clusters by wordclouds representation with or without TFIDF normalization.

Wordclouds representing taxa of all significant bacteria according to $\mathbf{A}$, their frequencies or $\mathbf{B}$, after TFIDF normalization. The size of the name of bacteria is proportional to the frequency of the cluster in the cohorts. 
Fig.6: Predicted functional metagenomics analyses of discriminant enzymes and according to the

\section{fibrosis score.}

A,D: Heatmap (Clustering Image Map (CIM)), B,E: Sample plot, each point corresponds to an individual and is colored according to its liver fibrosis score (red=F0, green=F1/2), C,F: ROC classification performances of A-C: enzymes, and D-F: pathways, on a CSS normalized enzyme table count of the F0 versus F1/2 groups of patients.

G-I: Loading plot representing the contribution of each enzyme $(\mathbf{G}, \mathbf{H})$, and pathways $(\mathbf{I}, \mathbf{J})$ selected to build the first and second components (red=F0, green=F1/2).

K,L: main metabolic pathways from the MetaCyc database identified from the Loading plots for the K: F1-2 and K: F0 liver fibrosis scores.

\section{Supplementary Figure 1: mean frequencies of discriminating taxa}

Boxplot representing the frequencies of A Proteobacteria, B Actinobacteria C Firmicutes phyla and D Caulobacteraceae, E, Flavobacteriaceae, and F, Propionibacteriaceae families throughout two groups of liver fibrosis scores (red=F0, green=F1, blue=F2).

\section{Supplementary Figure 2: alpha and beta microbial diversity}

Boxplot showing microbial alpha diversity $\mathbf{A}$ at the OTU, B, phylum, C, and family taxonomic level calculated according to the Chao, Shannon, Simpson, inv Simpson indexes for the 3 liver fibrosis scores. D PCoA showing Bray Curtis beta diversity of the normalized OTU table count. Dots are assigned to individual patients and colored according to their fibrosis score (red=F0, blue=F2, green=F1). E Hierarchical clustering of patients colored according to their fibrosis score (red=F0, blue=F2, green=F1) based on Bray Curtis OTU distance. 
bioRxiv preprint doi: https://doi org/10.1101/2020.1210.419051; this version posted December 12, 2020. The copyright holder for this preprint (which was not certified by peer review) is the author/funder, who has granted bioRxiv a license to display the preprint in perpetuity. It is made available under aCC-BY-NC-ND 4.0 International license.

\section{Supplementary Figure 3: Discriminant microbial signatures identified by linear effect size}

LEfSe cladogram and LDA scores of taxonomic assignments from 16S rDNA sequence data of two liver biopsy fibrosis groups A F1 vs F2, and B F0 vs F2. 
bioRxiv preprint doi: https://doi.org/10.1101/2020.12.10.419051; this version posted December $12,2020$. The copyright holder for this preprint (which was not certified by peer review) is the author/funder, who has granted bioRxiv a license to display the preprint in perpetuity. It is made available under aCC-BY-NC-ND 4.0 International license.

Table 1. Baseline characteristics of patients with biopsy-proven fibrosis.

\begin{tabular}{|c|c|c|c|c|c|c|c|}
\hline Characteristics & $\begin{array}{c}\text { All patients } \\
\quad \mathrm{N}=82\end{array}$ & $\begin{array}{c}\text { Stage F0 } \\
\mathrm{N}=34\end{array}$ & $\begin{array}{c}\text { Stage F1 } \\
\mathbf{N}=37\end{array}$ & $\begin{array}{c}\text { Stage F2 } \\
\mathrm{N}=11\end{array}$ & $\begin{array}{c}\text { p Va- } \\
\text { lue } \\
\text { F0vsF1 }\end{array}$ & $\begin{array}{c}\text { p Va- } \\
\text { lue } \\
\text { F2vsFo }\end{array}$ & $\begin{array}{c}\text { p Va- } \\
\text { lue } \\
\text { F2vsF1 }\end{array}$ \\
\hline Age (years) & $41.50 \pm 11.52$ & $39.5 \pm 12.77$ & $39 \pm 9.53$ & $50 \pm 9.15$ & 0.99 & 0.16 & $0.03 *$ \\
\hline Female (n) & $47(57 \%)$ & $15(18 \%)$ & $26(32 \%)$ & $6(7.3 \%)$ & 0.65 & 0.99 & 0.97 \\
\hline Height (m) & $1.67 \pm 0.08$ & $1.67 \pm 0.08$ & $1.7 \pm 0.08$ & $1.62 \pm 0.07$ & 0.99 & 0.61 & 0.14 \\
\hline Smoker (n) & $22(27 \%)$ & $10(12 \%)$ & $10(12 \%)$ & $2(3 \%)$ & 0.99 & 0.99 & 0.97 \\
\hline Weight (kg) & $118.5 \pm 23.99$ & $120 \pm 22.55$ & $118 \pm 21.59$ & $115.8 \pm 35.77$ & 0.99 & 0.99 & 0.97 \\
\hline $\operatorname{BMI}\left(\mathrm{kg} / \mathrm{m}^{2}\right)$ & $42.65 \pm 7.73$ & $43.25 \pm 6.9$ & $41.6 \pm 7.2$ & $41.52 \pm 11.41$ & 0.99 & 0.99 & 0.97 \\
\hline Waist $(\mathrm{cm})$ & $121 \pm 18.37$ & $124.5 \pm 19.4$ & $120 \pm 15.61$ & $120 \pm 24.12$ & 0.99 & 0.99 & 0.99 \\
\hline $\begin{array}{l}\text { Blood Glucose } \\
\text { (mg/dl) }\end{array}$ & $95.7 \pm 25.76$ & $95 \pm 27.46$ & $99 \pm 21.22$ & $95 \pm 34.63$ & 0.99 & 0.99 & 0.97 \\
\hline $\begin{array}{c}\text { Treated Diabetes } \\
\text { (n) }\end{array}$ & $7(8.5 \%)$ & $1(1.2 \%)$ & $2(2 \%)$ & $4(4.7 \%)$ & 0.99 & $0.02 *$ & $0.027 *$ \\
\hline Systolic (mm Hg) & $130 \pm 19.47$ & $130.5 \pm 20.76$ & $124 \pm 17.43$ & $134 \pm 18.45$ & 0.65 & 0.99 & 0.73 \\
\hline $\begin{array}{c}\text { Diastolic }(\mathrm{mm} \\
\mathrm{Hg})\end{array}$ & $80.0 \pm 11.59$ & $80.5 \pm 11.4$ & $75 \pm 10.31$ & $90 \pm 15.3$ & 0.88 & 0.99 & 0.97 \\
\hline $\begin{array}{l}\text { Treated Hyper- } \\
\text { tension }(\mathrm{n})\end{array}$ & $20(24 \%)$ & $8(9.7 \%)$ & $5(6 \%)$ & $7(8.2 \%)$ & 0.99 & 0.15 & $0.027 *$ \\
\hline $\begin{array}{l}\text { Treated Dysli- } \\
\text { pidemia (n) }\end{array}$ & $6(7.3 \%)$ & $2(2 \%)$ & $3(3.6 \%)$ & $1(1.2 \%)$ & 0.99 & 0.99 & 0.99 \\
\hline $\begin{array}{l}\text { Total Cholesterol } \\
\text { (mg/dL) }\end{array}$ & $189.1 \pm 39.78$ & $190.0 \pm 36.93$ & $\begin{array}{c}200.0 \pm \\
43.11\end{array}$ & $167.0 \pm 38.71$ & 0.99 & 0.99 & 0.97 \\
\hline $\begin{array}{l}\text { HDL Cholesterol } \\
\text { (mg/dL) }\end{array}$ & $43.91 \pm 13.38$ & $47 \pm 11.73$ & $43 \pm 13.48$ & $42 \pm 16.62$ & 0.99 & 0.61 & 0.97 \\
\hline GOT (U/1) & $20.85 \pm 17.56$ & $18.50 \pm 18.14$ & $22 \pm 18.97$ & $22 \pm 7.54$ & 0.99 & 0.99 & 0.97 \\
\hline GPT (U/1) & $27.50 \pm 25.23$ & $23.50 \pm 17.50$ & $29 \pm 31.91$ & $30 \pm 14.16$ & 0.65 & 0.99 & 0.97 \\
\hline GGT (U/1) & $29 \pm 23.04$ & $27.50 \pm 18.04$ & $30 \pm 25.84$ & $32 \pm 23.3$ & 0.65 & 0.61 & 0.99 \\
\hline $\mathrm{HCT}(\%)$ & $41 \pm 4.03$ & $40 \pm 4.09$ & $41.1 \pm 3.05$ & $40.5 \pm 6.13$ & 0.99 & 0.99 & 0.94 \\
\hline Leukocytes (G/L) & $7.84 \pm 2.63$ & $7.48 \pm 2.4$ & $8.1 \pm 2.39$ & $7.8 \pm 3.7$ & 0.99 & 0.61 & 0.97 \\
\hline Neutrophils (G/L) & $5 \pm 2.44$ & $4.8 \pm 2.36$ & $5.15 \pm 2.28$ & $5.3 \pm 3.2$ & 0.99 & 0.99 & 0.99 \\
\hline
\end{tabular}

Statistical significance is noted with * when $\mathrm{p}<0.05$ 
TABLE 2: Identification of specific bacterial signatures (unfair analyses).

\begin{tabular}{|c|c|c|c|}
\hline FO & & & \\
\hline OTU name & Phylum & Family & Genus \\
\hline Cluster_30 & Proteobacteria & Moraxellaceae & Acinetobacter \\
\hline Cluster_74 & Firmicutes & Ruminococcaceae & Faecalibacterium \\
\hline Cluster_35 & Actinobacteria & Microbacteriaceae & Rhodoluna \\
\hline Cluster_28 & Actinobacteria & Micrococcaceae & Kocuria \\
\hline Cluster_21 & Proteobacteria & Caulobacteraceae & Caulobacter \\
\hline
\end{tabular}

\begin{tabular}{|c|c|c|c|}
\hline F1 & & & \\
\hline OTU name & Phylum & Family & Genus \\
\hline Cluster_43 & Proteobacteria & Pseudomonadaceae & Pseudomonas \\
\hline Cluster_31 & Proteobacteria & Pseudomonadaceae & Pseudomonas \\
\hline Cluster_25 & Proteobacteria & Enterobacteriaceae & Multi-affiliation \\
\hline Cluster_37 & Proteobacteria & Rhodobacteraceae & Paracoccus \\
\hline Cluster_40 & Bacteroidetes & Chitinophagaceae & Ferruginibacter \\
\hline
\end{tabular}

\begin{tabular}{|c|c|c|c|}
\hline \multicolumn{1}{|c|}{ F2 } & \multicolumn{2}{|c|}{ Family } & Genus \\
\hline OTU name & Phylum & Lachnospiraceae & Multi-affiliation \\
\hline Cluster_122 & Firmicutes & Corynebacterium \\
Cluster_59 & Actinobacteria & Corynebacteriaceae & 1 \\
\hline Cluster_34 & Bacteroidetes & Weeksellaceae & Cloacibacterium \\
\hline Cluster_48 & Firmicutes & Peptostreptococcaceae & Romboutsia \\
\hline Cluster_42 & Proteobacteria & Burkholderiaceae & Tepidimonas \\
\hline Cluster_26 & Firmicutes & Streptococcaceae & Lactococcus \\
\hline Cluster_53 & Bacteroidetes & Weeksellaceae & Cloacibacterium \\
\hline Cluster_18 & Proteobacteria & Enterobacteriaceae & Pantoea \\
\hline Cluster_115 & Proteobacteria & Burkholderiaceae & Delftia \\
\hline Cluster_50 & Actinobacteria & Microbacteriaceae & Clavibacter \\
\hline Cluster_91 & Actinobacteria & Corynebacteriaceae & Corynebacterium \\
\hline Cluster_54 & Proteobacteria & Burkholderiaceae & Ralstonia \\
\hline
\end{tabular}

Clusters were identified from the overall database prior to applying the fair strategies. The impact of countries is observed as shown in Fig 2. 
TABLE 3. Identification of clusters of cohort-independent 16SrDNA associated with the different

low scores of fibrosis

\begin{tabular}{|l|l|l|l|l|}
\hline sPLSDA & \multicolumn{2}{l}{} \\
\cline { 1 - 2 } OTU name & Phylum & Family & Genus & Significance \\
\hline Cluster_20 & Proteobacteria & Burkholderiaceae & Ralstonia & F0 VS F1 \\
\hline Cluster_15 & Proteobacteria & Xanthobacteraceae & Bradyrhizobium & F0 VS F1 \\
\hline Cluster_16 & Proteobacteria & Enterobacteriaceae & Multi-affiliation & F0 VS F1 \\
\hline Cluster_31 & Proteobacteria & Pseudomonadaceae & Pseudomonas & F0 VS F1 \\
\hline Cluster_24 & Proteobacteria & Enterobacteriaceae & Kluyvera & F0 VS F1 \\
\hline Cluster_14 & Proteobacteria & Xanthomonadaceae & Stenotrophomonas & F0 VS F1 \\
\hline Cluster_4 & Proteobacteria & Enterobacteriaceae & Multi-affiliation & F0 VS F1 \\
\hline Cluster_25 & Proteobacteria & Enterobacteriaceae & Multi-affiliation & F0 VS F1 and F0 VS F2 \\
\hline Cluster_11 & Proteobacteria & Pseudomonadaceae & Pseudomonas & F0 VS F1 \\
\hline Cluster_89 & Actinobacteria & Corynebacteriaceae & Corynebacterium 1 & F0 VS F1 and F0 VS F2 \\
\hline Cluster_5 & Bacteroidetes & Flavobacteriaceae & Flavobacterium & F0 VS F1 and F0 VS F2 \\
\hline
\end{tabular}

\begin{tabular}{|l|l|l|l|l|}
\hline Fair-tree & \multicolumn{5}{l}{ Significance } \\
\hline OTU name & Phylum & Family & Genus & F0 VS F1 \\
\hline Cluster_31 & Proteobacteria & Pseudomonadaceae & Pseudomonas & F1 VS F2 and F0 VS F2 \\
\hline Cluster_66 & Proteobacteria & Pasteurellaceae & Haemophilus & F0 VS F1 \\
\hline Cluster_335 & Proteobacteria & Burkholderiaceae & Janthinobacterium & F0 VS F1 \\
\hline Cluster_42 & Proteobacteria & Burkholderiaceae & Tepidimonas & F0 VS F1 \\
\hline Cluster_341 & Proteobacteria & Enterobacteriaceae & Enterobacter & F0 VS F1 and F0 VS F2 \\
\hline Cluster_248 & Proteobacteria & Reyranellaceae & Reyranella & F0 VS F1 \\
\hline Cluster_231 & Proteobacteria & Enterobacteriaceae & Multi-affiliation & F1 VS F2 and F0 VS F2 \\
\hline Cluster_36 & Bacteroidetes & Flavobacteriaceae & Flavobacterium & F1 VS F2 and F0 VS F2 \\
\hline Cluster_64 & Actinobacteria & Corynebacteriaceae & Lawsonella & F1 VS F2 \\
\hline Cluster_339 & Proteobacteria & Burkholderiaceae & Limnohabitans & F0 VS F1 \\
\hline Cluster_15 & Proteobacteria & Xanthobacteraceae & Bradyrhizobium & F0 VS F1 and F0 VS F2 \\
\hline Cluster_44 & Actinobacteria & Intrasporangiaceae & Multi-affiliation & F0 VS F1 \\
\hline Cluster_25 & Proteobacteria & Enterobacteriaceae & Multi-affiliation & F0 VS F1 \\
\hline Cluster_45 & Proteobacteria & Burkholderiaceae & Comamonas & F0 VS F1 \\
\hline Cluster_14 & Proteobacteria & Xanthomonadaceae & Stenotrophomonas & \\
\hline
\end{tabular}

\begin{tabular}{|l|l|l|l|l|}
\hline Fair Random Forest & \multicolumn{2}{l|}{} \\
\cline { 1 - 2 } OTU name & Phylum & Family & Genus & Significance \\
\hline Cluster_14 & Proteobacteria & Xanthomonadaceae & Stenotrophomonas & F0 VS F1 \\
\hline Cluster_77 & Proteobacteria & Enterobacteriaceae & Multi-affiliation & F1 VS F2 and F0 VS F2 \\
\hline Cluster_35 & Actinobacteria & Microbacteriaceae & Rhodoluna & F0 VS F1 \\
\hline Cluster_36 & Bacteroidetes & Flavobacteriaceae & Flavobacterium & F0 VS F1 \\
\hline Cluster_16 & Proteobacteria & Enterobacteriaceae & Multi-affiliation & F0 VS F1 and F0 VS F2 \\
\hline Cluster_312 & Proteobacteria & Enterobacteriaceae & Kosakonia & F0 VS F1 \\
\hline Cluster_24 & Proteobacteria & Enterobacteriaceae & Kluyvera & FO VS F1 \\
\hline
\end{tabular}


bioRxiv preprint doi: https://doi org/101101/2020.1210.419051; this version posted December 12, 2020. The copyright holder for this preprint (which was not certified by peer review) is the author/funder, who has granted bioRxiv a license to display the preprint in perpetuity. It is made available under aCC-BY-NC-ND 4.0 International license.

\begin{tabular}{|l|l|l|l|l|}
\hline Fair I1_spectral clustering & \multicolumn{2}{l|}{} & Genus & Significance \\
\hline OTU name & Phylum & Family & F0 VS F1 \\
\hline Cluster_31 & Proteobacteria & Pseudomonadaceae & Pseudomonas & F0 VS F1 \\
\hline Cluster_15 & Proteobacteria & Xanthobacteraceae & Bradyrhizobium & F0 VS F1 \\
\hline Cluster_20 & Proteobacteria & Enterobacteriaceae & Enterobacter & F0 VS F1 \\
\hline Cluster_4 & Proteobacteria & Burkholderiaceae & Ralstonia & F0 VS F1 \\
\hline Cluster_2 & Proteobacteria & Enterobacteriaceae & Multi-affiliation & F0 VS F1 \\
\hline Cluster_27 & Proteobacteria & Enterobacteriaceae & Escherichia-Shigella & F0 VS F1 \\
\hline Cluster_3 & Proteobacteria & Enterobacteriaceae & Serratia & F0 VS F1 \\
\hline Cluster_24 & Proteobacteria & Pseudomonadaceae & Pseudomonas & F0 VS F1 \\
\hline Cluster_22 & Proteobacteria & Enterobacteriaceae & Kluyvera & F0 VS F1 \\
\hline Cluster_16 & Proteobacteria & Burkholderiaceae & Multi-affiliation & F0 VS F1 \\
\hline
\end{tabular}


bioRxiv preprint doi: https://doi.org/101101/20201210.419051; this version posted December 12, 2020. The copyright holder for this preprint (which was not certified by peer review) is the author/funder, who has granted bioRxiv a license to display the preprint in perpetuity. It is made available under aCC-BY-NC-ND 4.0 International license.

TABLE 4. Microbial signatures common to all strategies.

\begin{tabular}{|l|l|l|l|l|l|}
\hline OTU name & Phylum & Family & Genus & Species & Significance \\
\hline Cluster_31 & Proteobacteria & Pseudomonadaceae & Pseudomonas & $\begin{array}{l}\text { Pseudomonas } \\
\text { putida }\end{array}$ & F0 VS F1 \\
\hline Cluster_15 & Proteobacteria & Xanthobacteraceae & Bradyrhizobium & $\begin{array}{l}\text { Bradyrhizobium } \\
\text { sp. }\end{array}$ & F0 VS F1 \\
\hline Cluster_25 & Proteobacteria & Enterobacteriaceae & Multi-affiliation & Multi-affiliation & F0 VS F1 \\
\hline Cluster_14 & Proteobacteria & Xanthomonadaceae & Stenotrophomonas & Multi-affiliation & F0 VS F1 \\
\hline Cluster_16 & Proteobacteria & Enterobacteriaceae & Multi-affiliation & Multi-affiliation & F0 VS F1 \\
\hline Cluster_24 & Proteobacteria & Enterobacteriaceae & Kluyvera & Multi-affiliation & F0 VS F1 \\
\hline Cluster_20 & Proteobacteria & Burkholderiaceae & Ralstonia & Multi-affiliation & F0 VS F1 \\
\hline Cluster_4 & Proteobacteria & Enterobacteriaceae & Multi-affiliation & Multi-affiliation & F0 VS F1 \\
\hline
\end{tabular}


bioRxiv preprint doi: https://doi.org/10.1101/2020.12.10.419051; this version posted December 12, 2020. The copyright holder for this preprint (which was not certified by peer review) is the author/funder, who has granted bioRxiv a license to display the preprint in perpetuity. It is made available under aCC-BY-NC-ND 4.0 International license.

Table 5: Identification of specific enzymes and pathways, signatures of low score of fibrosis.

\begin{tabular}{|c|c|c|}
\hline & Name & Function \\
\hline \multirow{30}{*}{ Enzymes } & EC:4.1.2.52 & 4-hydroxy-2-oxoheptanedioate aldolase \\
\hline & $E C: 3.5 .4 .1$ & Cytosine deaminase \\
\hline & EC:3.2.2.4 & AMP nucleosidase \\
\hline & $E C: 4.3 .3 .7$ & 4-hydroxy-tetrahydrodipicolinate synthase \\
\hline & EC:6.3.4.20 & 7-cyano-7-deazaguanine synthase \\
\hline & EC:1.7.1.13 & PreQ(1) synthase \\
\hline & EC:5.4.99.19 & 16S rRNA pseudouridine(516) synthase \\
\hline & EC:4.3.99.3 & 7-carboxy-7-deazaguanine synthase \\
\hline & EC:3.6.1.41 & Bis(5'-nucleosyl)-tetraphosphatase (symmetrical) \\
\hline & EC:3.4.24.70 & Oligopeptidase A \\
\hline & EC:2.1.1.197 & Malonyl-[acyl-carrier protein] O-methyltransferase \\
\hline & EC:4.1.3.40 & Chorismate lyase \\
\hline & $E C: 3.1 .1 .85$ & Pimeloyl-[acyl-carrier protein] methyl ester esterase \\
\hline & EC:2.1.1.200 & tRNA (cytidine(32)/uridine(32)-2'-0)-methyltransferase \\
\hline & EC:2.1.1.173 & 23S rRNA (guanine(2445)-N(2))-methyltransferase \\
\hline & EC:2.1.1.264 & 23S rRNA (guanine(2069)-N(7))-methyltransferase \\
\hline & EC:2.3.1.183 & Phosphinothricin acetyltransferase \\
\hline & $\mathrm{EC}: 2.5 .1 .17$ & Cob(I)yrinic acid a,c-diamide adenosyltransferase \\
\hline & EC:1.1.1.95 & Phosphoglycerate dehydrogenase \\
\hline & EC:2.4.1.21 & Starch synthase \\
\hline & $\mathrm{EC}: 2.4 .1 .18$ & 1,4-alpha-glucan branching enzyme \\
\hline & EC:2.6.1.52 & Phosphoserine transaminase \\
\hline & EC:2.1.1.207 & tRNA (cytidine(34)-2'-O)-methyltransferase \\
\hline & EC:4.1.3.3 & $\mathrm{N}$-acetylneuraminate lyase \\
\hline & $\mathrm{EC}: 3.2 .1 .22$ & Alpha-galactosidase \\
\hline & EC:2.4.1.187 & mannosaminyltransferase \\
\hline & EC:3.1.21.4 & Type II site-specific deoxyribonuclease \\
\hline & EC:2.7.6.2 & Thiamine diphosphokinase \\
\hline & EC:3.2.1.89 & Arabinogalactan endo-beta-1,4-galactanase \\
\hline & EC:3.5.99.6 & Glucosamine-6-phosphate deaminase \\
\hline \multirow{11}{*}{ Pathways } & PWY-7664 & oleate biosynthesis IV (anaerobic) \\
\hline & PWY-6282 & palmitoleate biosynthesis I (from (5Z)-dodec-5-enoate) \\
\hline & FASYN-ELONG-PWY & fatty acid elongation -- saturated \\
\hline & PWY-5989 & stearate biosynthesis II (bacteria and plants) \\
\hline & PWY0-862 & (5Z)-dodec-5-enoate biosynthesis \\
\hline & PWY-5417 & catechol degradation III (ortho-cleavage pathway) \\
\hline & PWY-5431 & aromatic compounds degradation via \&beta,-ketoadipate \\
\hline & PWY0-42 & 2-methylcitrate cycle I \\
\hline & PWY-5747 & 2-methylcitrate cycle II \\
\hline & PWY-5855 & ubiquinol-7 biosynthesis (prokaryotic) \\
\hline & PWY-5856 & ubiquinol-9 biosynthesis (prokaryotic) \\
\hline
\end{tabular}


bioRxiv preprint doi: https://doi.org/10.1101/2020.12.10.419051; this version posted December $12,2020$. The copyright holder for this preprint (which was not certified by peer review) is the author/funder, who has granted bioRxiv a license to display the preprint in perpetuity. It is made available under aCC-BY-NC-ND 4.0 International license.

\begin{tabular}{|c|c|}
\hline PWY-5857 & ubiquinol-10 biosynthesis (prokaryotic) \\
\hline PWY-6708 & ubiquinol-8 biosynthesis (prokaryotic) \\
\hline UBISYN-PWY & superpathway of ubiquinol-8 biosynthesis (prokaryotic) \\
\hline FAO-PWY & fatty acid \&beta,-oxidation I \\
\hline $\begin{array}{l}\text { PROTOCATECHUATE- } \\
\text { ORTHO-CLEAVAGE-PWY }\end{array}$ & protocatechuate degradation II (ortho-cleavage pathway) \\
\hline FASYN-INITIAL-PWY & superpathway of fatty acid biosynthesis initiation (E. coli) \\
\hline PWYG-321 & mycolate biosynthesis \\
\hline PWY-6519 & 8-amino-7-oxononanoate biosynthesis I \\
\hline P562-PWY & myo-inositol degradation I \\
\hline $\begin{array}{l}\text { BIOTIN-BIOSYNTHESIS- } \\
\text { PWY }\end{array}$ & biotin biosynthesis I \\
\hline PWY-6608 & guanosine nucleotides degradation III \\
\hline GLYCOGENSYNTH-PWY & glycogen biosynthesis I (from ADP-D-Glucose) \\
\hline PWY-5667 & CDP-diacylglycerol biosynthesis I \\
\hline PWY0-1319 & CDP-diacylglycerol biosynthesis II \\
\hline PWY-6703 & preQ0 biosynthesis \\
\hline OANTIGEN-PWY & O-antigen building blocks biosynthesis (E. coli) \\
\hline PWY-6630 & superpathway of L-tyrosine biosynthesis \\
\hline PWY-5022 & 4-aminobutanoate degradation $\mathrm{V}$ \\
\hline PWY-7431 & aromatic biogenic amine degradation (bacteria) \\
\hline P221-PWY & octane oxidation \\
\hline PWY4FS-7 & phosphatidylglycerol biosynthesis I (plastidic) \\
\hline PWY4FS-8 & phosphatidylglycerol biosynthesis II (non-plastidic) \\
\hline PHOSLIPSYN-PWY & superpathway of phospholipid biosynthesis I (bacteria) \\
\hline PWY-5154 & L-arginine biosynthesis III (via N-acetyl-L-citrulline) \\
\hline PWY-6628 & superpathway of L-phenylalanine biosynthesis \\
\hline REDCITCYC & TCA cycle VIII (helicobacter) \\
\hline UDPNAGSYN-PWY & UDP-N-acetyl-D-glucosamine biosynthesis I \\
\hline PWY-7254 & TCA cycle VII (acetate-producers) \\
\hline $\begin{array}{l}\text { CATECHOL-ORTHO- } \\
\text { CLEAVAGE-PWY }\end{array}$ & catechol degradation to \&beta,-ketoadipate \\
\hline $\begin{array}{l}\text { GLYCOLYSIS-TCA-GLYOX- } \\
\text { BYPASS }\end{array}$ & $\begin{array}{c}\text { superpathway of glycolysis, pyruvate dehydrogenase, TCA, and glyoxylate } \\
\text { bypass }\end{array}$ \\
\hline PWY-7328 & $\begin{array}{l}\text { superpathway of UDP-glucose-derived O-antigen building blocks biosyn- } \\
\text { thesis }\end{array}$ \\
\hline PWY-5384 & sucrose degradation IV (sucrose phosphorylase) \\
\hline PWY0-1241 & ADP-L-glycero-\&beta,-D-manno-heptose biosynthesis \\
\hline PWY-621 & sucrose degradation III (sucrose invertase) \\
\hline GLYCOCAT-PWY & glycogen degradation I (bacterial) \\
\hline $\begin{array}{c}3- \\
\text { HYDROXYPHENYLACETATE- } \\
\text { DEGRADATION-PWY }\end{array}$ & 4-hydroxyphenylacetate degradation \\
\hline PWY-6737 & starch degradation $\mathrm{V}$ \\
\hline GLUCOSE1PMETAB-PWY & glucose and glucose-1-phosphate degradation \\
\hline PWY-5419 & catechol degradation to 2-oxopent-4-enoate II \\
\hline
\end{tabular}


bioRxiv preprint doi: https://doi.org/10.1101/2020.12.10.419051; this version posted December $12,2020$. The copyright holder for this preprint (which was not certified by peer review) is the author/funder, who has granted bioRxiv a license to display the preprint in perpetuity. It is made available under aCC-BY-NC-ND 4.0 International license.

\begin{tabular}{|c|c|}
\hline PWY-7323 & $\begin{array}{c}\text { superpathway of GDP-mannose-derived O-antigen building blocks biosyn- } \\
\text { thesis }\end{array}$ \\
\hline PWY-5420 & catechol degradation II (meta-cleavage pathway) \\
\hline COLANSYN-PWY & colanic acid building blocks biosynthesis \\
\hline ASPASN-PWY & superpathway of L-aspartate and L-asparagine biosynthesis \\
\hline PWY-5651 & L-tryptophan degradation to 2-amino-3-carboxymuconate semialdehyde \\
\hline PWY-5941 & glycogen degradation II (eukaryotic) \\
\hline PWY-6713 & L-rhamnose degradation II \\
\hline THISYN-PWY & superpathway of thiamin diphosphate biosynthesis I \\
\hline LACTOSECAT-PWY & lactose and galactose degradation I \\
\hline PWY-6728 & methylaspartate cycle \\
\hline RHAMCAT-PWY & L-rhamnose degradation I \\
\hline PWY-6317 & galactose degradation I (Leloir pathway) \\
\hline PWY-7196 & superpathway of pyrimidine ribonucleosides salvage \\
\hline FUC-RHAMCAT-PWY & superpathway of fucose and rhamnose degradation \\
\hline PWY-6629 & superpathway of L-tryptophan biosynthesis \\
\hline PWY-5088 & L-glutamate degradation VIII (to propanoate) \\
\hline GLCMANNANAUT-PWY & $\begin{array}{l}\text { superpathway of } \mathrm{N} \text {-acetylglucosamine, } \mathrm{N} \text {-acetylmannosamine and } \mathrm{N} \text { - } \\
\text { acetylneuraminate degradation }\end{array}$ \\
\hline P441-PWY & superpathway of $\mathrm{N}$-acetylneuraminate degradation \\
\hline PWY-6071 & superpathway of phenylethylamine degradation \\
\hline PWY0-1533 & methylphosphonate degradation I \\
\hline POLYAMSYN-PWY & superpathway of polyamine biosynthesis I \\
\hline ARG+POLYAMINE-SYN & superpathway of arginine and polyamine biosynthesis \\
\hline PWY0-1296 & purine ribonucleosides degradation \\
\hline PWY0-1298 & superpathway of pyrimidine deoxyribonucleosides degradation \\
\hline PWY-5838 & superpathway of menaquinol-8 biosynthesis I \\
\hline PWY-5840 & superpathway of menaquinol-7 biosynthesis \\
\hline PWY-5861 & superpathway of demethylmenaquinol-8 biosynthesis \\
\hline PWY-5899 & superpathway of menaquinol-13 biosynthesis \\
\hline PWY-5897 & superpathway of menaquinol-11 biosynthesis \\
\hline PWY-5898 & superpathway of menaquinol-12 biosynthesis \\
\hline PWY-7315 & dTDP-N-acetylthomosamine biosynthesis \\
\hline ALL-CHORISMATE-PWY & superpathway of chorismate metabolism \\
\hline PWY-5863 & superpathway of phylloquinol biosynthesis \\
\hline PWY-5837 & 1,4-dihydroxy-2-naphthoate biosynthesis I \\
\hline PWY-5860 & superpathway of demethylmenaquinol- 6 biosynthesis I \\
\hline PWY-5862 & superpathway of demethylmenaquinol- 9 biosynthesis \\
\hline PWY-5896 & superpathway of menaquinol-10 biosynthesis \\
\hline PWY-5845 & superpathway of menaquinol-9 biosynthesis \\
\hline PWY-5850 & superpathway of menaquinol-6 biosynthesis I \\
\hline
\end{tabular}




\section{PCA: variables $=$ clinical parameters \\ Groups = countries}

A

PCA - Biplot

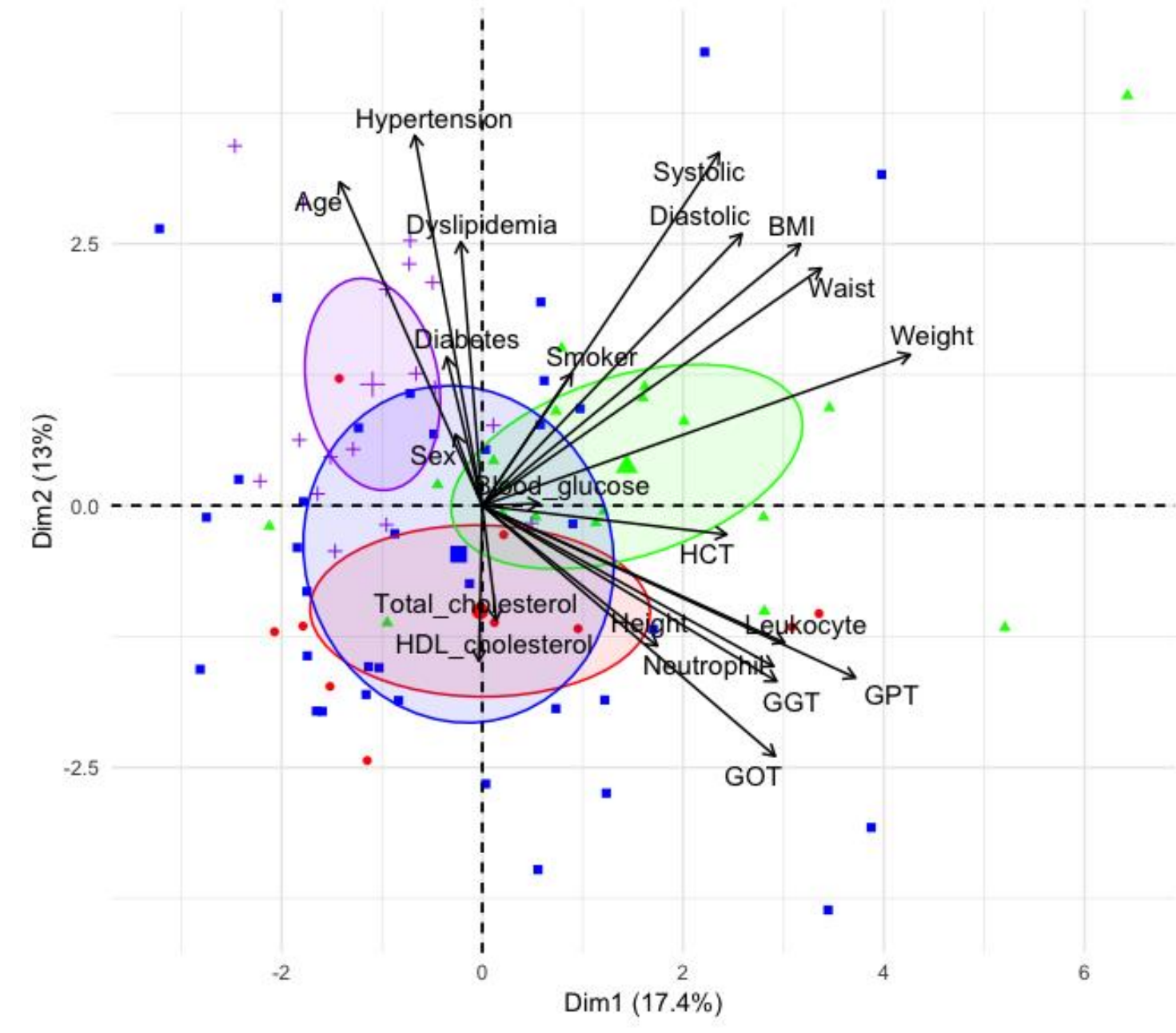

PCA $:$ variables $=$ clinical parameters

Groups $=$ Fibrosis score

B

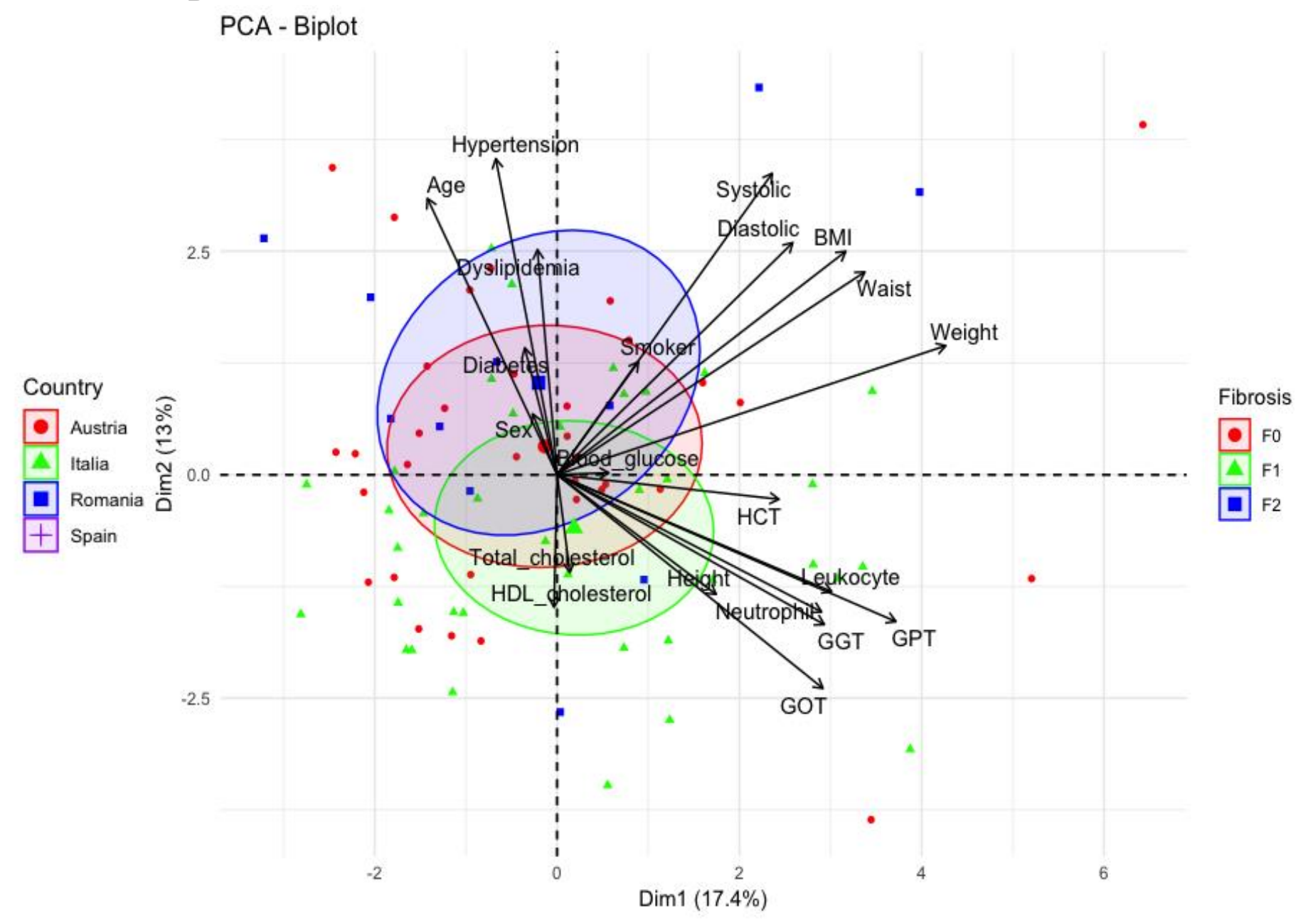




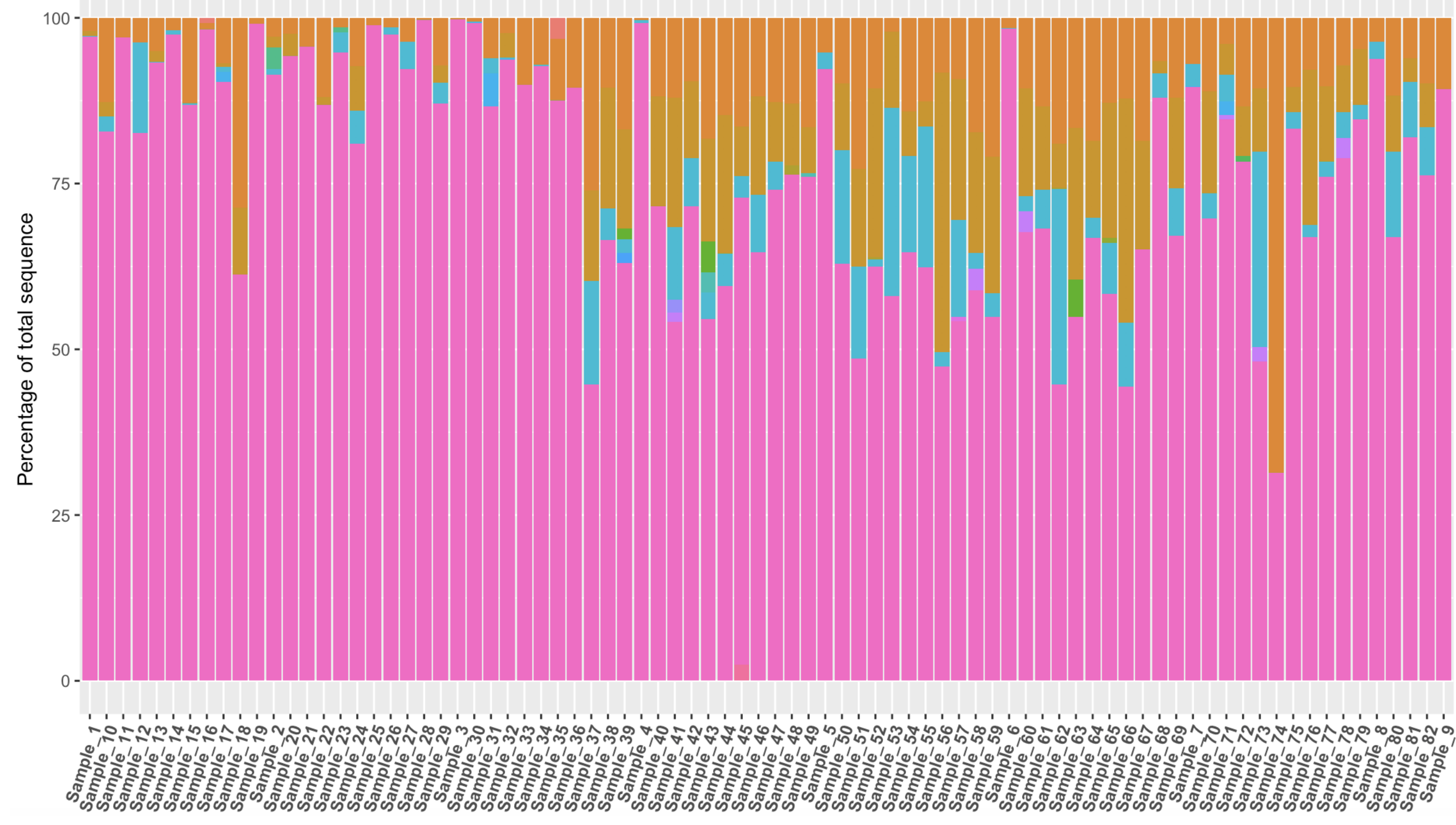

Bacterial Phyla

Acidobacteria

Actinobacteria

Bacteroidetes

Chlamydiae

Deinococcus-Thermus

Dependentiae

Elusimicrobia

Epsilonbacteraeota

FBP

Firmicutes

Fusobacteria

Lentisphaerae

Omnitrophicaeota

Patescibacteria

Planctomycetes

Proteobacteria

Verrucomicrobia

Figure 2, Champion et al 


\section{Barplot : overall cohort and per fibrosis scores (Phyla)}

D

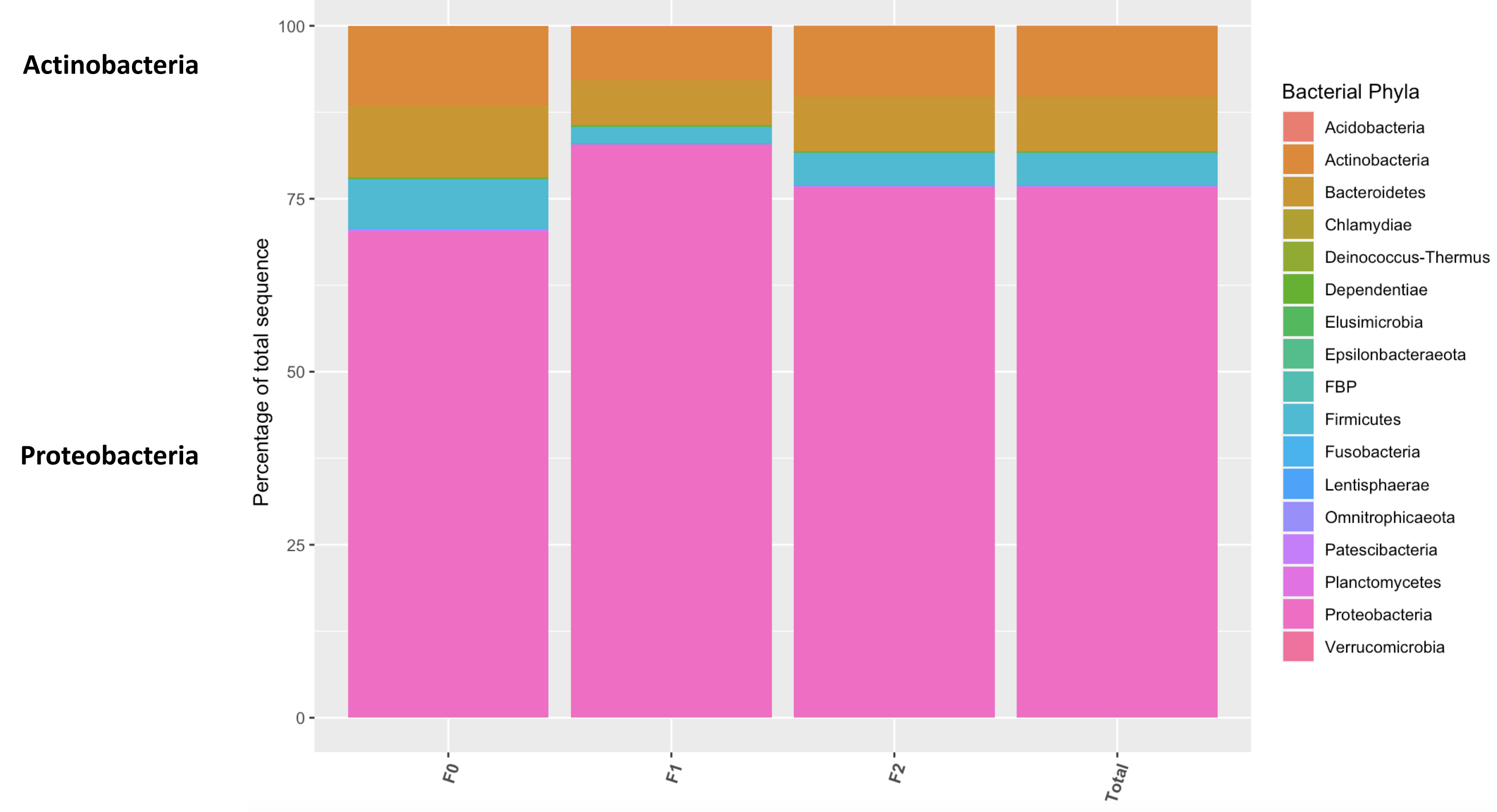

Figure 2, Champion et al 


\section{E}

\section{Burkholderiaceae}

\section{Enterobacteriaceae}

Flavobacteriaceae

Micrococcaceae

\section{Pseudomonadaceae}

\begin{abstract}
100 -
\end{abstract}
$5-$

$25-$

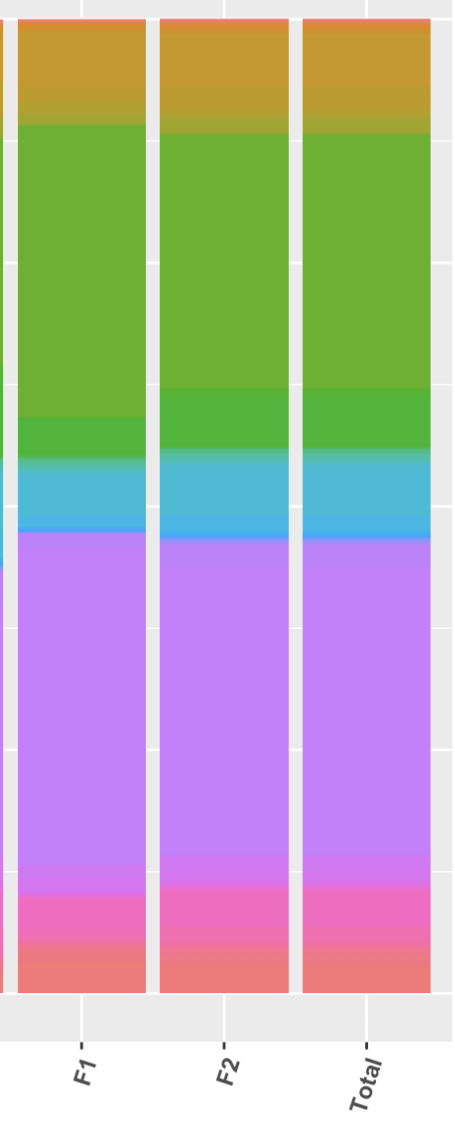

Bacterial Families

0319-6G20

A0839

Acetobacteraceae

Actinomycetaceae

Aerococcaceae

Aeromonadaceae

Alcanivoracaceae

Azospirillaceae

Bacillaceae

Bacteroidaceae

Bdellovibrionaceae

Beijerinckiaceae

Bifidobacteriaceae

Bogoriellaceae

Brevibacteriaceae

Burkholderiaceae

Caedibacteraceae

Carnobacteriaceae

Caulobacteracea

Cellvibrionaceae

\begin{tabular}{|l|}
\hline Chitinophagaceae \\
\hline Clostridiaceae 1 \\
\hline Clostridiales vadinBB60 group \\
\hline Coriobacteriaceae \\
\hline Corynebacteriaceae \\
\hline Crocinitomicaceae \\
\hline Cryptosporangiaceae \\
\hline Deinococcaceae \\
\hline Dermabacteraceae \\
\hline Dermacoccaceae \\
\hline Dietziaceae \\
\hline Diplorickettsiaceae \\
\hline Dysgonomonadaceae \\
\hline Enterobacteriaceae \\
\hline Enterococcaceae \\
\hline env.OPS 17 \\
\hline Family XI \\
\hline Flavobacteriaceae \\
\hline FTLpost3 \\
\hline Fusobacteriaceae \\
\hline
\end{tabular}

Gaiellaceae Geodermatophilaceae Haliangiaceae Halieaceae

Halomonadaceae Helicobacteraceae Hydrogenophilaceae Hymenobacteraceae Hyphomicrobiaceae Hyphomonadaceae

lamiaceae

Ilumatobacteraceae

Intrasporangiaceae

Kineosporiaceae

Lachnospiraceae

Lactobacillaceae

Legionellaceae

Leptotrichiaceae

Listeriaceae

Methylophilaceae
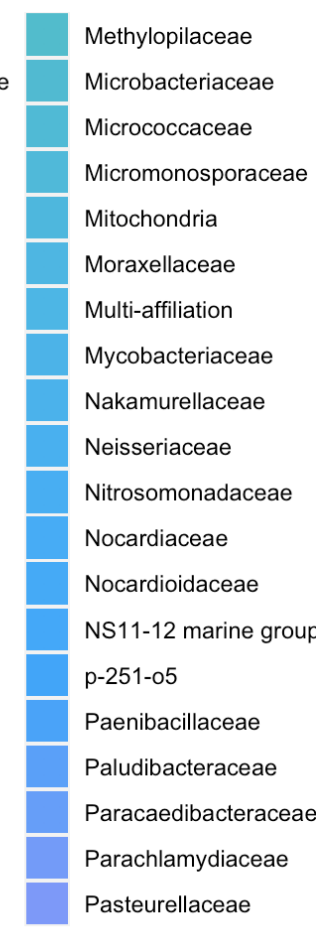

Pedosphaeraceae Peptostreptococcaceae Phycisphaeraceae Planococcaceae Pleomorphomonadacea Polyangiaceae Prevotellaceae

Propionibacte

Propionibacteriaceae
Pseudomonadaceae Pseudonocardiacea

Reyranellaceae

Rhizobiaceae

Rhodobacteraceae

Rhodocyclaceae

Rickettsiaceae

Rubrobacteriaceae

Ruminococcaceae

Saprospiraceae

Simkaniaceae

SM2D12

Figure 2, Champion et al 
Venn diagram, variables $=$ OTUs

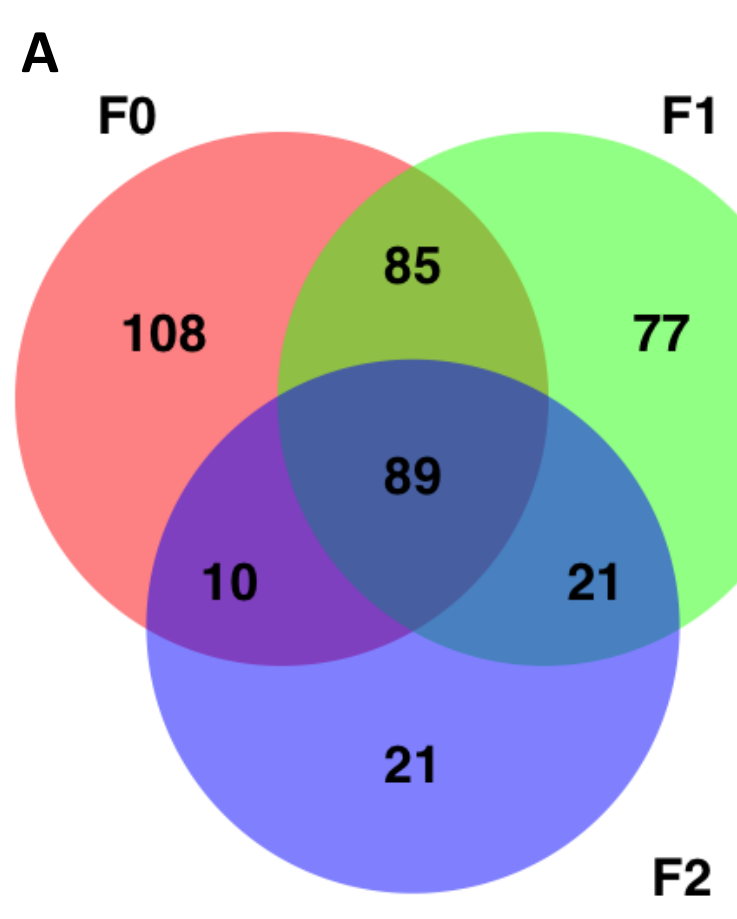

Venn diagram,

variables $=$ OTUs with a threshold

B

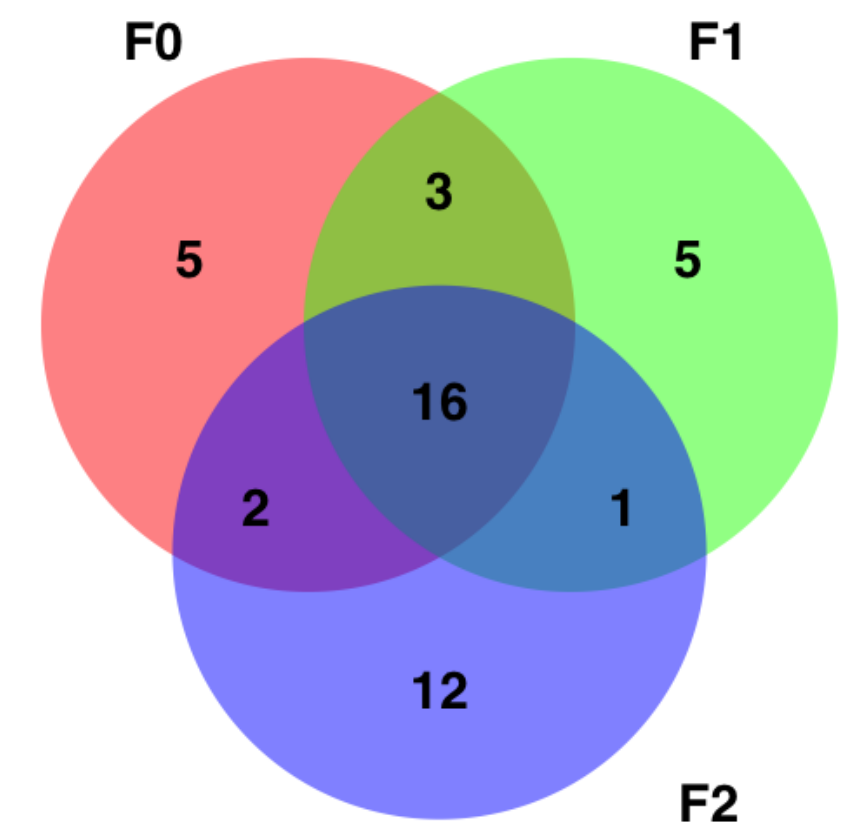

Figure 3, Champion et al 


\section{Heatmap (Fibrosis score \\ Variables= OTUs)}
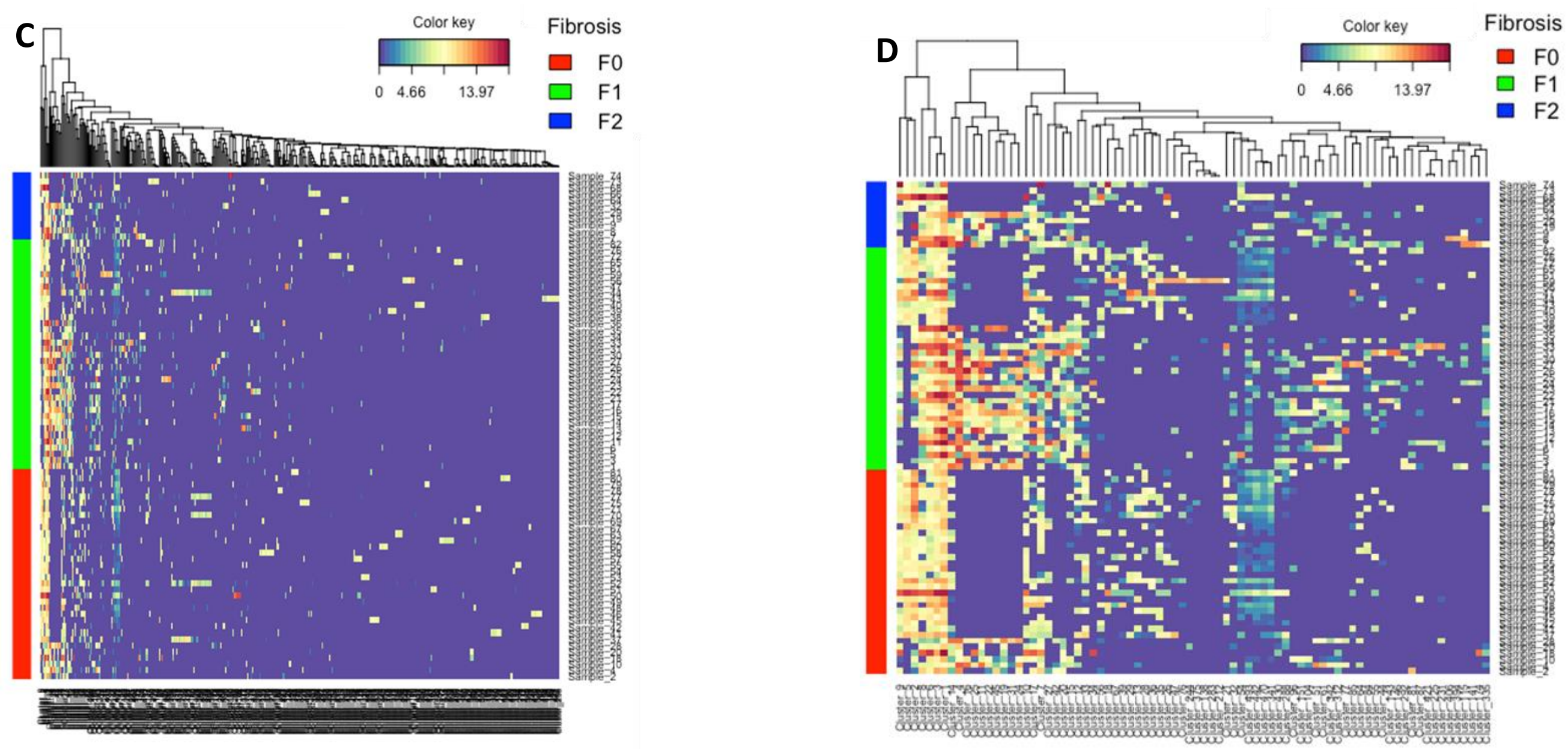

Figure 3, Champion et al 
E

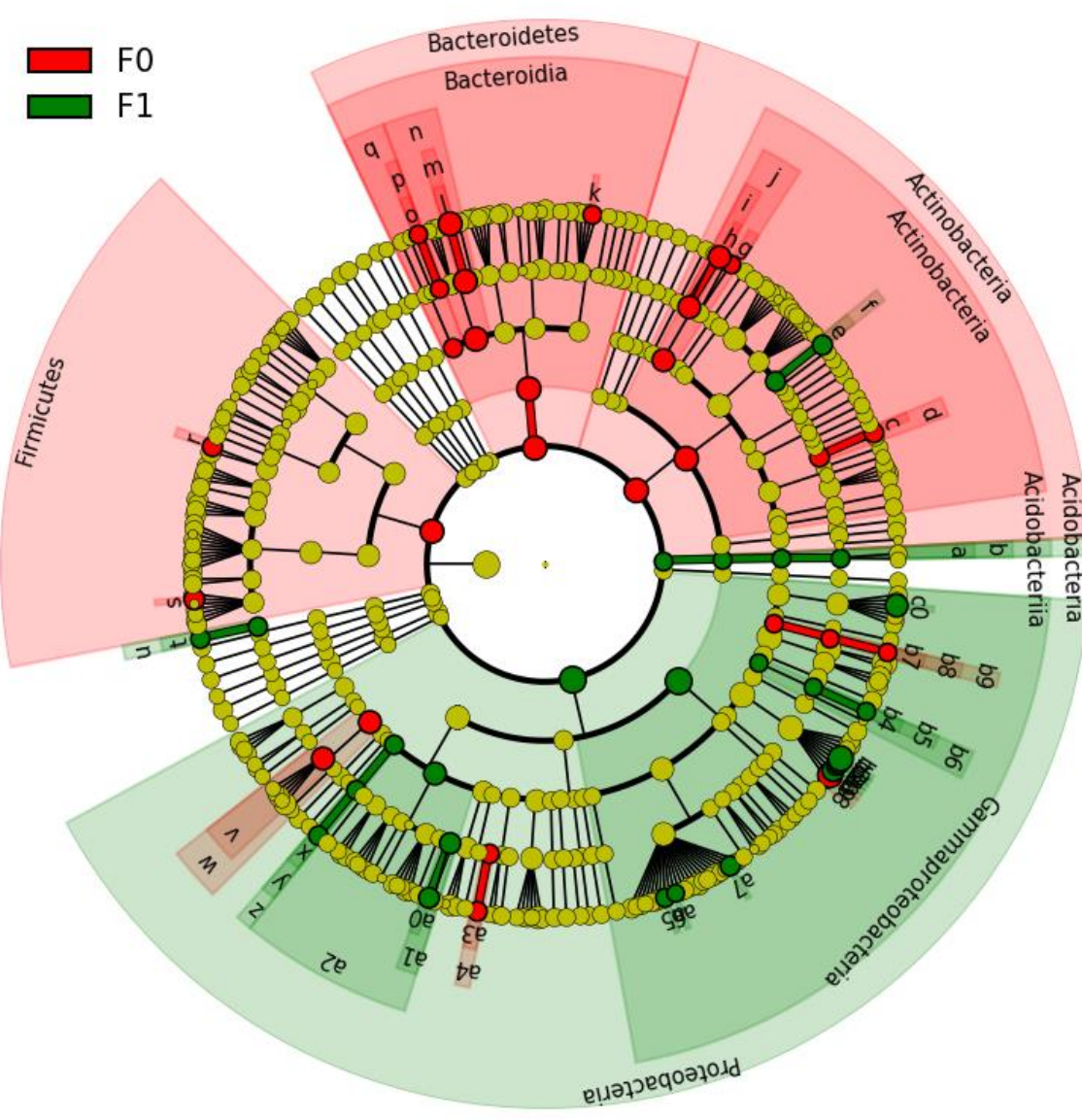

a: Solibacteraceae_Subgrour

b: Solibacterales

c: Rhodococcus

d: Nocardiaceae

f: Intrasporangiacea

g: Marmoricola

i: Propionibacteriacea

j: Propionibacteriales

k: Prevotella

I: Flavobacterium

$\mathrm{n}$ : Flavobacteriales

o: Unknown

p: NS11 12marinegroup

q: Sphingobacteriales

r: Lactococcus

s: Faecalibacterium

t: Fusobaterium

u: Fusobacteriaceae

v: Caulobacteraceae

w: Caulobacterales

x: Reyranella

y: Reyranellacea

z: Reyranellales

a0: Bradyrhizobium

a2: Rhizobiales

a3: Unknown

a4: Mitochondri

a5: Delftia

$\square$ a6: Janthinobacterium

$\square$ a7: Tepidimonas

a9: Escherichia_Shigella 


\section{sPLSDA F0 \&F1/F2}
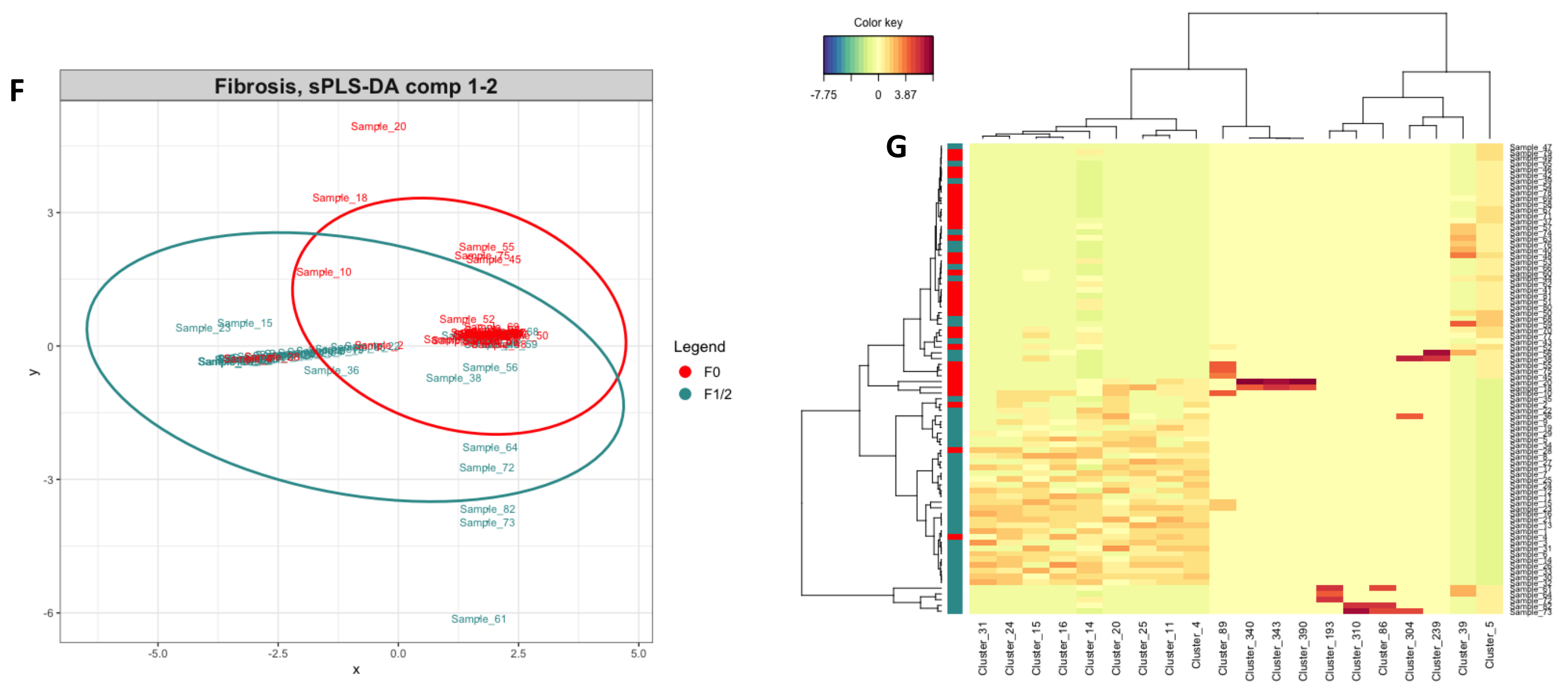

Figure 3, Champion et al 
sPLSDA F0 F1F2, heatmap with discriminant variables and roc curve
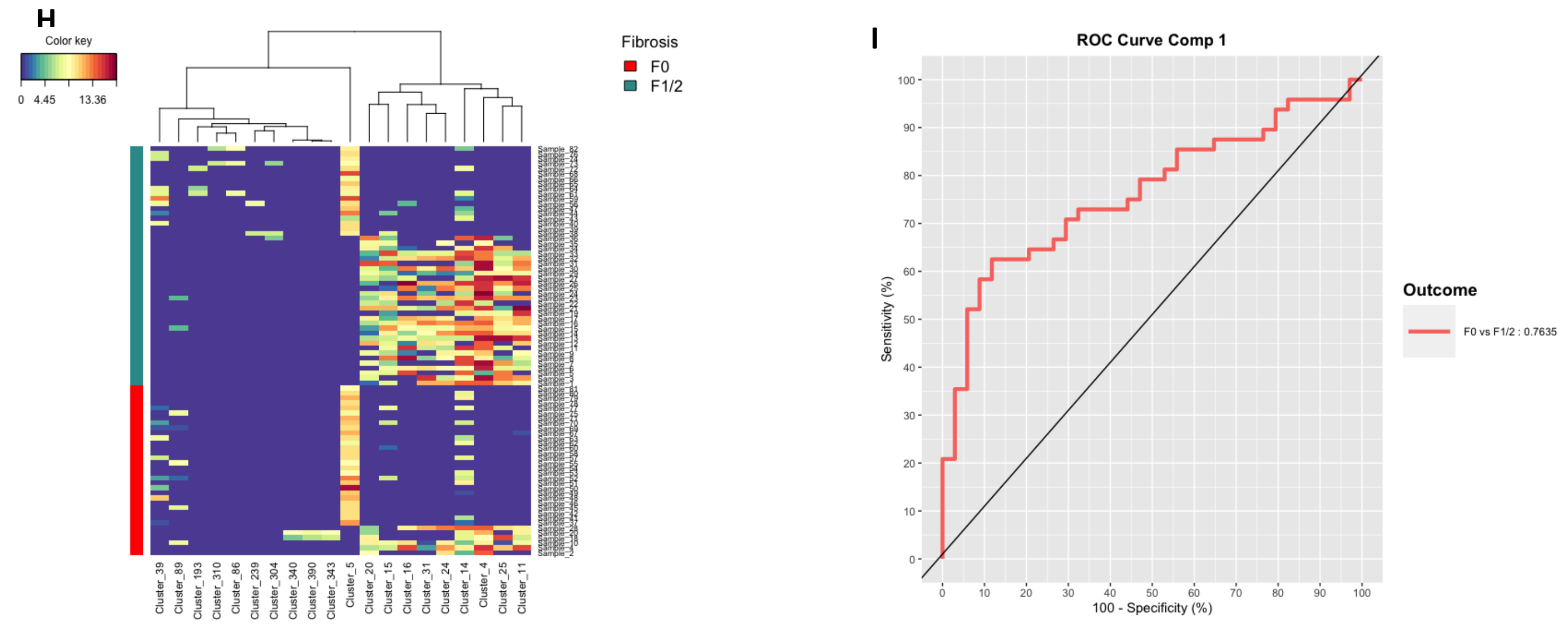

Figure 3, Champion et al 


\section{Random Forest on decorrelated principal components}

4A

PCA_COMPONENT_1

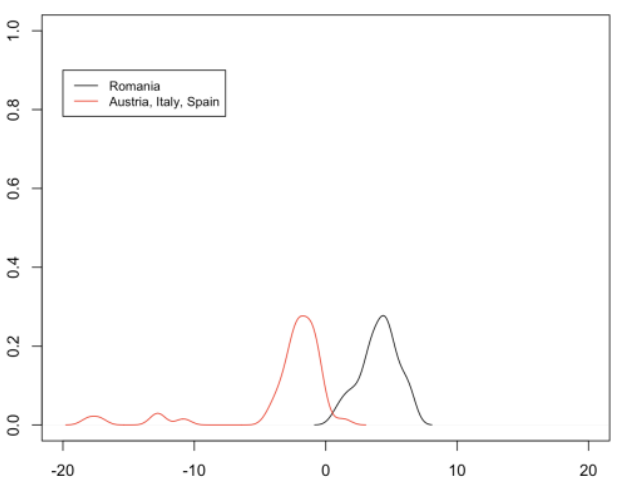

4B PCA_COMPONENT_6

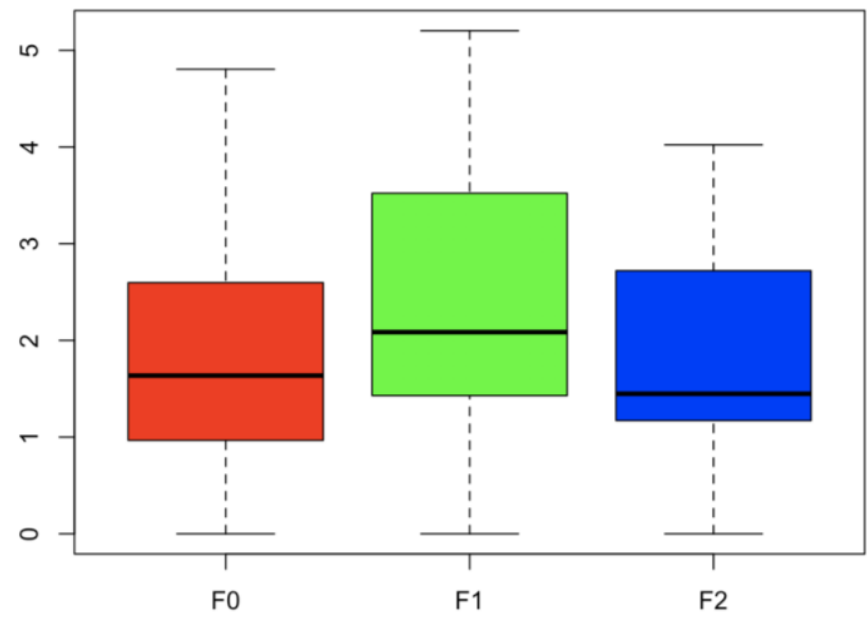

$p=0.03$ F0 VS F1
PCA_COMPONENT_2

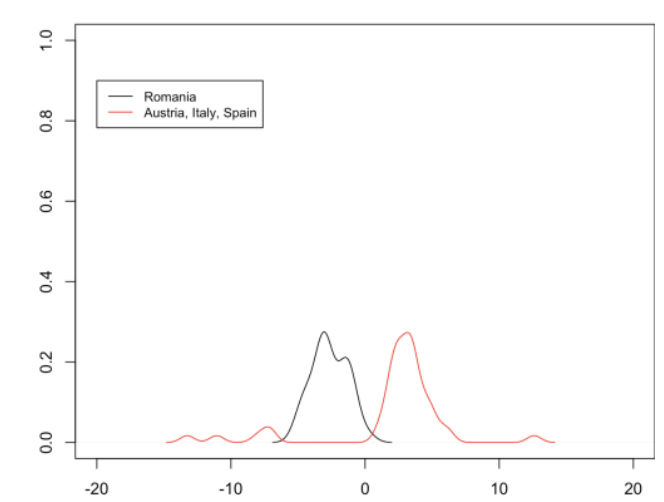

PCA_COMPONENT_3

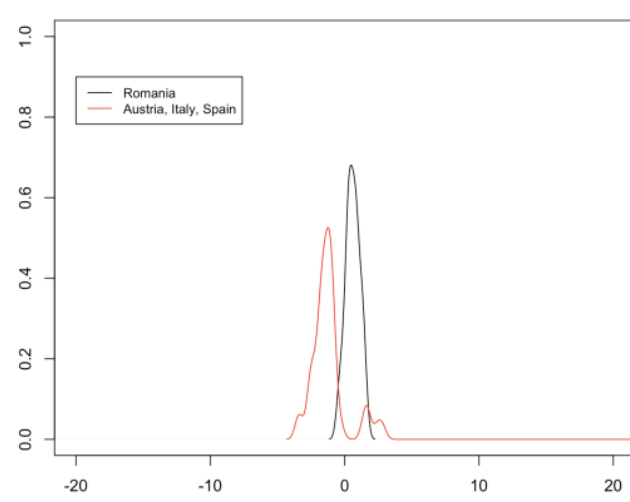

4C PCA_COMPONENT_24

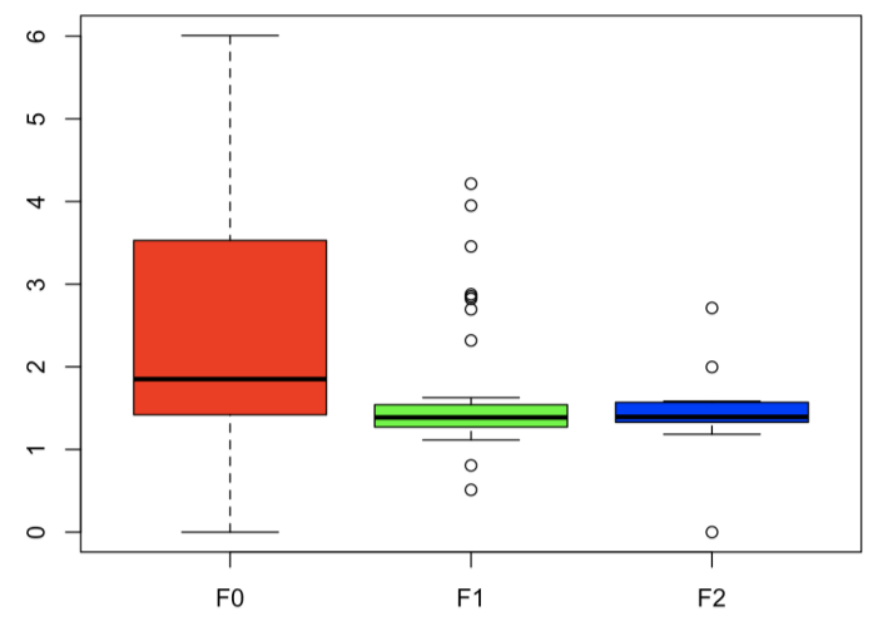

$p=0.01$ F0 VS F2
PCA_COMPONENT_4

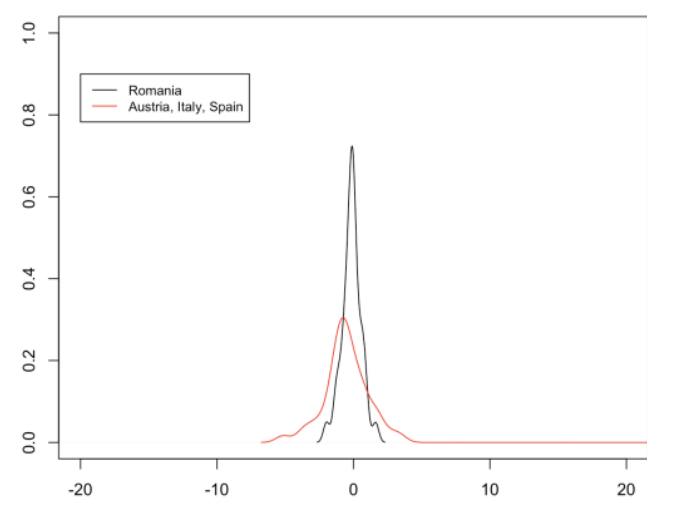

PCA_COMPONENT_5

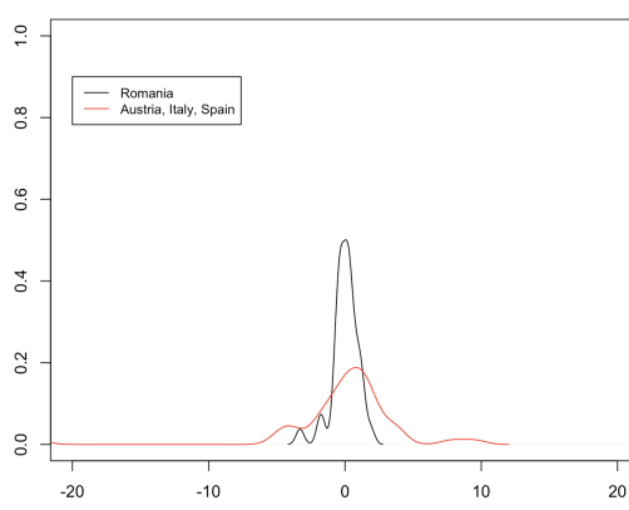

4D PCA_COMPONENT_52

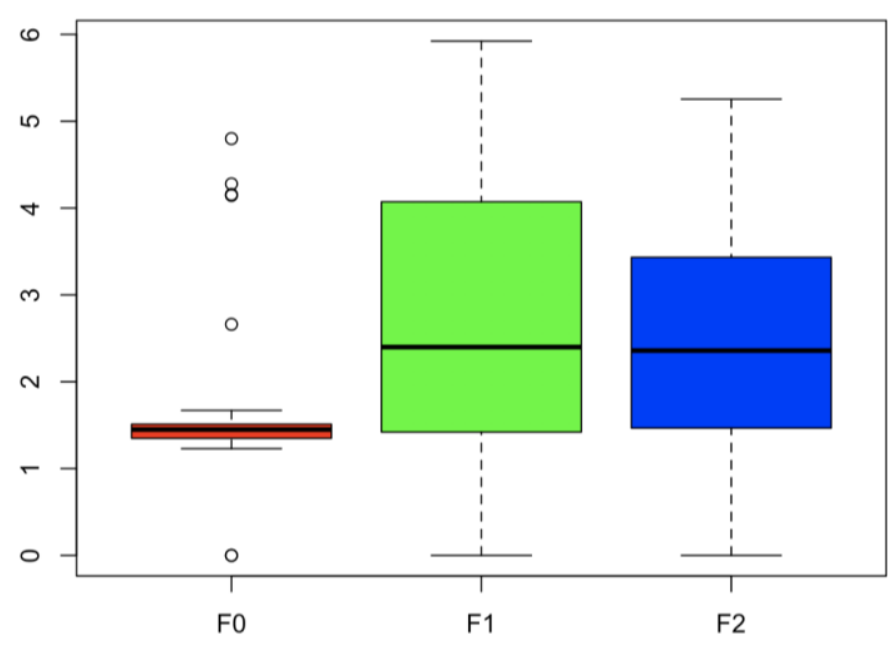

$p=0.0007$ FO VS F1

Figure 4, Champion et al 


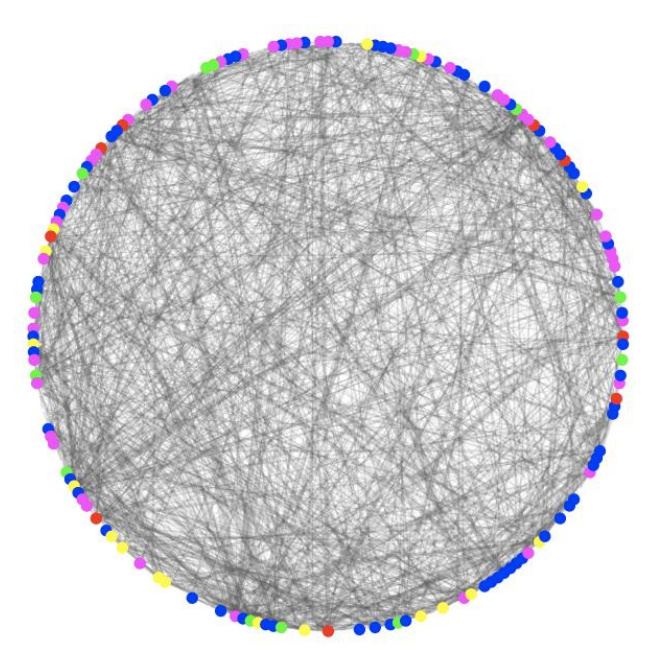

Cluster 3

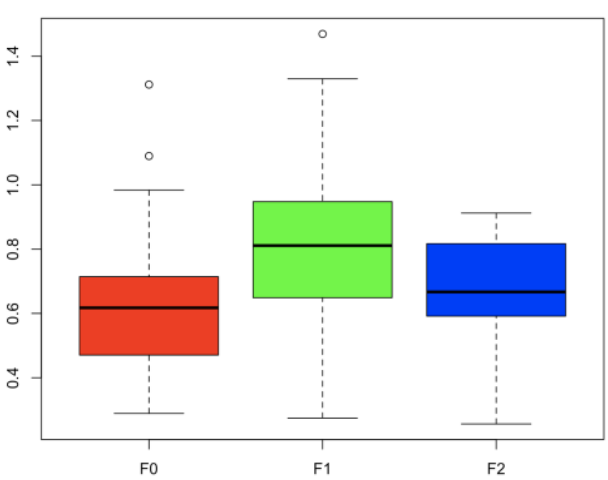

$p=0.004$ F0 VS F1
Cluster 4

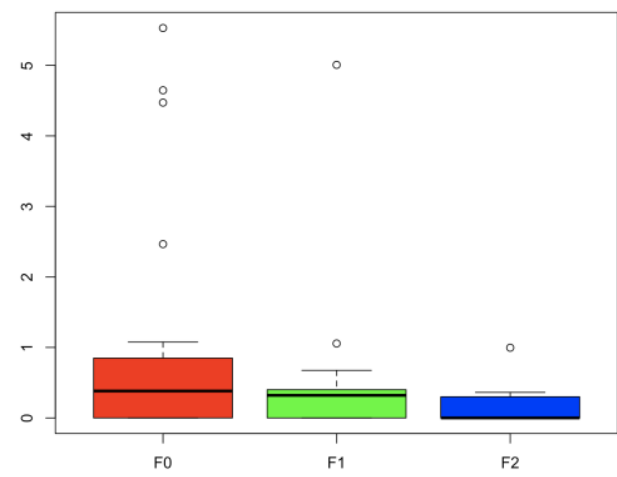

$p=0.01$ F0 VS F2
Cluster 5

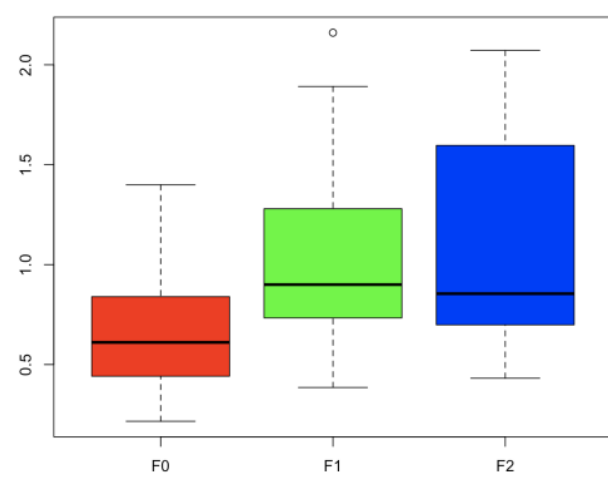

$p=0.02$ F0 VS F2 $P=0.0001$ FO VS F1
4G Cluster 1, fair clustering

$p=0.02$ F0 VS F1

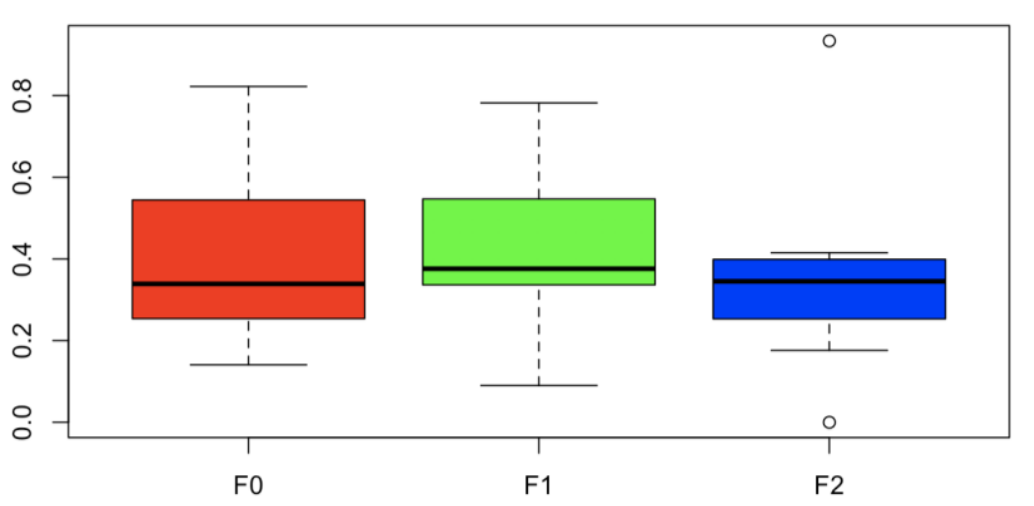

4H Cluster 2, fair clustering

$p=0.00002$ F0 VS F1

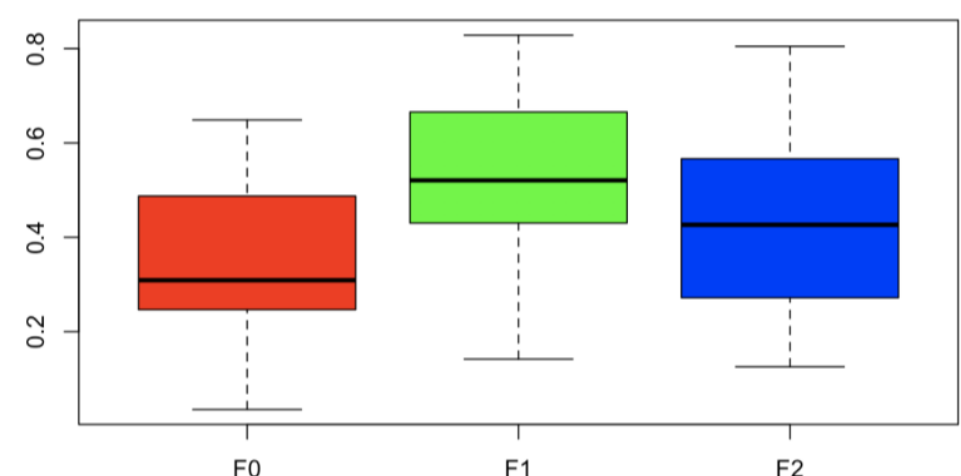

Figure 4, Champion et al 
Common discriminant OTUs

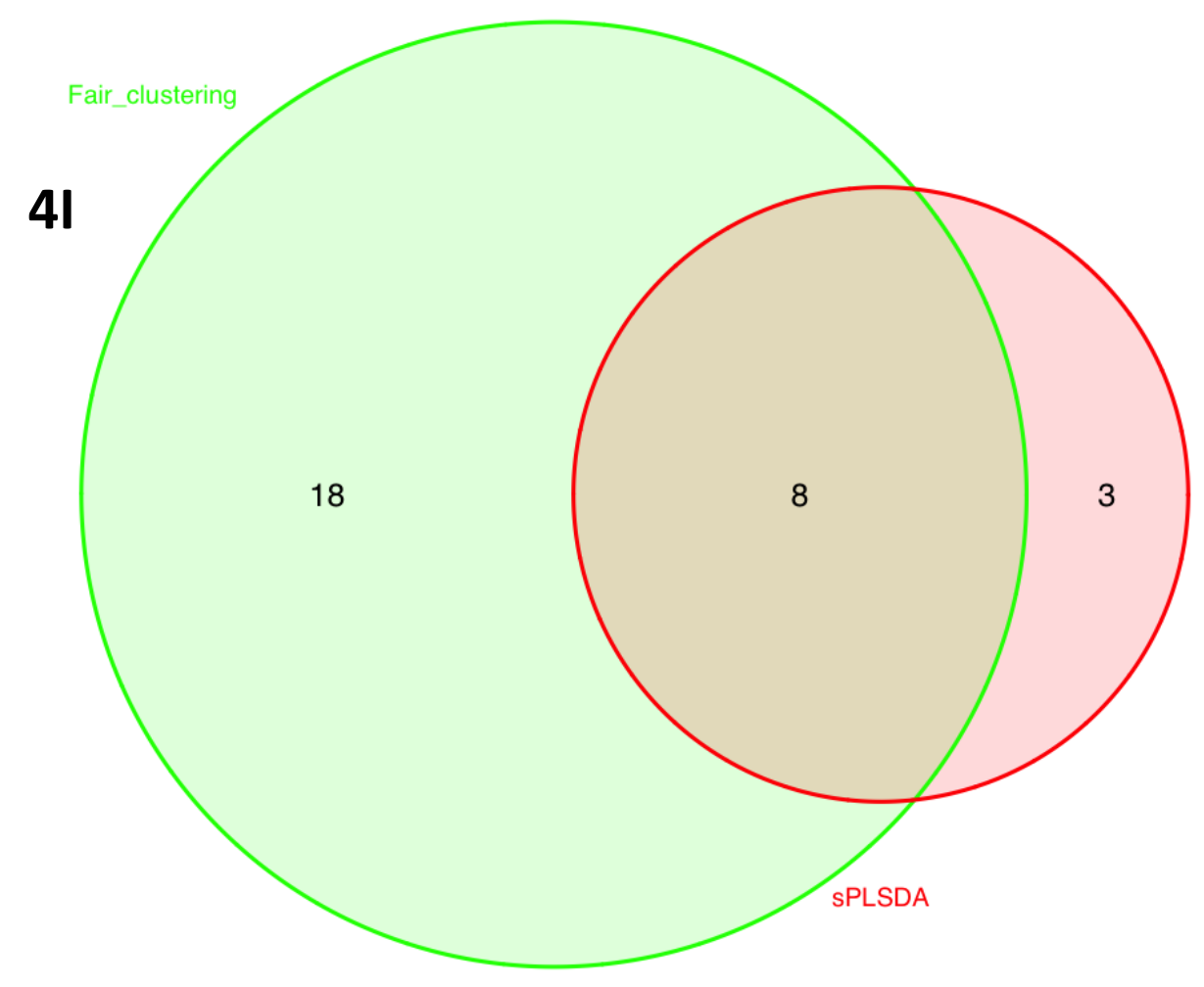

Figure 4, Champion et al 


\section{A Wordcloud unormalized}

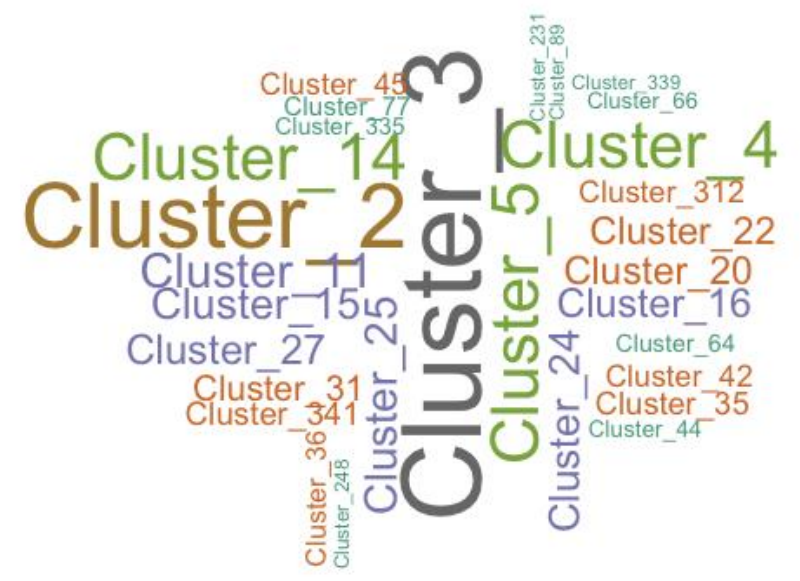

5B Wordcloud TFIDF

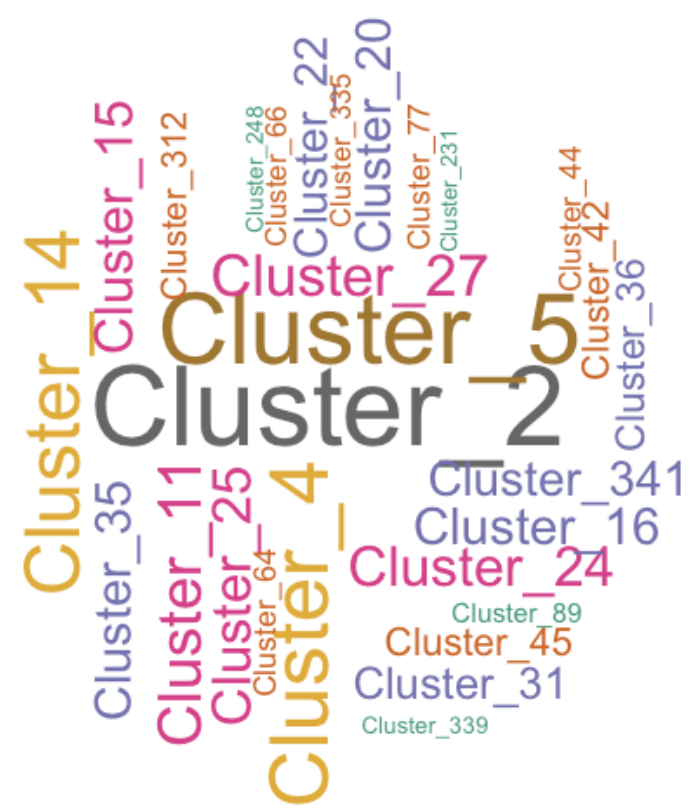

Figure 5, Champion et al 
$6 A$

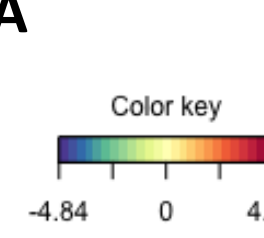

$\begin{array}{lll}-4.84 & 0 & 4.84\end{array}$

- $\mathrm{F} 0$

- F1/2

$\mathrm{F}_{1 / 2}$

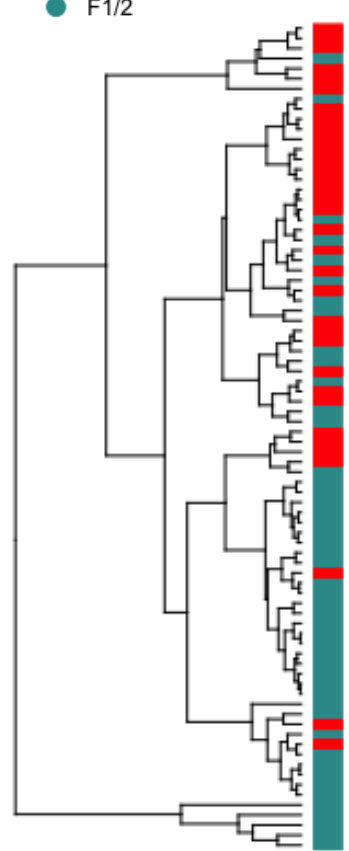

Heatmap (CIM)
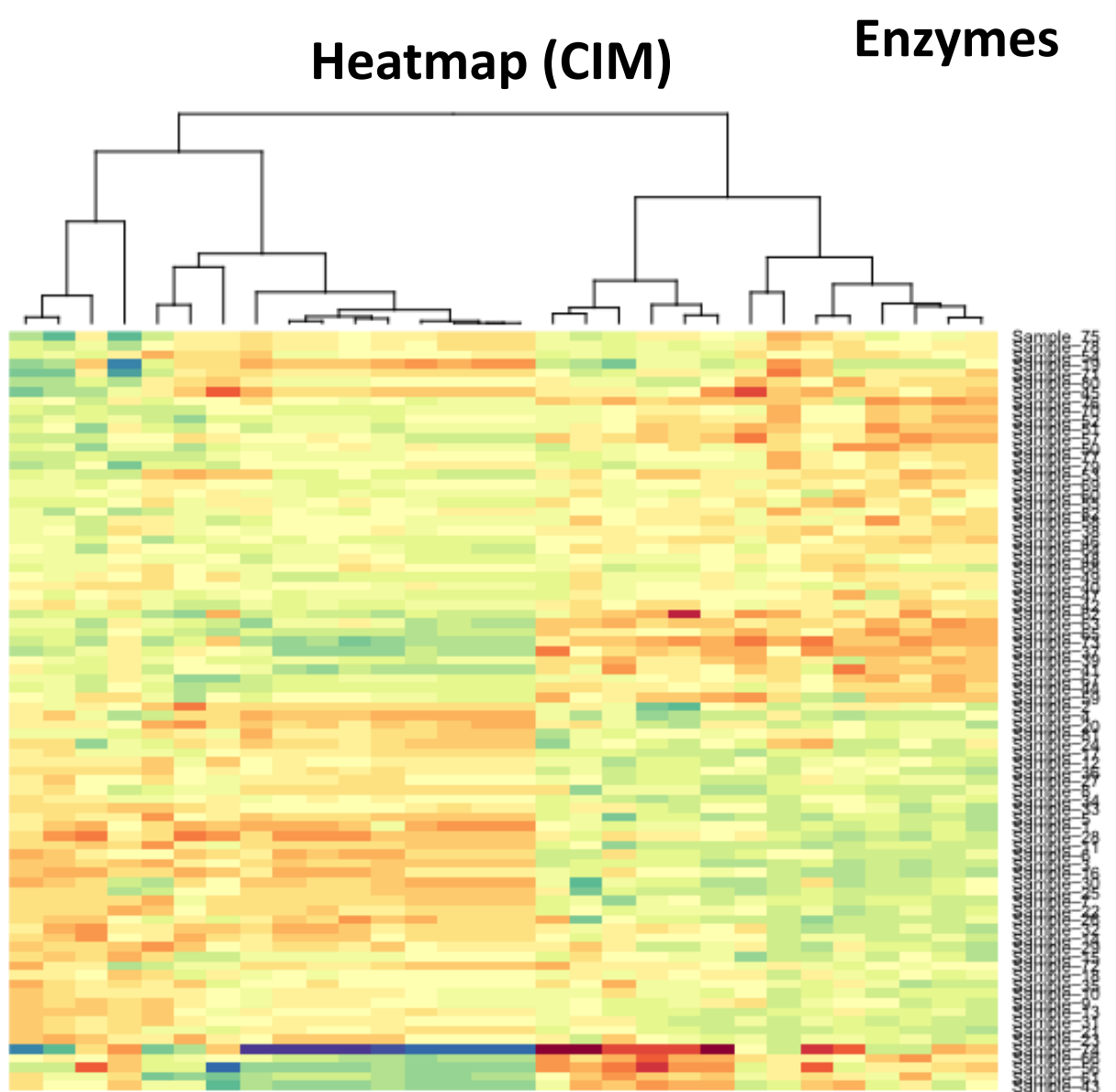

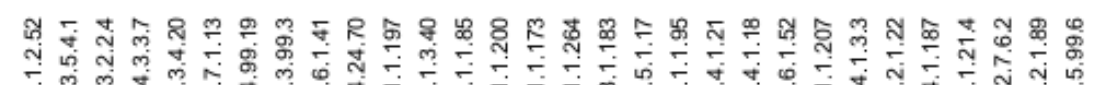

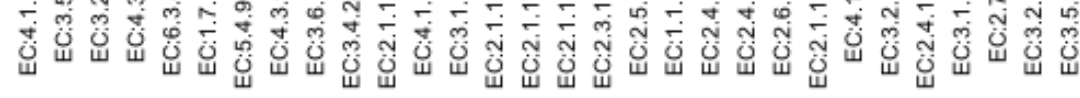

\section{B}

Fibrosis, sPLS-DA comp 1-2

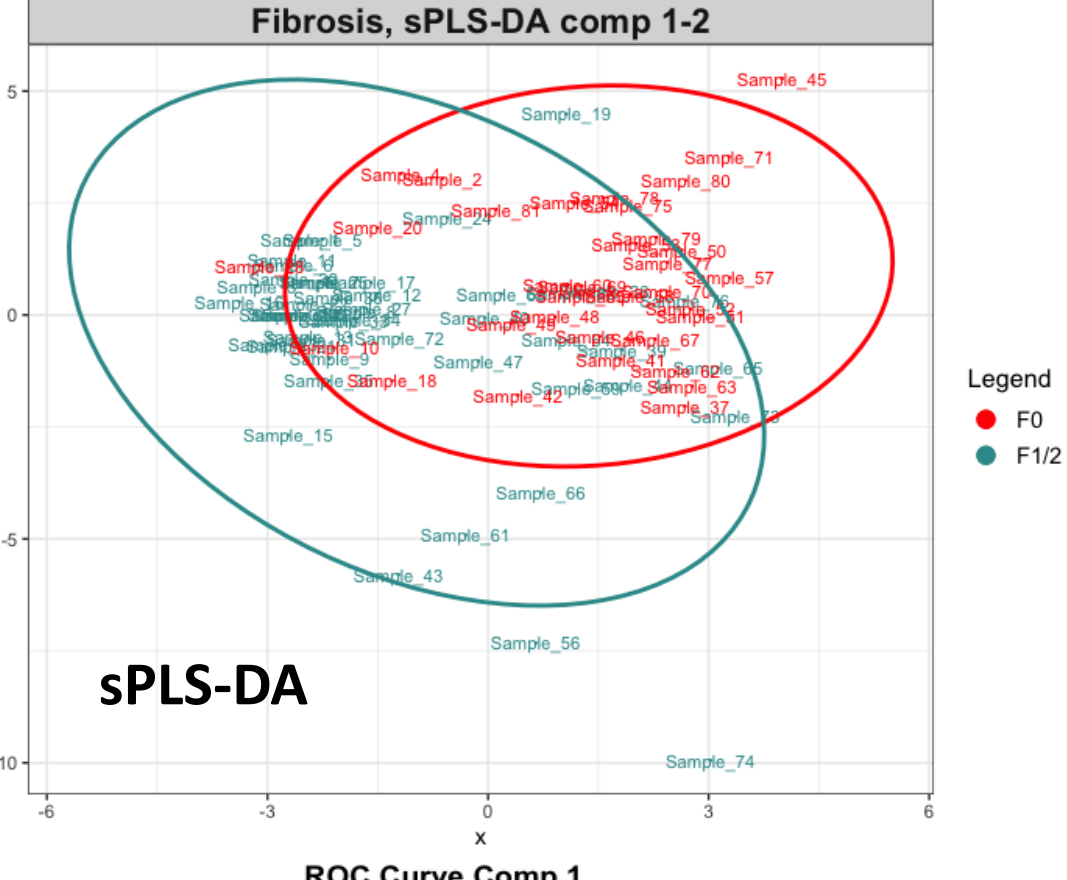

$6 C$

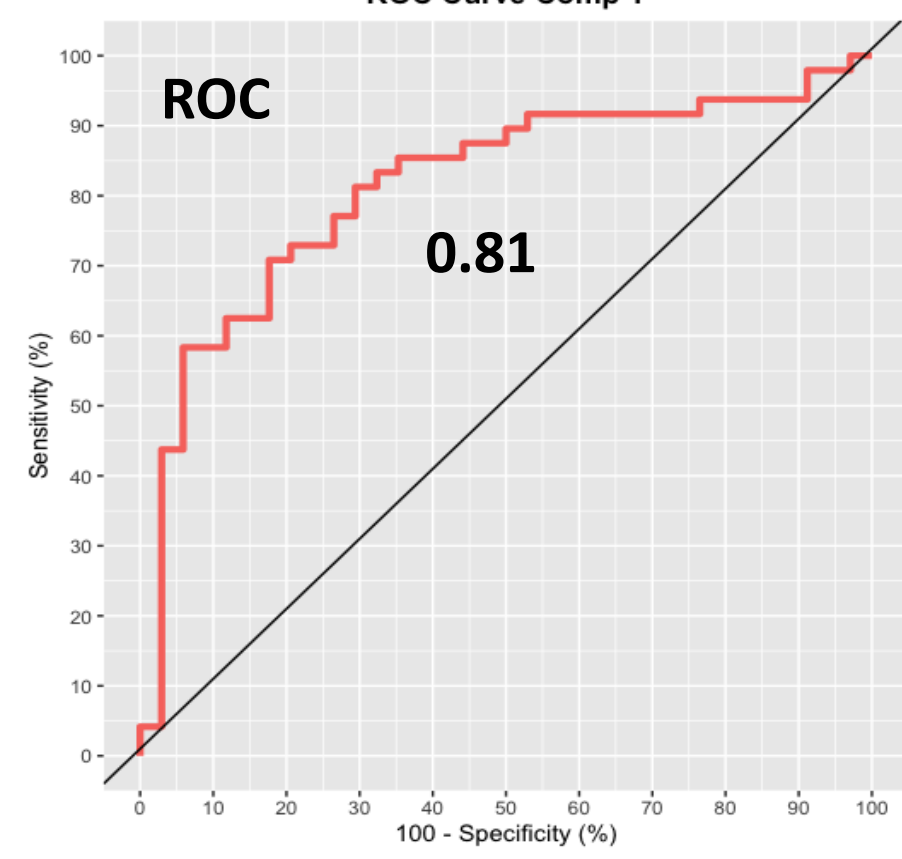

Outcome

Figure 6, Champion et al 


\section{Pathways}

\section{D}

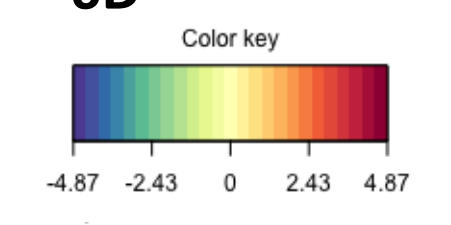

- $F 0$
- F $1 / 2$

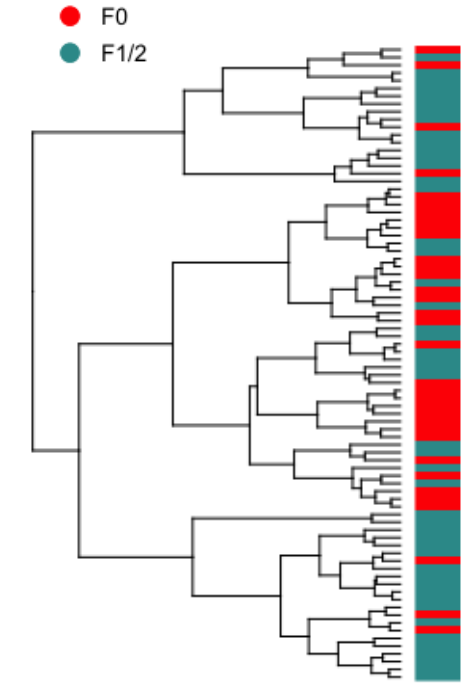

\section{Heatmap (CIM)}

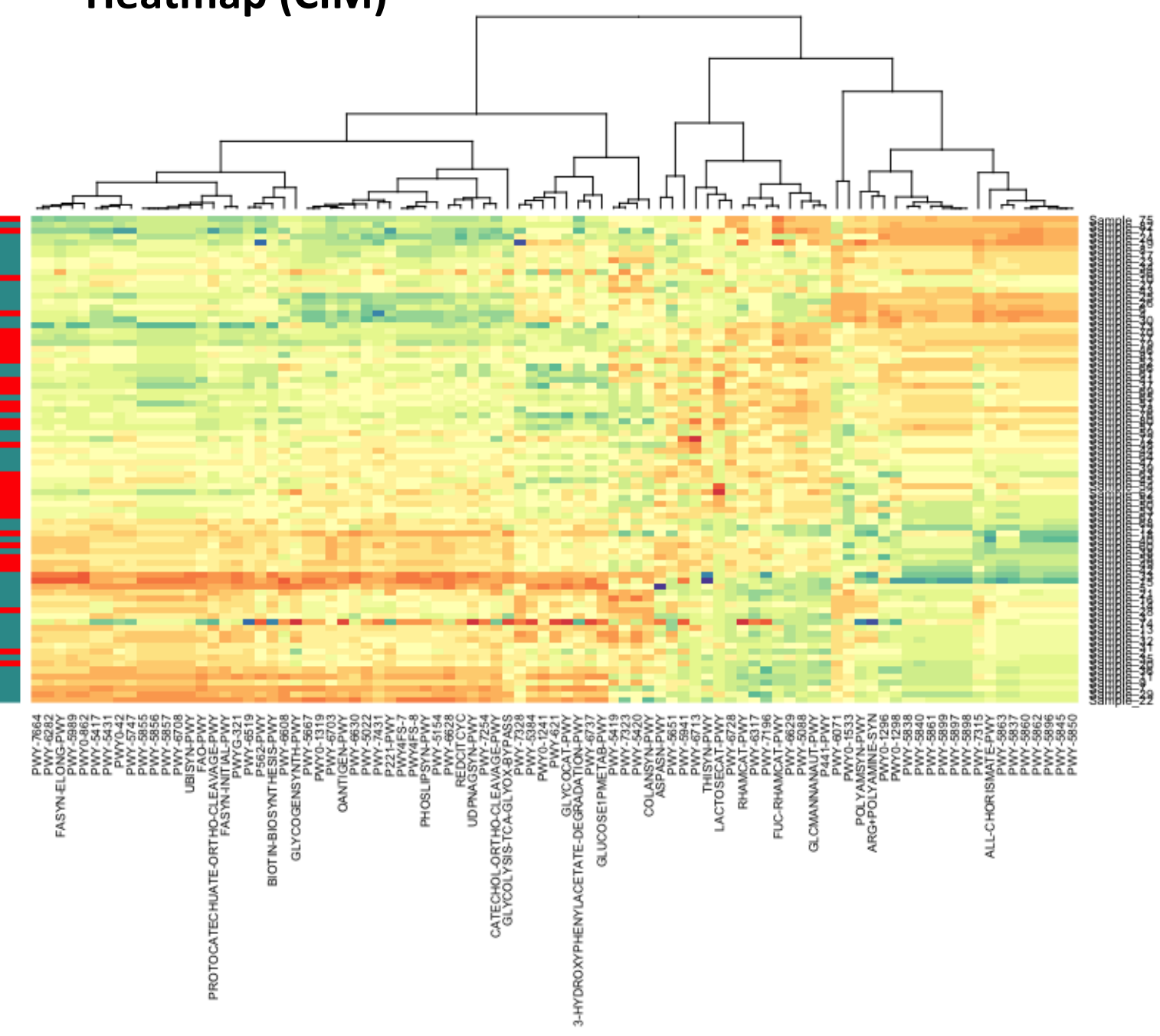

$6 \mathrm{E}$
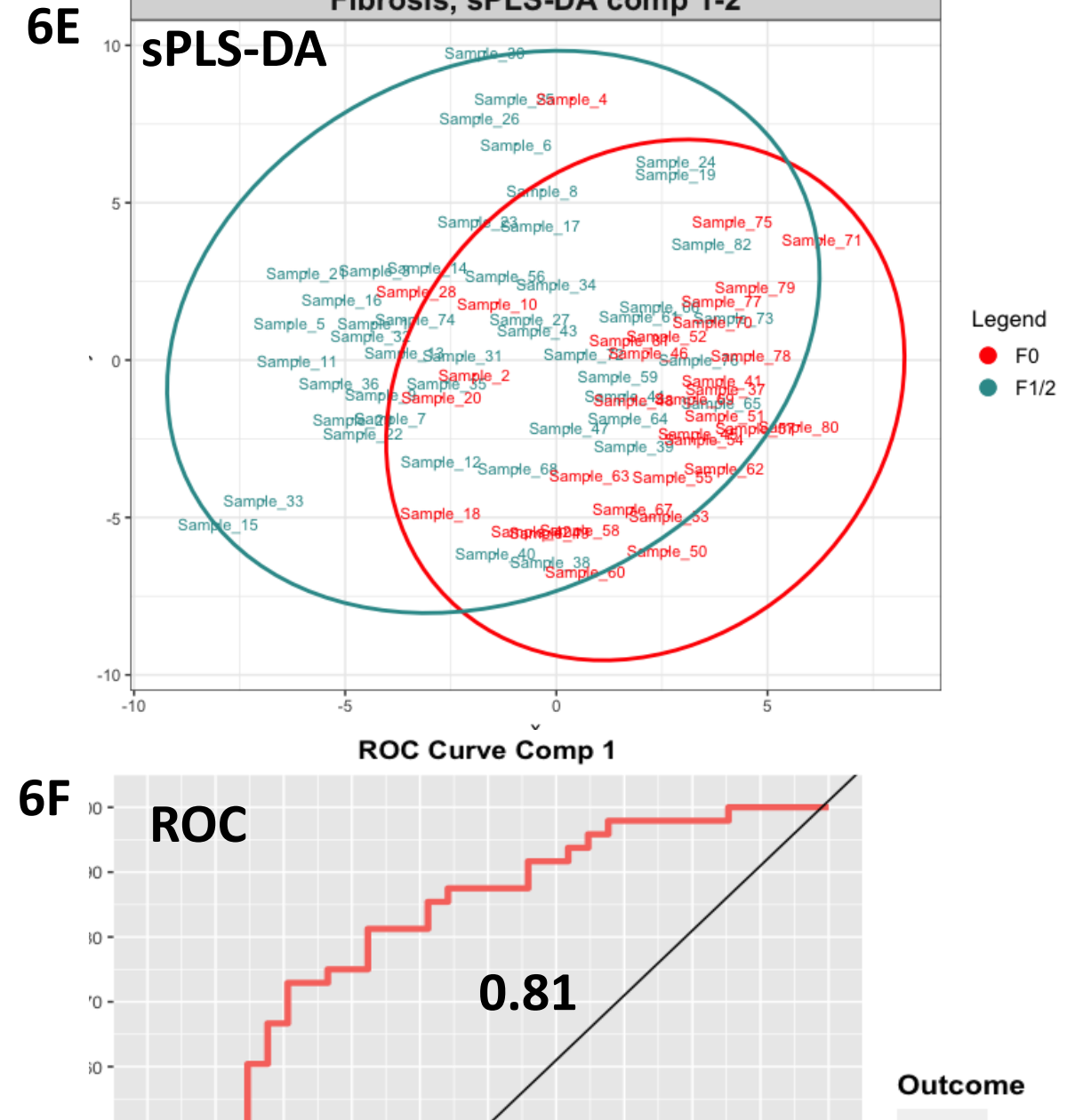

Fovs F1/2:0.8119

Figure 6, Champion et al 
Enzyme contribution to compo 1 and 2

6G

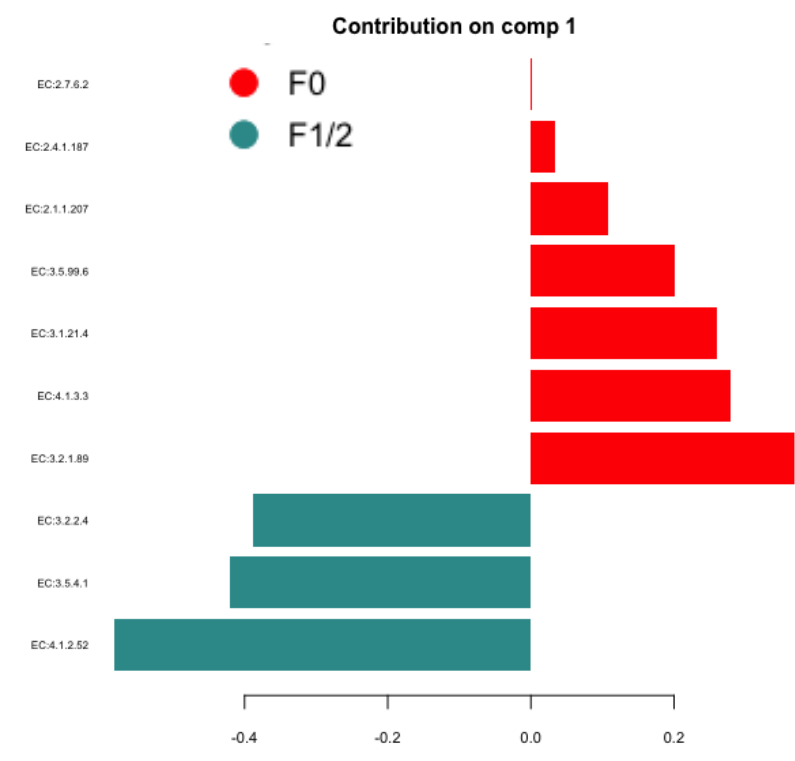

$6 \mathrm{H}$

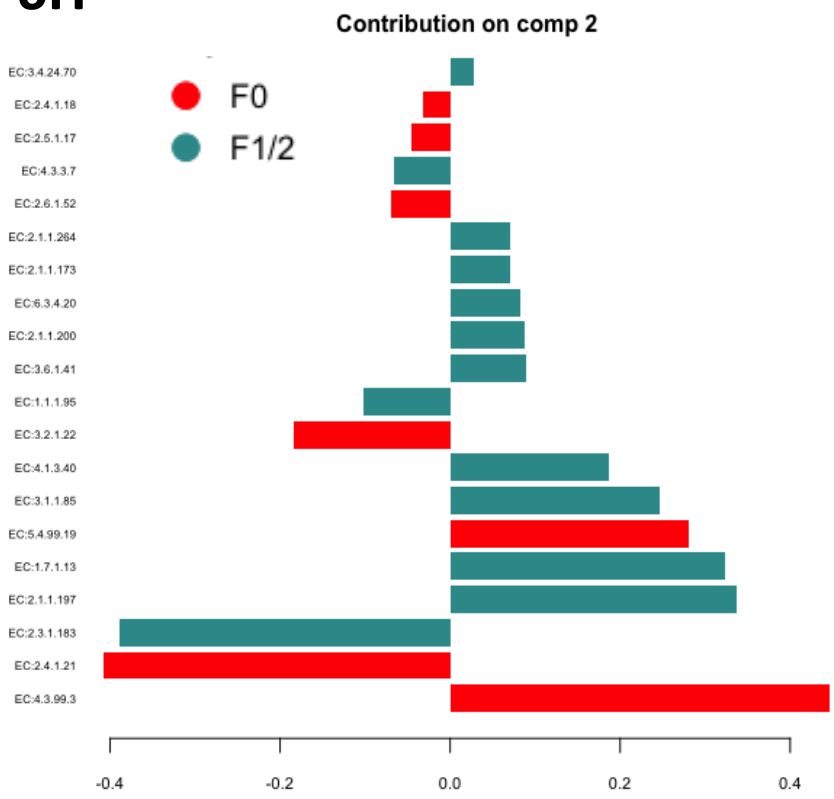

Pathway contribution to compo 1 and 2

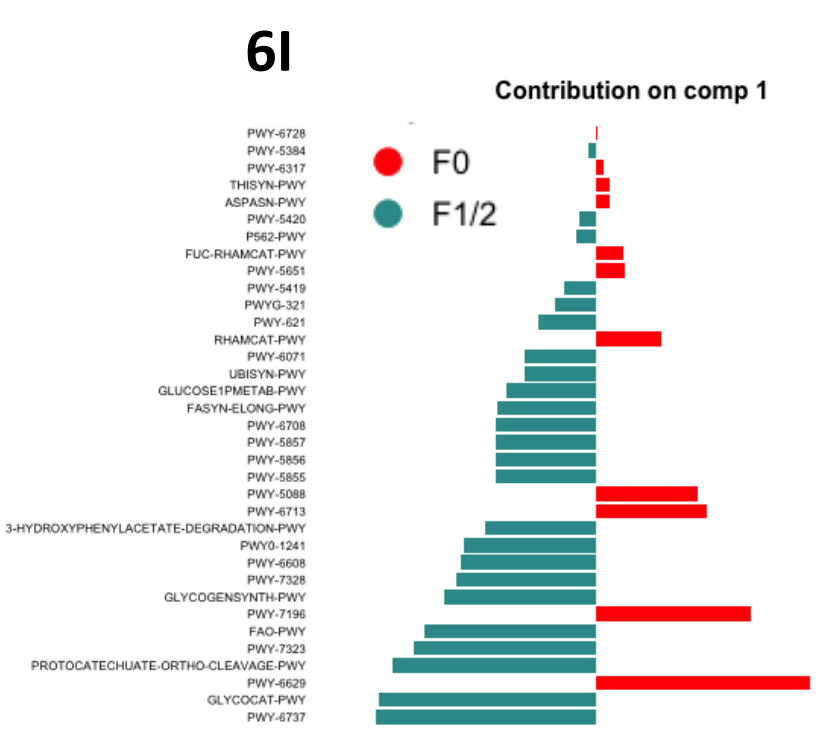

6J

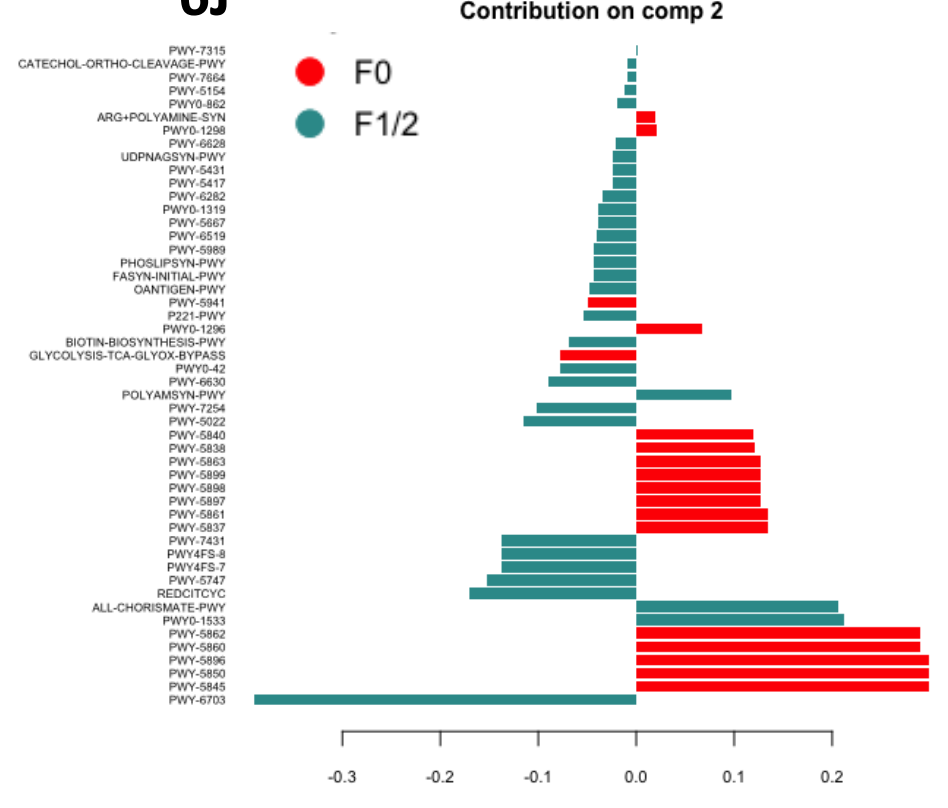


6etabolic microbial pathway mainly

6K Metabolic microbial pathway mainly associated with F1-2 liver fibrosis score
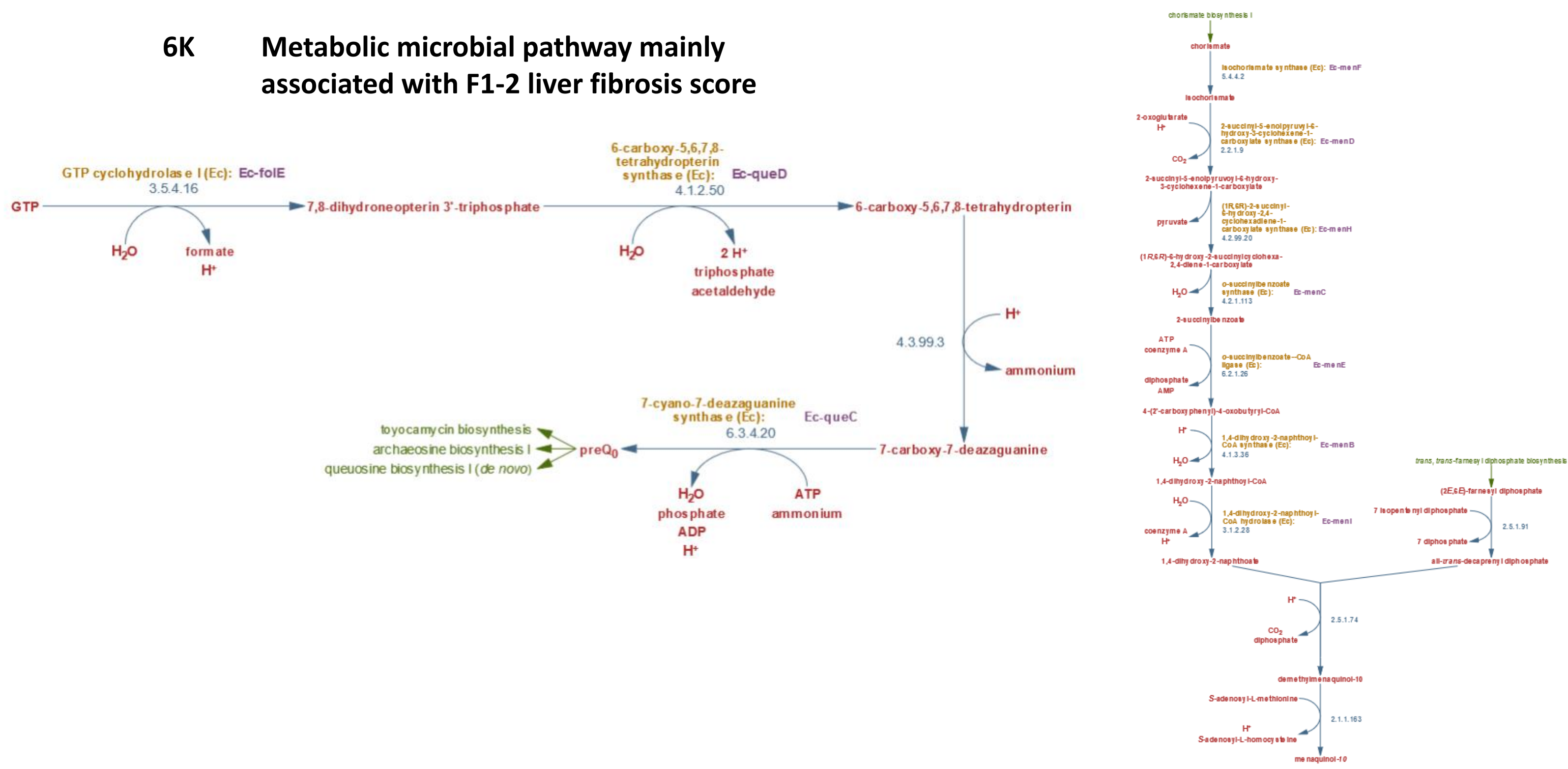

Figure 6, Champion et al 
A

Proteobacteria $p=0.0006$

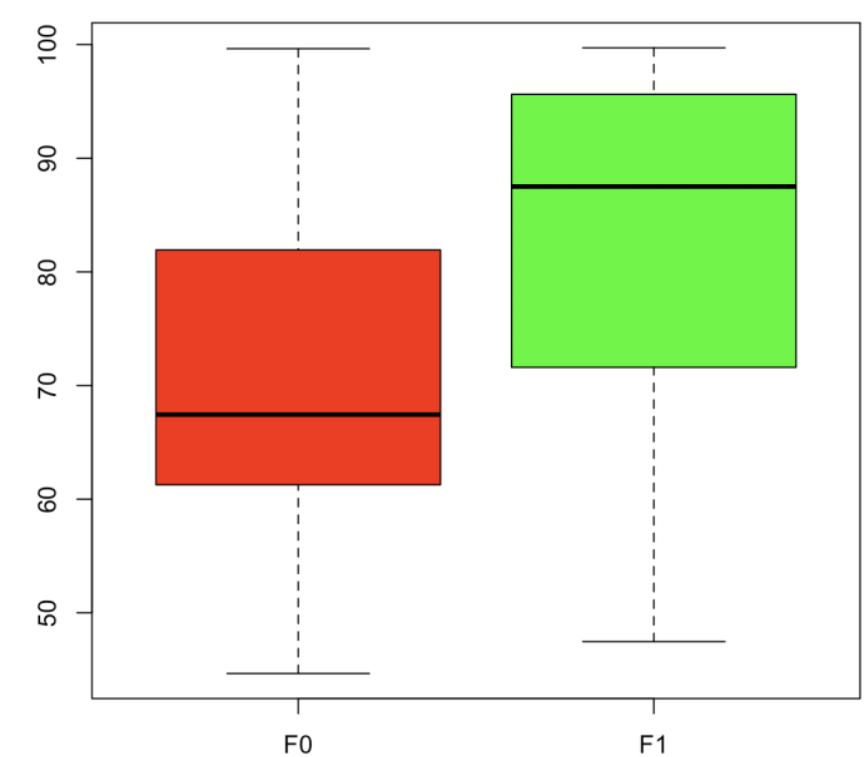

B

Actinobacteria $p=0.01$

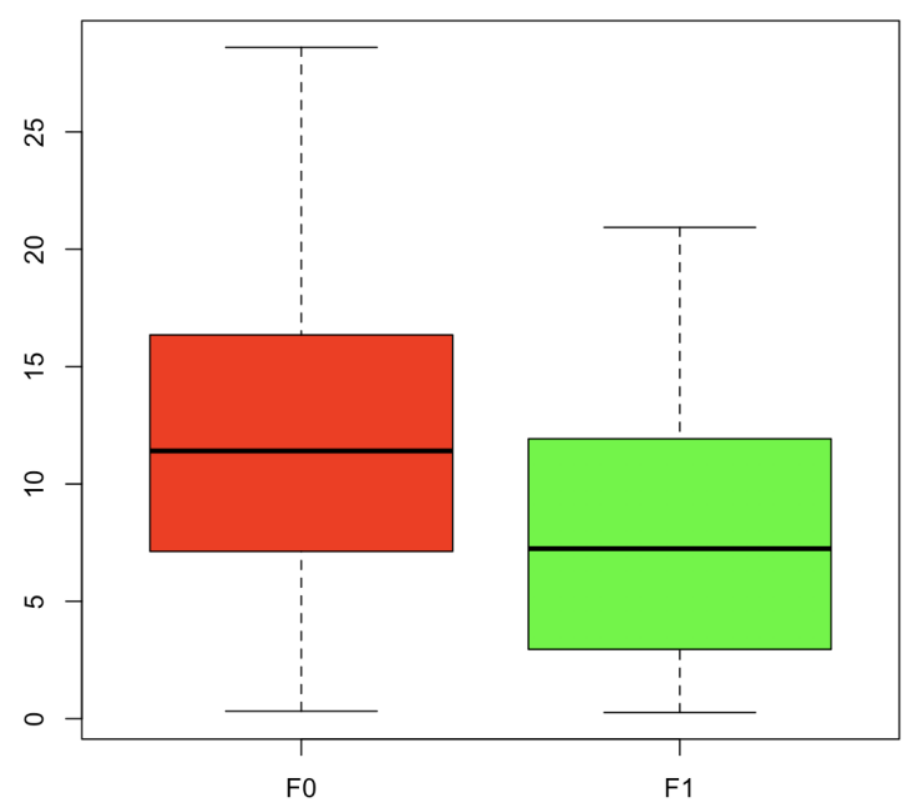

C

Firmicutes $p=0.02$

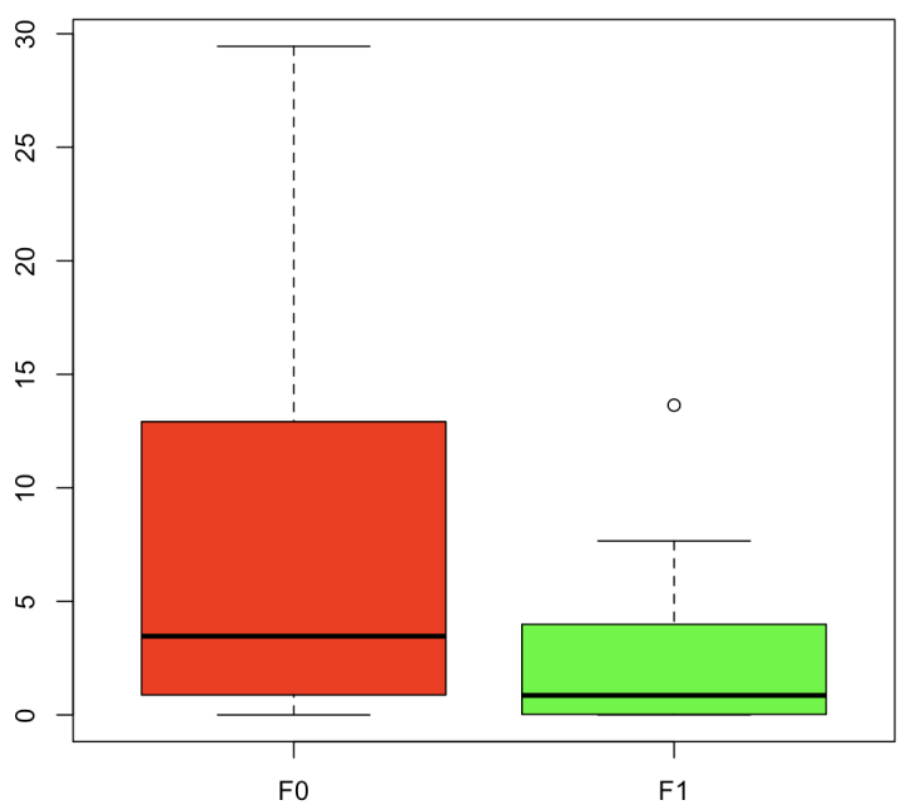




\section{Alpha diversity}

A

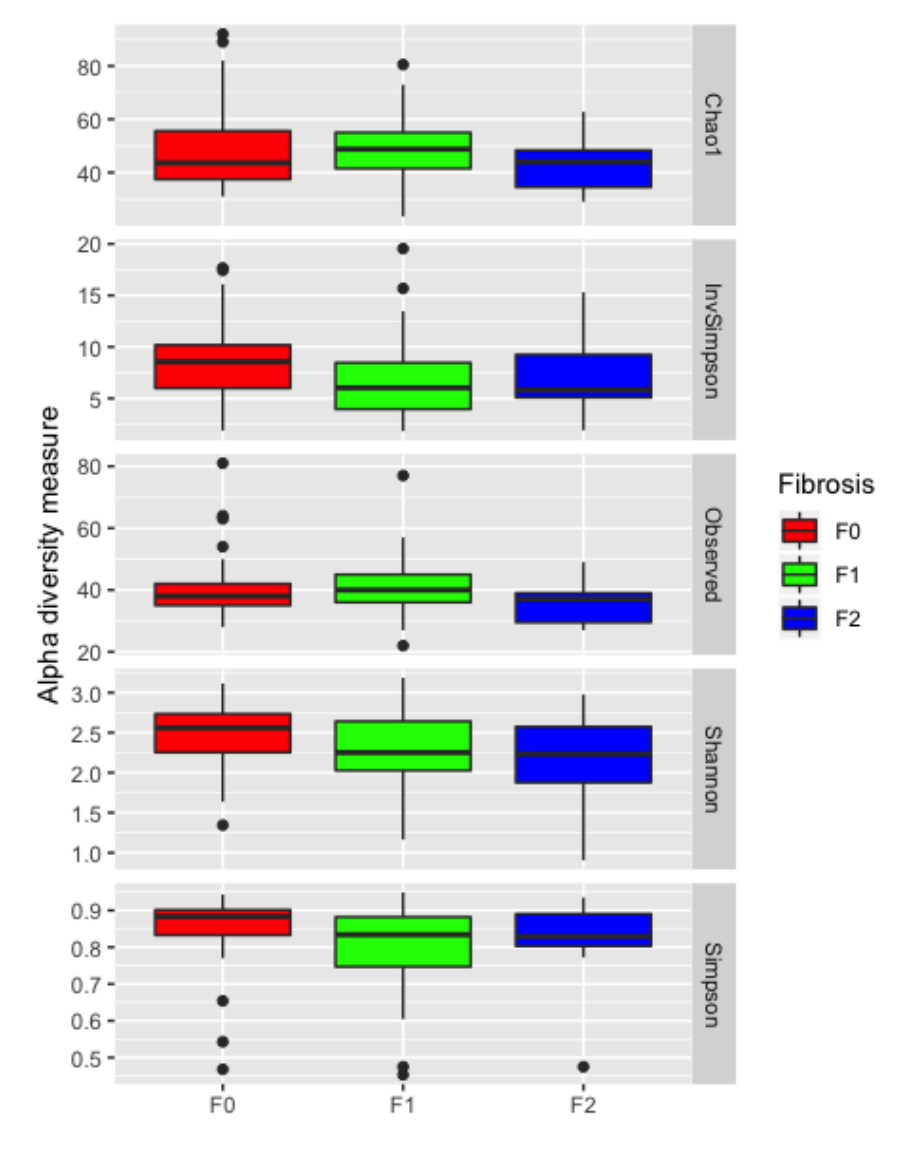

OTU
Observed: $p=0.007$ FO VS F1

Shannon: $p=0.007$ F0 VS F1

C

Simpson: $p=0.001$ F0 VS F1

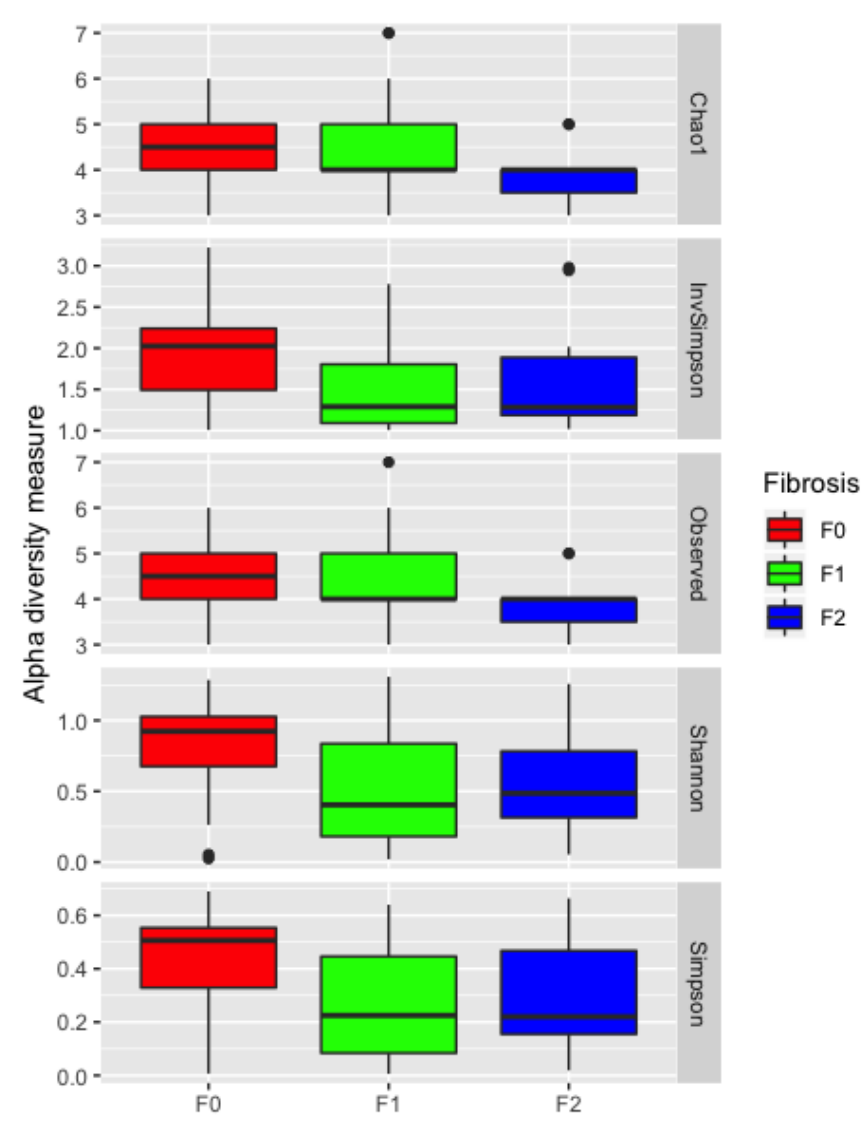

Phyla
Observed: $p=0.008$ F0 VS F1

Shannon: $p=0.008$ FO VS F1

Simpson: $p=0.02$ F0 VS F1

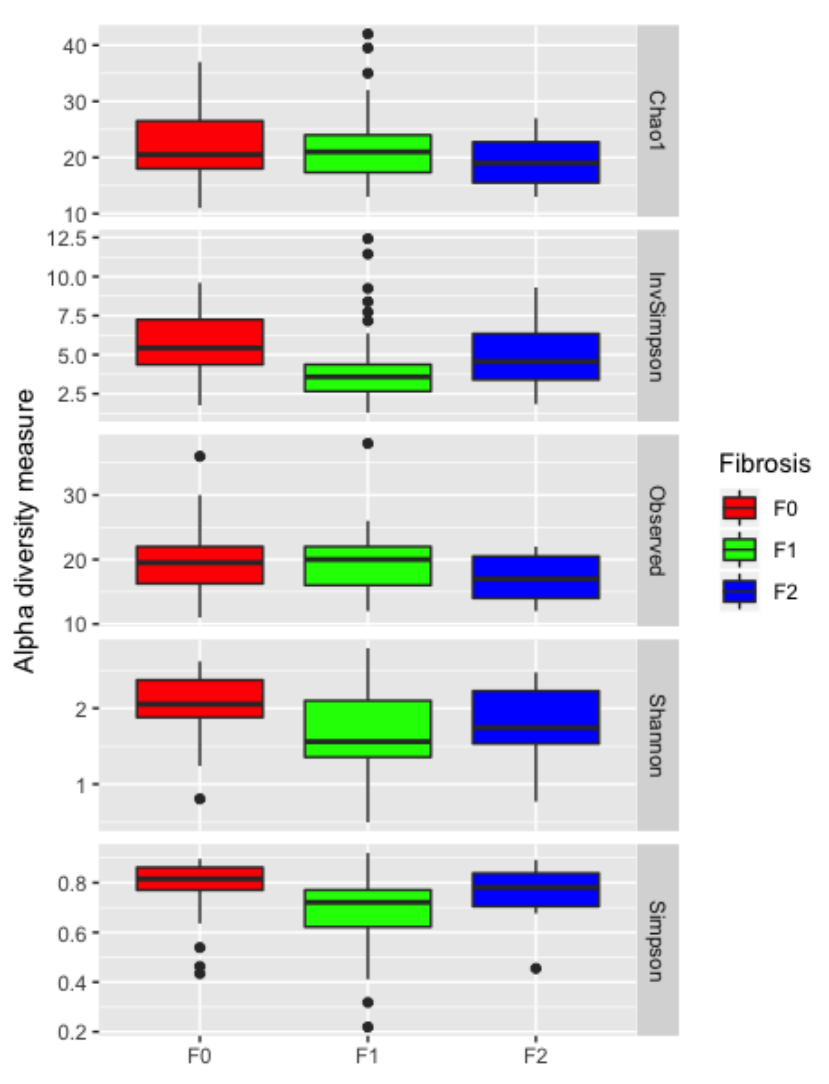

Families 


\section{Beta diversity}

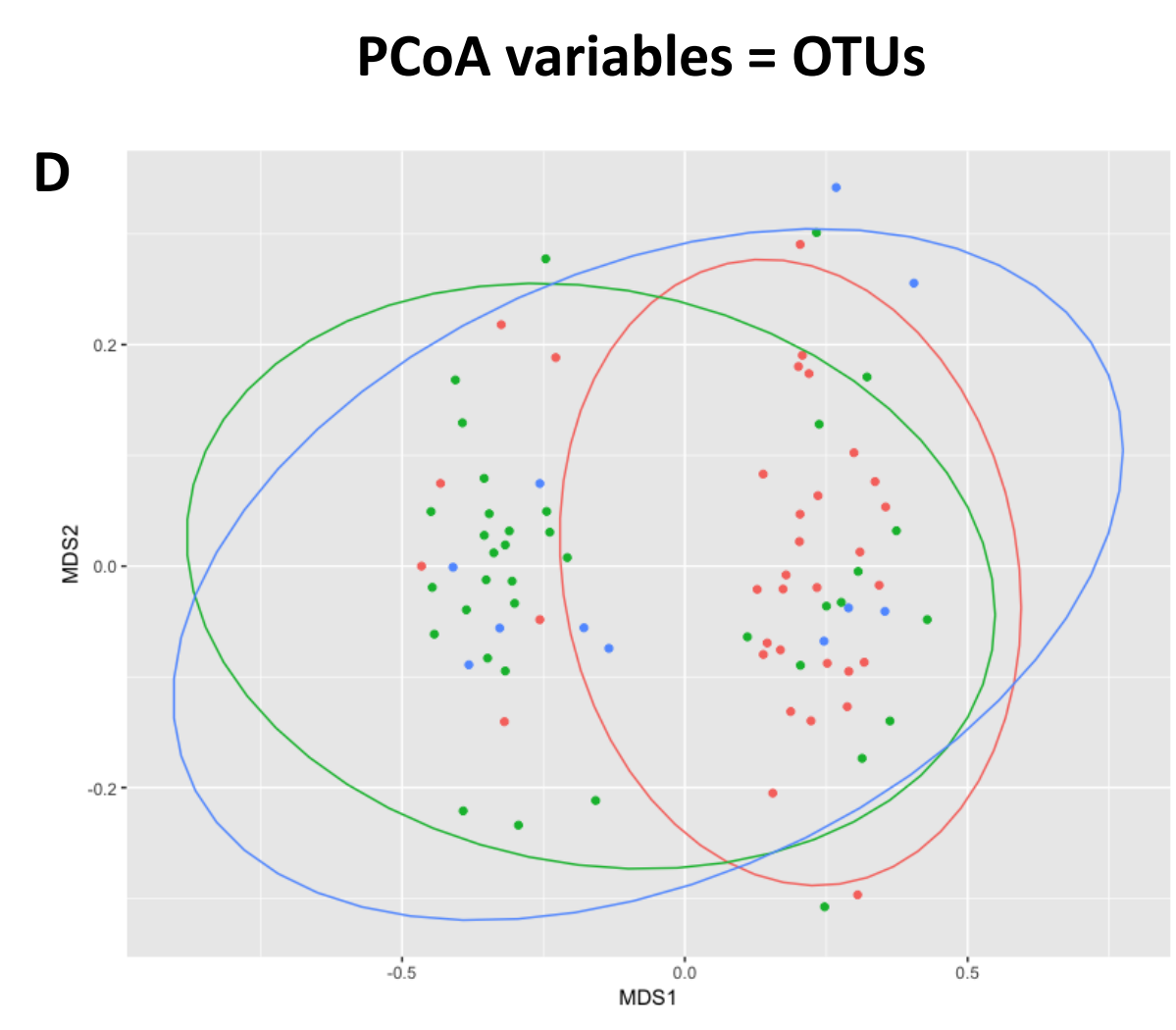

Fibrosis

Bray Curtis distance

$\rightarrow$ Fo

$\rightarrow F 1$

$\rightarrow F 2$
Fibrosis

$\rightarrow$ F0

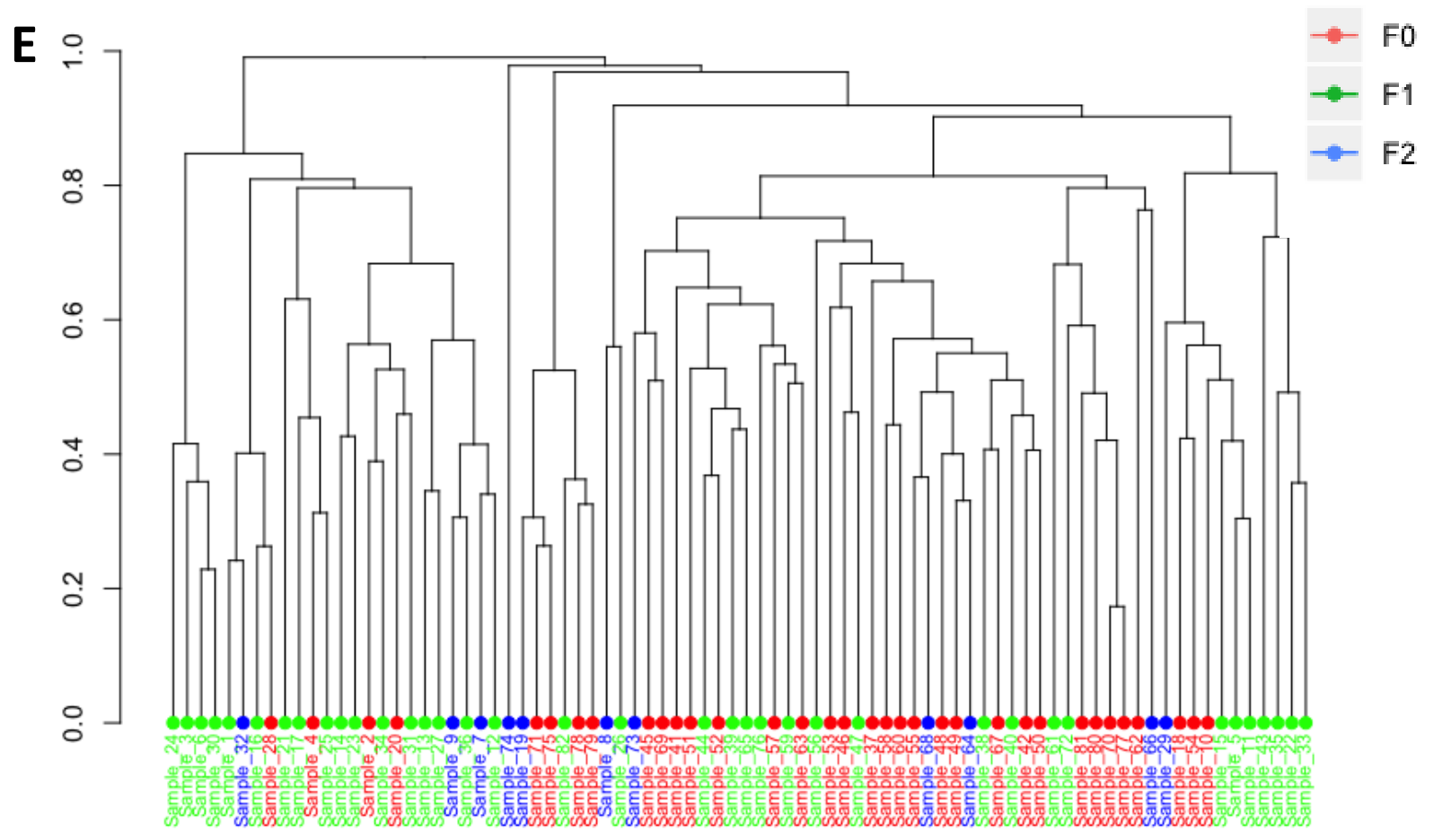

Figure sup 2, Champion et al 
A

$\square$ F2

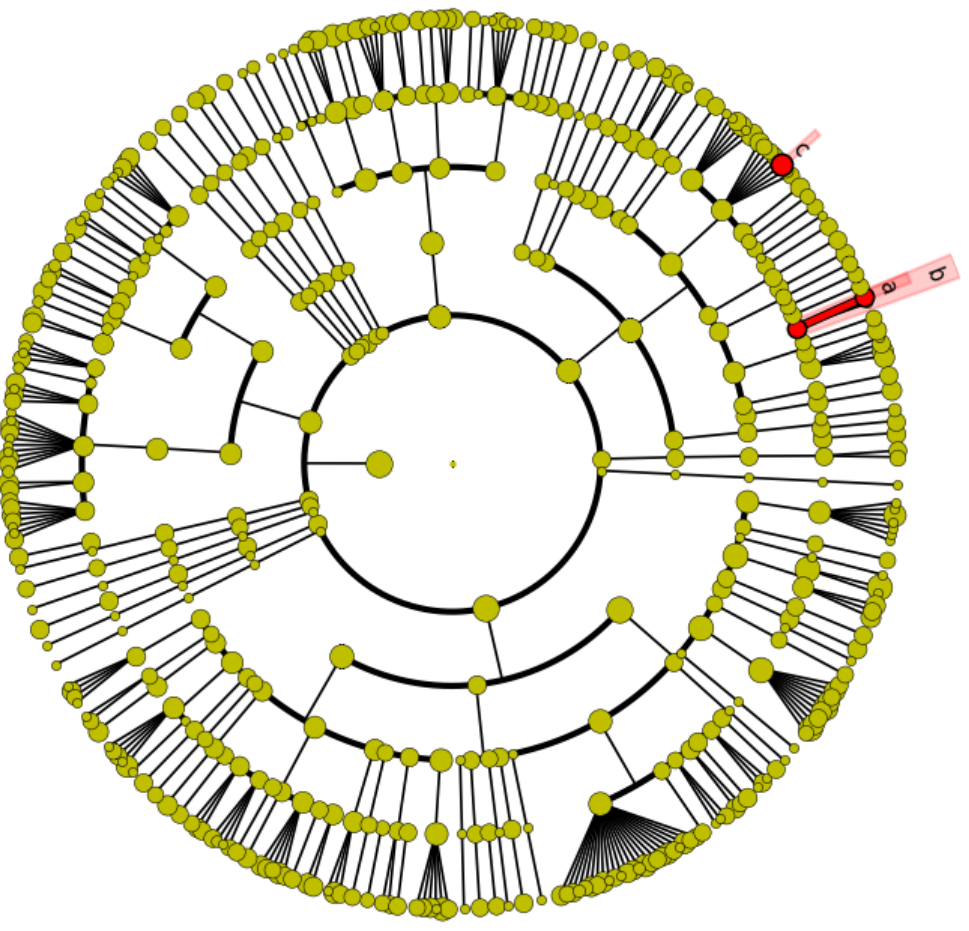

a: Rhodococcus

b: Nocardiaceae

c: Clavibac 
B

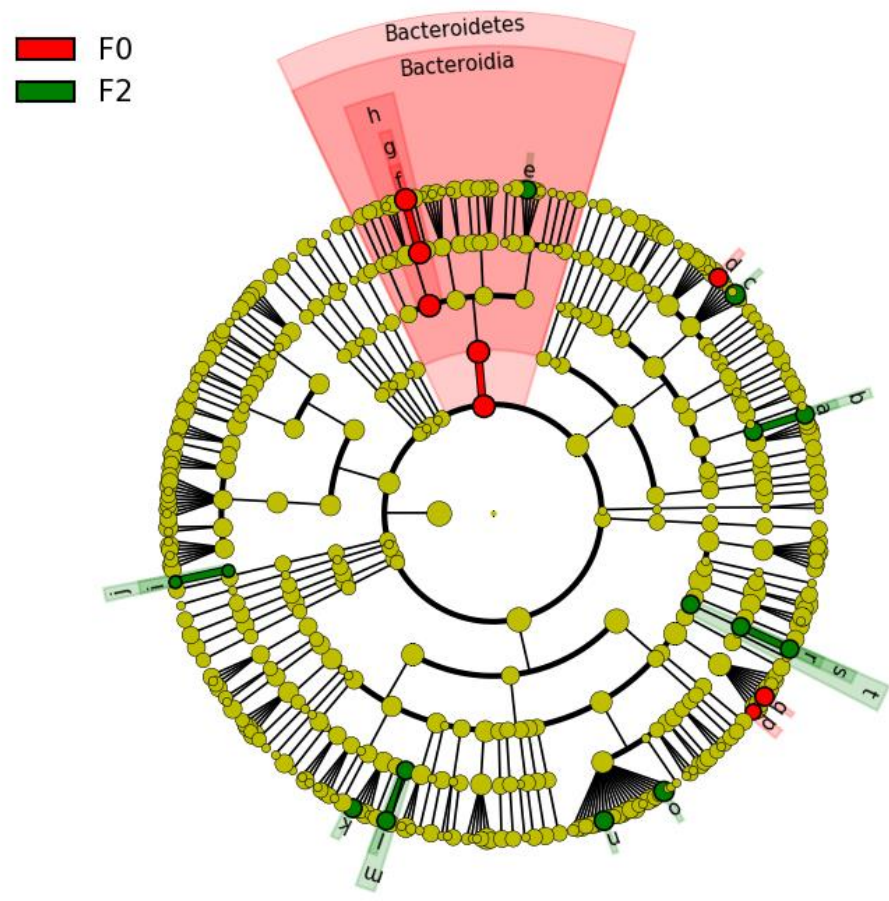

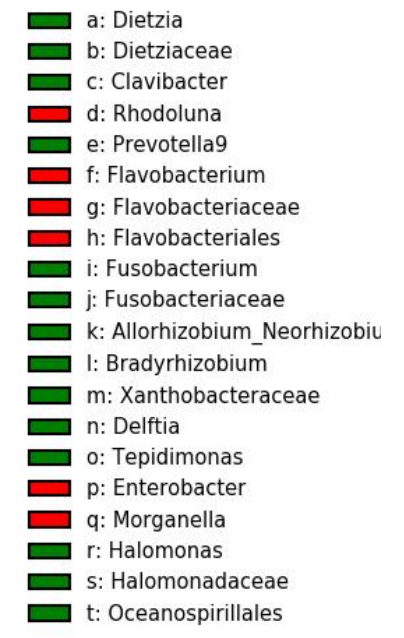

a: Dietzia

- Ocomospilla

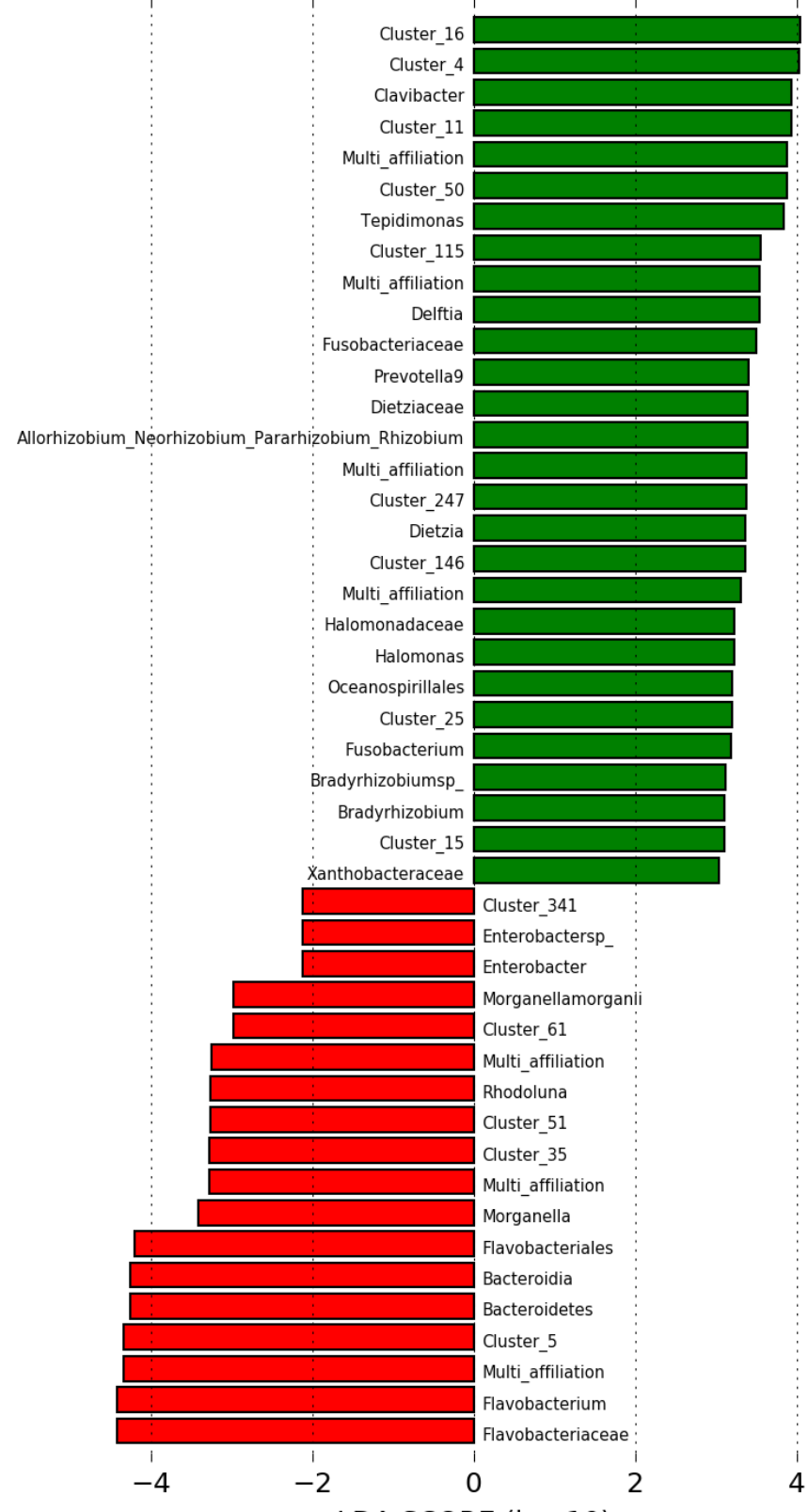

LDA SCORE (log 10)

Figure sup 3, Champion et al 